\title{
Die Krise der Psychologie.
}

\author{
Von Professor Dr. Karl Bühler, Wien.
}

Vorbemerkung: Herrn Kollegen Menzer bin ich für die freundliche Aufforderung zu diesem Artikel in den Kantstudien und für die sachverständige Geduld, mit der er dem sehr langsamen Ausreifen der Arbeit zusah, herzlich zu Dank verpflichtet. Schließlich ist ein kleines Buch daraus geworden. Hier blieb alles Entbehrliche, vor allem die Bezugnahme auf andere Versuche, die Krise zu lösen, weg. Eine Buchausgabe im Verlag von Gustav Fischer in Jena wird diese Ergänzung und noch einiges andere mit enthalten. Wenn tiefgreifende und weit verbreitete Strömungen wie die Psychoanalyse hier weder eine eigene Anerkennung noch eine eigene Kritik erfahren, so liegt das nur daran, daß sie den Rahmen der Erlebnispsychologie zwar erweitern, aber nicht in derselben Art wie der Behaviorismus durch etwas anderes zu ersetzen versuchen. In der Buchausgabe werde ich näher auf sie eingehen. Wenn wir erst mit der prinzipiellen Konstitution unserer Wissenschaft ins reine gekommen sind, wird das übrige (z. B. die Hypothesen über das Unbewußte) leichter zu klären sein.

I.

1. Man kann es schon in den Tageszeitungen lesen, es sei eine Krise in der Psychologie eingetreten. Und die es schreiben, dürften recht haben, wenn auch kaum zwei von ihnen genau dasselbe meinen. Vielfach heißt es summarisch, die naturalistische, sensualistische, mechanistische, atomistische Grundauffassung des Seelenlebens aus der zweiten Hälfte des 19. Jahrhunderts habe Schiffbruch erlitten, und es sei noch nichts Einheitliches an ihre Stelle getreten. Das ist gewiß nicht ganz falsch. Dem Impressionismus der Künstler entsprach eine Wissenschaft vom Seelischen, die an allem, was in uns lebt und webt, den Anteil der Sinne, das Eindrucksmäßige, aufspürte und in den Vordergrund schob. Ernst Mach war der typische Vertreter einer solchen Eindruckstheorie des Seelischen. Und was das heute viel gehörte Schlagwort des "Atomismus " treffen will, es war in der Tat so, daß der und jener die Sinnesdaten absuchte, um darin, um im Inhaltlichen, die Erlebniskonstanten schlechthin zu finden. So könnten wir auch alle übrigen ismus.Vorwürfe gegen die Psychologie unserer Väter durchsprechen und würden Züge an ihr, würden Psychologen finden, auf die sie zutreffen. Ist nur die Frage, ob eine mit all den genannten Zügen ausgestattete Theorie je in eine m Kopfe lebendig war, oder ob das nicht etwa ein Popanz ist, von uns eigens dafür ausstaffiert, um mit Recht verbrannt zu werden. Ich will dem hier nicht weiter nachgehen, sondern nur daran erinnern, daß in den zwei 
Generationen von Forschern, über die heute so leichthin der Stab gebrochen wird, ein Lotze und Brentano samt allen, die von ihnen ausgegangen sind, gelebt haben. Ich möchte den sehen, der z. B. gegen Stumpfs Psychologie auch nur einen einzigen von den aufgezählten Vorwürfen aufrechterhalten könnte.

Manchmal wird ebenso summarisch ein Verdikt gesprochen über die Forschungsmethoden, die in den Laboratorien ausgebildet worden sind. Experiment und Statistik sollen dem Geist der echten Psychologie zuwiderlaufen. Die Induktion in jeder Form sogar ist von diesem und jenem Kritiker schon abgelehnt worden. Auch darüber, meine ich, sollte eine philosophische Besinnung rasch hinwegführen, indem sie schärfer, als das zu geschehen pflegt, unterscheidet zwischen Intuition und Beweis. Es ist etwas Herrliches zweifellos um den genialen Blick des Entdeckers, um jenen Blick, mit dem Goethe z. B. die Urform der Pflanzen aus einem oder einigen Exemplaren herauszuschauen glaubte. Solch ein Entdeckerblick ist den forschenden Psychologen unserer Zeit mehr als je vonnöten. Wer unter ihnen z. B. darangeht, das Gesamtgepräge der Menschen, Charaktere, Temperamente, Begabungen mit den Mitteln der Wissenschaft zu erfassen, der prüfe sich zuvor, ob er den Blick, mit dem allein man Typen entdecken kann, besitzt oder nicht. Wenn nicht, dann muß er sich ein anderes Forschungsfeld aussuchen oder sich darauf beschränken, nachzuprüfen, was andere vor ihm entdeckt zu haben glauben. Auch in anderen Wissenschaften hat es Phasen gegeben, in denen nur noch große Konzeptionen à la Newton oder Darwin oder meinethalben auch Einstein weiterführen konnten. Hat man aber je gehört, daß darum von den Physikern oder Biologen der ganze Kleinkram einer strengen Induktion über Bord geworfen worden wäre? Sie stünden, diese anderen Wissenschaften, heute nicht so vor uns, daß wir sie beneiden könnten, wenn sie es getan hätten. Mich dünkt, es ist überflüssig, darüber viel Worte zu verlieren. Daß die Wege, auf denen man zu ersten Vermutungen und Ideen gelangt, andere sind als die Wege der Erprobung und des Beweisens, darin steht selbst die Mathematik den anderen Wissenschaften gleich. Der Intuition, der Gabe des gottbegnadeten Entdeckers, wird genau wie sonstwo auch in der Psychologie das erste, der streng disziplinierten Beobachtung aber, der Treue im Kleinen und der Induktion das letzte Wort gebühren. Und wenn über all das seit einigen Jahren bei uns lebhafter als sonstwo nachgedacht und disputiert worden ist, so gäbe dies keinen Grund ab, von einer Krise in der Psychologie zu sprechen.

Nein, es ist letzten Endes ein rasch erworbener und noch unbewältigter Reichtum neuer Ideen, neuer Ausblicke und Möglichkeiten, was den krisenartigen Zustand in der Psychologie heraufbeschworen hat. Wir wollen das Wichtigste zunächst einmal einfach 
aufzählen und kurz charakterisieren. Man blättere etwa aus dem letzten Jahrzehnt des vergangenen Jahrhunderts die ersten. Bände der Zeitschrift für Psychologie nach. Wie, eng umschrieben war dort das Programm: Psychophysik und Gedächtnisforschung, Gebiete, auf denen sich das Experiment in der Form, wie es von Fechner, Wundt, Ebbinghaus u. a. ausgebildet war, bewährte, beherrschten die Lage. Mancher mochte denken, daß es nun in ruhiger Bahn weiterginge. Aber schon das nächste Jahrzehnt brachte eine folgenschwere Wendung, deren Tragweite heute noch nicht von allen erkannt ist. Ein Kreis junger Psychologen um Külpe in Würzburg erweiterte den Forschungsbereich des Experimentes auf das Denken und den Willen. Und siehe da! Das tradierte Schema von den Vorstellungsverknüpfungen erwies sich im ersten Anlauf als unzureichend, die Beobachtungstatsachen zu erklären. Auf den Erlebnisstoff der Vorstellungen und ihre Kontinuitätsverkittungen war dies Schema zugeschnitten, und die Beobachtung lehrte, daß die Konstanten des geordneten Denkverlaufes durchaus nicht stofflich allein zu bestimmen sind. Wer uns etwa belehren wollte, daß $B$ es bei einem komplexen Zahlenausdruck nicht nur auf die Ziffern, sondern ebensosehr auf die Operationszeichen, ob Addition, Multiplikation usw. ankommt, wer uns an den sichtbaren Tätigkeiten eines ausführenden Künstlers, Handwerkers oder sonst eines an materiellen Objekten schaffenden Menschen auf die Methoden des Vorgehens, die Verfahrungsweisen, Techniken hinweisen und sagen wollte, das seien mindestens ebenso wichtige Konstanten, Bestimmungsmomente, als der manchmal sehr zufällige und variable Stoff, der würde uns im Grunde genommen dasselbe sagen, was auch die Denkpsychologie Schritt für Schritt herausgearbeitet hat. Es ist mit dem schaffenden Denken genau so wie mit anderen produktiven Tätigkeiten, daß ein Fond von Operationen dazugehört; die entscheidenden letzten Konstanten im Denken sind gar nicht die Vorstellungsbilder, die kettenförmig eines nach dem anderen getreu den Assoziationsgesetzen in uns abrollen, sondern bestimmte, einfache und komplexe Denkoperationen an dem wechselnden Material von Vorstellungsbildern.

Diese Grunderkenntnis gab vor etwa zwanzig Jahren den ersten Ansto $3 \mathrm{zu}$ einer Neuorientierung in der Psychologie. Man lese dazu die programmatische Akademieabhandlung von Stumpf: ,Erscheinungen und psychische Funktionen" aus dem Jahre 1907 und ganz ähnliche Gedankengänge von Külpe aus demselben Jahre in den Göttinger Gel. Anz. nach. Gleichviel, wie man heute über viele Einzelheiten denken mag, jenes Programm verlangte klar und zwingend eine bestimmte Umstellung der Interessen der Erlebnispsychologie. Es war, um einen Vergleich aus anderem Gebiete zu bringen, wie wenn man Kunstinteressen umsteuern will von der vorwiegenden Richtung aufs Inhaltliche zur Richtung aufs Formale, Funktionale. Ich will hier nicht beschreiben, wie und in welchem 
Ausmaß das Programm in der neuen Psychologie des Willens und des Denkens verwirklicht worden ist; jedenfalls war mit ihm das einfache Schema der klassischen Assoziationstheorie durchbrochen und ein neuer Horizont für die Wissenschaft von den Erlebnissen erschlossen.

Im letzten Grund geht die Intention auf den Sinn der Erlebnisse und führt zu teleologischen Bestimmungen, wenn man es unternimmt, das seelische Leben und Weben in sich selbst zu erfassen, ,die qualitativen Unterschiede im psychischen Verhalten, in der Art und Weise, wie der seelische Organismus arbeitet" (Stumpf), zu begreifen. Dessen war sich die Denkpsychologie von Anfang an klar bewußt, in meiner ersten Arbeit von 1907 z. B. steht ausdrücklich der Satz vom teleologischen Charakter der Denkerlebnisse. Wenn es also je eine rein ,mechanistische“" d.h. sinnfreie Theorie des Seelenlebens gab, so war die Abwendung von ihr bereits vor zwei Dezennien vollzogen. Die derart gestellte Sinnfrage aber führt konsequent erstens zu neuen Aufgaben der deskriptiven Bestimmung der Erlebnisse und zweitens zu spezifisch teleologischen Verlaufsgesetzen des seelischen Geschehens. Wie vage und formelhaft waren doch die seit Lockes und Humes Zeiten überlieferten deskriptiven Grundbegriffe ,,Wahrnehmung“, ,,Vorstellung", „Gefühl"“ usw. in der Assoziationstheorie stehengeblieben! Wenn die neue Beschreibung das empfindungsmäßige Bild von dem gedanklichen Gehalt einer Vorstellung unterschied, so konnte sie sich dabei vor allem auf die an der Sprache klar erkennbare und nie verkannte Zweiheit von Klangbild und Wortbedeutung stützen; diese Analogie und das an ihr abzulesende komplexe Verhältnis von Zeichen und Bedeutung ist in den mannigfachsten Modifikationen an allen sinnhaften Erlebnissen wiederzufinden. Ich werde es im zweiten Abschnitt in den Mittelpunkt der Betrachtung stellen und darum hier nicht weiter behandeln. Von anderen Aufgaben und Leistungen der neu belebten Deskription sei z. B. auf die Beschreibung des Willensaktes durch N. Ach, der Vorgänge des Schließens durch Störring und Lindworsky, auf die weit ausholenden Untersuchungen über Gestalten und die Relationswahrnehmung nur kurz verwiesen. Anderes, z. B. das weite Gebiet der Affekte und das zentrale Denkerlebnis des Urteils, harrt noch einer gleich intensiven Bearbeitung.

Aber nicht nur die mehr oder minder scharf abgrenzbaren einzelnen Erlebnisse, die man in Klassen ordnen kann, sondern auch ihr Ablauf, ihr Kommen und Verschwinden in geschlossenen Reihen und Verbänden ist sinnerfüllt und sinnbestimmt in einer Art, der die Assoziationstheorie mit ihren Mitteln nicht gerecht werden konnte. O. Selz hat sich in seinen zwei Büchern über den geordneten Denkverlauf 1913 und 1922 und neuerdings in einer kurz gefaBten Darstellung ,,Die Gesetze der produktiven und reproduktiven Geistestätigkeit" (Bonn 1924) wirkungsvoll mit ihr auseinandergesetzt. Doch so tiefgreifend diese ganze Neuorientierung 
war und noch zu werden verspricht, sie ändert nichts an dem seit Descartes und Locke festgelegten Ausgangspunkt und Endziel der Psychologie als der Wissenschaft von den Erlebnissen. Den vom Ich gehaltenen oder jedenfalls in ihm zusammentreffenden Kosmos seelischer Ereignisse abzustecken und als geschlossenes System zu begreifen, war bis vor kurzem das gemeinsame Programm. Es sind aber nun solche aufgetreten, die es für verfehlt, für undurchführbar oder wenigstens für unzureichend erklärt haben. Und erst durch sie ist die Krise der Psychologie akut geworden.

2. Ungefähr gleichzeitig mit der besprochenen deutschen Bewegung um die Jahrhundertwende ist in Amerika der Behaviorismus entstanden. Um all den Unsicherheiten, mit denen die Bestimmungen subjektiver Tatbestände behaftet sind, zu entgehen, haben die Amerikaner das Ideal einer ,objektiven" Psychologie entworfen. Sie reformierten die Tierpsychologie, von der sie ausgingen, und gewannen in der Tat einen neuen Grundaspekt vom Gegenstand der Seelenlehre. Unsere Weisheit gipfelte in dem Satze: Erkenne dich selbst oder, wie der Dichter sagt: „Willst du die andern versteh'n, blick' in dein eigenes Herz." Der Amerikaner aber kam und lehrte: Betrachte das Verhalten der Menschen und Tiere von a ußen, du wirst, wenn du es nur systematisch genug vollbringst, auch damit zu wichtigen Erkenntnissen gelangen. Also nicht im Sinne der ersten Zeilen unseres Dichters ,Willst du dich selber erkennen, so sieh, wie die ander'n es treiben", sondern ganz von außen, ohne Selbstbeobachtung, ganz „objektiv" sollen wir das Verhalten, das Benehmen (englisch behavior) der Lebewesen betrachten. Voraussagen, wie der und jener in gegebener Situation sich benehmen wird, das ist doch wohl, was wir letzten Endes von der Psychologie erwarten. Nun gut, praktische Leute, wie die Behavioristen sind, legen ihre ganzen wissenschaftlichen Bemühungen von vornherein auf dies Endgeschäft des Voraussagens an; sie inventarisieren die möglichen Situationen, sie inventarisieren die Verhaltungsweisen, welche jedem Lebewesen zur Verfügung stehen, und dann kommt es ja nur darauf an, die gesetzmäßigen Zuordnungen des einen zum anderen, der Reaktionen zu den Situationen zu finden; eine Korrelationsforschung größten Stils soll die Krönung dieses Werkes sein.

Es ist hier nicht der Ort, die Schwächen, Entgleisungen und die notwendige Ergänzungsbedürftigkeit dieses echt amerikanischen Programms sauber herauszustellen. Entsprungen aus den besonderen Bedingungen der Tierpsychologie, hat es dort auch seine ersten Erfolge gezeitigt. Wir seben und unterscheiden heute dank dieser Untersuchungen viel schärfer als früher das angeborene und das individuell erworbene Moment im sinnvollen Verhalten der Tiere und kennen Methoden, beides objektiv zu bestimmen, die Instinkte und die Arten des Lernens. Noch mehr, wir wissen, daß schon die einzelligen Tiere, die Amöben, keine Automaten 
sind, sondern in ihrem freilich noch winzigen Lebenskreise einen kleinen Spielraum für eine erste, einfachste Art des Lernens besitzen. Von da bis zu den höchsten Wirbeltieren und uns selbst ist freilich ein weiter und keineswegs geradlinig ansteigender Weg. Die merkwürdig hochspezialisierten Instinkte der Gliedertiere, der Ameisen und Bienen z. B., weisen in ihrer relativen Starrheit nachdrücklich auf eine andere Entwicklungsrichtung hin und sind in ihrer Art das Vollendetste, was die Natur in dieser Richtung hervorgebracht hat. Im Vergleich mit ihnen mag uns im ersten Anblick der Mensch instinktarm und im hohen Grade instinktunsicher erscheinen, besonders der naturferne Kulturmensch. Gewiß, und doch ist dies nicht das letzte Wort über die Instinkte des Menschen. Erst derjenige, dem aus der vergleichenden Betrachtung die Augen geöffnet sind für den anderen Charakter des Instinktiven im Menschen, wird richtig erkennen, wie ungemein reich es ist, und wie es, freilich als durchaus unselbständiges Moment, mit an den höchsten geistigen Leistungen in seiner Art beteiligt ist.

Es wäre falsch, zu meinen, daß wir dies alles den Amerikanern verdanken. Wir wollen nur flüchtig daran erinnern, daß schon die erste wissenschaftliche Psychologie, die Seelenlehre des Aristoteles, durchaus biologisch orientiert war. Die Amerikaner haben sich schon bei dem Versuch einer reinlichen Scheidung des angeborenen und individuell erworbenen Momentes im sinnvollen Verhalten der Tiere in überflüssige und vermeidbare Schwierigkeiten verwickelt, und sie haben, was die dritte große Entwicklungsrichtung angeht, jene Richtung, die im menschlichen Intellekte kulminiert, zwar die Ansätze zu einer objektiven behavioristischen Bestimmung richtig getroffen, aber dann versagt. Vom Menschen und den höheren Wirbeltieren aus gesehen, kann man das Instinktive als den Nährboden bezeichnen, aus dem das Höhere herauswächst. Dies Höhere läßt sich dann ziemlich scharf in zwei Klassen zerlegen. Jeder von uns weiß, daß er anders vorgeht, wenn er z. B. in einem Fall als Anfänger Vokabeln einer völlig fremden Sprache lernt und in einem anderen dem Nervus probandi eines geometrischen Lehrsatzes nachspürt. Niemand wundert sich, zu erfahren, daß in Sachen des sogenannten mechanischen Lernens und Behaltens manch ein leicht schwachsinniger Mitmensch uns bei weitem übertrifft. Nun gerade diese Art des Lernens, diese Art der Ausbildung erworbener sinnvoller Verhaltungsweisen, bei der es in erster Linie auf Wiederholungen ankommt, reicht in ihren Anfängen in der Tat hinab bis zu den Infusorien. Es ist keine Entwürdigung des Menschen, wenn wir diese Verbindungslinie ziehen und feststellen, da $\beta$ er auch im Felde des mechanischen Lernens die Höchstleistungen aufzuweisen hat. Nicht nur das Sprechen und Gehen, sondern auch das Umherblicken und Greifen muß das menschliche Kind erst üben, um es vollendet zu vollbringen, und bis in die Höchstleistungen des Sports, 
jeder Handfertigkeit, jeder Gewandtheit selbst in Sachen der Kunst und Wissenschaft hinein gilt für ihn das Gesetz, daß erst Übung den Meister macht. Vollendung durch Übung, das ist die Wesensformel, ist das Strukturgesetz des (mechanischen) Lernens. Es kann keine Rede davon sein, daß ihm die wabenbauende Biene genau so unterworfen wäre wie der Mensch; und es ist ebenso greifbar, daß auch der Intellekt seinem Wesen nach durch diese Formel nicht erfaßt wird. Ich habe darum Instinkt, Dressur und Intellekt als die drei Grundrichtungen, die drei Dimensionen des sinnvollen Verhaltens von $T$ ier und Mensch charakterisiert. Es ist eine noch unentschiedene Frage, wie es mit den Anfangsstadien des Intellektes im Tierreich bestellt ist.

Doch das sind nur illustrierende Beispiele, um dem deutschen Leser die fremde Sache einigermaßen nahezubringen. Der Behaviorismus schiebt die alte Erlebnispsychologie beiseite und erhebt den Anspruch, etwas Vollkommeneres an ihrer Stelle zu errichten, eine Wissenschaft vom $B e$ nehmen, von den objektiv zu bestimmenden Verhaltungsweisen der Tiere und Menschen. Daß dies (in gewissen Grenzen und unter bestimmten Voraussetzungen) möglich ist, erkennt man klar an den drei Kategorien von Verhaltungsweisen, die wir unterschieden haben. Es gibt objektive Kriterien für Instinkt, Dressur und Intellekt. Daß sich der Behaviorismus im Fortgang seiner kurzen Geschichte immer ablehnender verhält zu allem, was an psychologischen Bestimmungen aus der Selbstbeobachtung stammt, ist ebenso begreiflich, wie es verhängnisvoll für seine Grundbegriffe und Axiome werden kann und zum Teil schon geworden ist. Man gelangt in ein Dilemma: Auf der einen Seite besteht die metho dische Forderung, die Begriffe und Konstatierungen der Benehmenslehre rein zu halten von allem, was sich an vorschneller Deutung, an unkontrollierten Suppositionen aus dem Bereich unserer anthropomorphisierenden Auffassung der Tiere immer wieder eindrängt, auf der anderen Seite dagegen erweist es sich als sach lich unmöglich, Einheiten und jene Ordnung im Bereich der wahrnehmbaren Körperbewegungen zu erkennen, auf welche die Psychologie wesensgesetzlich eingestellt ist, ohne die Grundmomente von Zielen und Leistungen, ohne ein teleologisches Koordinatensystem ${ }^{1}$. Es ist gewiß kein Zufall, daß uns diese Wendung ins Teleologische genau so aus dem Schoße des Behaviorismus wie aus der Erlebnispsychologie entgegentritt. Im Namen dieses einigenden Prinzips wird die Synthese der beiden divergierenden Forschungsrichtungen

1 Eine ausführliche Begründung dieser These für die Instinktlehre bei K. Bühler, Die Instinkte des Menschen. Ber. über den IX. Kongr. für Psychol. 1926 (Sammelreferat). - Für die Kinderpsychologie: Ch. Bühler, Die ersten sozialen Verhaltungsweisen des Kindes. Quellen und Studien zur Jugendkunde, Heft 5 (1926). Dort auch eine kurze Entwicklungsgeschichte des Behaviorismus. 
vollzogen werden müssen. Und genauer besehen, ist sie tatsächlich schon vorbereitet, denn der Grundbegriff der psychischen Operationen bleibt nicht unübertragbar auf die Sphäre der Erlebnispsychologie eingeschränkt.

Doch wir werden, um die philosophische Dialektik, die in dem skizzierten Tatbestand angelegt ist, tiefer zu erfassen und reinlich zu Ende zu führen, im zweiten und dritten Abschnitt weiter ausholen. Eines sei noch über den Behaviorismus gesagt: Wo er sich seines Wesens am klarsten bewußt wird, sucht er die Tiere und den Menschen in ihrer natürlichen Lebenssphäre auf, weil er doch voraussagen will, wie sie sich benehmen werden. Es liegt ein Zug zu größerer Lebensnähe und eine Hinneigung zu den praktischen Aufgaben der Psychologie in ihm, weil er von vornherein das Ganze aus dem Individuum, seiner Lage und seinen Tätigkeiten in seine Systembedingungen aufnehmen muß.

3. Und noch einmal eine neue, eine dritte Grundbestimmung des Gegenstandes der Psychologie ist vom Gebiete der Geisteswissenschaften her gewonnen worden. Úberflüssig zu beweisen, daß jedes Menschenwerk etwas von der seelischen Eigenart seines Schöpfers an sich trägt. Und wenn es im einzelnen wahr ist, daß die Mumien und Pyramiden vom Ewigkeitsstreben der Pharaonen, die Akropolis von der Harmonie der griechischen Seele, die gotischen Dome und Goethes Faust vom besonderen Charakter des abendländischen Menschen erzählen, so wird es auch im Ganzen wahr sein, daß die unabsehbare Fülle der Gebilde des ,objektiven Geistes“" als Ausgangsbasis für die psychologische Forschung gewählt werden kann. Im Grunde genommen hat dies schon W. Wundt und haben es die Völkerpsychologen vor ihm gesehen. Wundts Völkerpsychologie ist wenigstens dem Umfang nach ein erstaunliches Werk und der Idee nach eine weit ausholende psychologische Interpretation der Erscheinungen des objektiven Geistes. Damit ist das Stichwort gesagt. Die Ausführung der Wundtschen Idee freilich befriedigt heute keinen mehr. Ein anderer, W. Dilthey, ist von der geisteswissenschaftlichen Psychologie zum Vorbild genommen worden. Um einen seiner geistvollen Versuche als Beispiel auf eine kurze Formel zu bringen: Angenommen, es gibt drei radikal verschiedene, sachlich nicht weiter ableitbare, in der europäischen Geistesgeschichte aber typisch immer wiederkehrende Weltanschauungen, so werden diesen drei Weltanschauungen vermutlich drei typisch verschiedene Geistesverfassungen ihrer Schöpfer, der großen Denker, entsprechen. Nämlich erstens dem Naturalismus aller Stufen und Nuancen der hingegebene, naturgebundene, natureingeordnete Mensch, dessen geistiges Zentrum gewöhnlich in den Sinnen liegt. Zweitens dem Idealismus der Freiheit, einer Weltanschauung, wie sie in höchster $\mathrm{Zu}$ spitzung z. B. Fichte vertreten hat, der heroische Mensch, dessen Zentrum im Willen liegt, der im Umschaffen alles Vorgefundenen den Sinn des 
Lebens sieht. Drittens dem objektiven Idealismus, der Weltanschauung Spinozas, der auch Goethe nahesteht, der kontemplative Mensch, Persönlichkeiten, die den Gegensatz von Natur und Geist in sich selbst zum Ausgleich gebracht haben und beiden Polen des Seins gleich nah und gleich fern in verstehender Liebe zugewandt sind. ,Alles verstehen heißt alles verzeihen."

Nun, in diesem Musterbeispiel aus Dilthey ist mancherlei angelegt, was von den Späteren in verschiedener Richtung ausgebaut worden ist. Wir legen den Finger auf die doppelte Typisierung, dort bestimmter, der Geschichte entnommener geistiger Gebilde, hier bestimmter seelischer Gesamthaltungen des Menschen und betonen als drittes die Parallele, die $\mathbf{z}$ wischen beiden gezogen wird. In ihr liegt das Verfahren der Interpretation beschlossen. Man wird, wie immer die Sache gewendet und gemodelt, und worauf das Verfahren auch angewandt werden mag, nie dies dritte, die Zuordnung, als Brücke vom objektiven geistigen Gebilde zu seinem subjektiven Mutterboden oder seiner subjektiven Wirkung, Verwirklichung oder wie sonst diese Beziehung genannt werden mag, entbehren können. Auf die Tragfähigkeit dieser Brücke, auf die Gesetzmäßigkeit solcher Zuordnungen wird zu guter letzt alles ankommen. Es ist bemerkenswert, daß Platon dieselbe Brücke in umgekehrter Richtung benutzte, wo er den idealen Staat und seine Stände nach dem Muster der menschlichen Seele und ihrer Organisation konstituierte. Darin liegt kein Widerspruch, aber eine Mahnung zur Vorsicht, daß man nicht unversehens erst hinüber und dann wieder herüber interpretiere. Denn wo immer eins durch etwas anderes bestimmt werden soll, darf es nur eine Unbekannte geben.

Was wir diesem Interpretationsverfahren bis heute verdanken, gehört fast ausnahmslos zu ein und demselben Kapitel der Psychologie, das man mit dem alten Stichwort Charakterologie oder umfassender mit dem neuen ,die Lehre von der Persönlichkeit“ überschreiben kann. Und das dürfte kein Zufall sein, denn wenn anders das biblische Wort: ,an ihren Früchten sollt ihr sie erkennen", eine psychologische Wahrheit enthält, wenn zwischen seelischem Gesamtgepräge eines Menschen und seinem Werk oder den Rollen, die er im Leben spielt, ein besonders inniger und relativ einfacher Zusammenhang besteht, dann empfiehlt es sich in der Tat, dies auf anderem Wege nur äußerst umständlich und unvollkommen zu erfassende Gesamtgepräge auf dem genannten Wege zu bestimmen. Ich möchte darauf hinweisen, daß er schon durch das Etymon des lateinischen Wortes persona angedeutet und empfohlen wird. Dies aus dem Etruskischen entlehnte Wort persona ist Name für die Tonmaske des antiken Schauspielers, dann für die Rollen im Drama und schließlich für die Rollen, die der Mensch im Leben spielt; persona patris, regis, accusatoris bezeichnet die Stellung des Vaters in der Familie, das 
Amt des Königs, die Funktion des Staatsanwaltes. Unser Wort Persönlichkeit will nicht mehr diese Rollen als solche treffen, aber dies da B und wie er sie spielt, von da aus versucht man die Wesensart eines Menschen zu bestimmen. Und das ist im Ganzen ein einleuchtendes Verfahren. So einfach freilich, wie es nach der Probe aus Dilthey erscheinen könnte, liegen die Dinge nicht auf der ganzen Linie. Es gibt außer den einfach-harmonischen Menschen, deren Ideale und Schöpfungen das eigene Wesen ungebrochen widerspiegeln, auch innerlich gespaltene und gespannte Naturen mit den mannigfachsten Relationen zu den Gebilden des objektiven Geistes; es gibt z. B. Menschen, die gerade das zu ihrem Ideale erheben, was sie selbst $n$ ich $t$ haben und sind, es gibt schaffende Menschen auf allen Gebieten, die sich im Schaffen befreien und ihrem Werke Züge dessen aufprägen, von dem sie sich innerlich losgelöst haben. Hier wird das Interpretationsverfahren eine sehr komplizierte und vielfach eine problematische Angelegenheit. Nun, irgendwo findet ja jede Methode ihre naturbestimmten Grenzen.

Angenommen nun, das Interpretationsverfahren sei im weitesten Ausmaß berechtigt und fruchtbar, so eröffnet es nicht nur einen neuen Horizont, was jeder anerkennen muß, sondern verspricht auch, wie manche meinen, eine neue Grundbestimmung vom Gegenstand der Psychologie. Sie soll eine Lehre vom subjektiven Geiste sein. Schon Hegel hat die in seinem System vorgeordneten Aufgaben der Psychophysik der Anthropologie, die Aufgaben der Erlebnisbeschreibung und -erklärung der Phänomenologie überantwortet, um der Psychologie im engsten Sinne des Wortes eine neue, systemhöhere Aufgabe zu stellen. Viele von den Neueren folgen ihm zumindesten in dem einen Punkt, dab sie eine Auslese treffen aus dem Material der Erlebnisse und nur die ,sinnhaften“, ,sinntragenden" in ihre Theorie aufnehmen. Ganz so schroff schematisch wie bei Hegel tritt die Teilung zwar nicht mehr auf, aber immer noch die Voraussetzung und das Vertrauen, daß die sinntragenden Erlebnisse als solche zu einem System, zu einem theoretisch abschließbaren und aus sich begreifbaren Ganzen sich zusammenschließen, und daß man Lücken in diesem Ganzen hypothetisch zu schließen berechtigt sei durch die Annahme von sinntragenden Dispositionen, wenn ich mich kurz so ausdrücken darf. Der Mensch ist Bürger im Reich des Sittlichen, sagt Kant. Die geisteswissenschaftlichen Psychologen erweitern den Satz, sie sehen den Menschen aktiv und passiv, selbst formend und geformt verflochten in ein mehrdimensionales System von Werten; lebt er doch ebenso in einer Welt von Sachgütern, in der Sphäre des Schönen und Erhabenen, in sozialer und staatlicher Ordnung und in religiöser Verbundenheit. Daran hat natürlich nie ein Psychologe gezweifelt, wenn es auch vielleicht der eine oder andere Spezialforscher fast vergessen hätte. Das Neue besteht nun darin, daß man erstens diese Verflechtungen zum Ausgangs- 
gegenstand der Psychologie wählt und zweitens die axiomatische Voraussetzung macht, daß die in den Erlebnissen aufzeigbaren „Sinnbänder“ (um einen Ausdruck Sprangers zu gebrauchen) einen Kosmos bilden, jene Kohärenz und Geschlossenheit aufweisen, die man von den Gegenständen eines Gebietes voraussetzen $\mathrm{mu} B$, um den Versuch einer einheitlichen Theorie für aussichtsreich zu halten. Die Sinnbändertheorie macht diesen interessanten Versuch, wir werden sehen, mit welchen Erfolgen.

4. Was kommen mußte nach dem Gesetz von der menschlichen Beschränkung jedes Forschers auf den eigenen Gesichtskreis, den er bahnbrechend selbst erschließen half, ist eingetreten. Wir haben es erlebt, daß Behavioristen der jung radikalen Richtung die ältere Erlebnispsychologie zum alten Eisen warfen, daß Interpretationspsychologen den Namen Psychologie für ihr Unternehmen ganz allein ,zurückgefordert" haben, während Psychophysiker und sonstige Experimentatoren in ihren Laboratorien sich peinlich frei zu halten strebten von den „,Systemdichtern" und sonstigen „Spekulanten“ aus dem Lager der ,Geistreichen und Schönschreiber". Mich dünkt, um die zuletzt angedeuteten und ganz überflüssigen Formpräliminarien zuerst aus dem Wege zu räumen, daß Exaktes auch in guter sprachlicher Form zu Darstellungen gelangen und Unzulängliches sich ebensowohl unter der schweren Rüstung einer übergelehrten, lebensfremden Terminologie und Grammatik wie unter dem Flittergewand brillanter Sätze verbergen kann; oder, um im Ausdruck auch den Quantitätsverehrern gerecht zu werden, ich vermute, daß ein statistisches Vierfelderverfahren keine großen positiven oder negativen Korrelationswerte zwischen den in Rede stehenden Eigenschaften ergeben würde. Das Meritorische aber (wie der Österreicher sagt) ist eine Angelegenheit philosophischer Besinnung auf den Gegenstand der Psychologie; gibt es drei Wissenschaften mit dem einen Familiennamen oder drei Arten des Vorgehens, die in getrennter Buchführung dasselbe verbuchen, oder wie steht es sonst mit dem Verhältnis der gezeichneten Richtungen zueinander? Daß sie nicht koordinatenfremd wie drei Weltanschauungen ne beneinander bestehen können und da $\beta$ der Hegelsche Kunstgriff des dialektischen Ử ber einanderbauens keinen befriedigenden Ausgleich zu schaffen vermag, darüber dürfte wohl kaum eine Meinungsverschiedenheit aufkommen. Nun, so wird eben eine gründliche Abrechnung stattfinden müssen. Wenn die vorausgehenden und noch folgenden Uberlegungen keinen anderen Fortschritt brächten als den, daß nun ein gewisser Komment, ein Reglement für diese Auseinandersetzungen vorgeschlagen und von den Parteien angenommen wird, so wären sie wohl schon dadurch gerechtfertigt. Es ist ohne weiteres zu übersehen, daß die entscheidenden Bemühungen auf die Klärung der drei Verhältnisse, die zwischen Erlebnis, Benehmen und dem geistigen Werke des Menschen bestehen, gerichtet sein müssen; oder setzen wir 
statt Werk, um vollständiger auch die Rückwirkungen des objektiven Geistes mit zu treffen, den Buchstaben $G$, der in den deutschen Wörtern Gegenstand, Gebilde und Geist vorkommt, dann lautet die Formel: Wie verhält sich $E: B, E: G, B: G$ ? Doch ich begnüge mich nicht damit, das Problem aufzustellen sondern gehe weiter und behaupte, da $B$ heute schon ein erster, wenn auch noch summarischer Schiedsspruch aus unseren philosophischen (logisch-erkenntnis-theoretischen) Betrachtungen begründet werden kann.

II.

Wie ist Psychologie möglich? So würde Kant in unserer Lage fragen. Es obliegt in der Tat dem Philosophen, bald über die Möglichkeit, bald über die Notwendigkeit des Gegebenen nachzudenken. Ich stelle die These auf, daß jeder der drei Aspekte möglich und keiner von ihnen entbehrlich ist in der einen Wissenschaft der Psychologie. Aus jedem entspringen eigene, der Psychologie unentbehrliche Aufgaben, die sinnlos werden, wenn man ihn aufgibt; jeder fordert die beiden anderen zu seiner Ergänzung, damit ein geschlossenes System wissenschaftlicher Erkenntnisse zustande kommt; Gegenstand der Psychologie ist die noch unbenannte Einheit, zu der die Erlebnisse, das sinnvolle Benehmen der Lebewesen und ihre Korrelation zu den Gebilden des objektiven Geistes als die konstitutiven Momente gehören. Das sind drei Umschreibungen für ein und dasselbe. Der Beweis soll exemplarisch an dem mir bestbekannten und scharf abgrenzbaren $\mathrm{Phänomen} \mathrm{der} \mathrm{Sprache} \mathrm{geführt} \mathrm{werden.} \mathrm{Gelingt}$ es, dann wird es nicht schwer sein, ihn auf andere Gebiete zu erweitern. Es ist eine Art transzendentaler Deduktion, die notwendig ist und erstrebt wird, man muß die Axiomatik der Psychologie a uf ihren Charakter und ihre Tragfähigkeit prüfen.

1. $\mathrm{Zu}$ den vielen Versuchen, die Sprache einzig und allein aus dem Aspekt der Erlebnispsychologie zu begreifen, gehört auch der von $W$. Wundt ${ }^{1}$. Ich zitiere einige entscheidende Sätze:

Die Sprache ist Ausdrucksbewegung, so heißt es immer wieder. „Als eine Ausdrucksbewegung, was sie auf allen ihren Entwicklungsstufen bleibt, geht sie vollkommen kontinuierlich aus der Gesamtheit der Ausdrucksbewegungen hervor, die das animalische Leben überhaupt kennzeichnen." „Wo irgendein Bewußtsein vorhanden ist, da finden sich auch Bewegungen, die diese Vorgänge des Bewußtseins nach außen kundgeben." Und was den Vergleich der menschlichen Sprache mit derjenigen der Tiere angeht, so stehen wir zwar vor einer Kluft, die wir durch keine Beobachtung direkt auszufüllen imstande sind. ,Diese Kluft ist aber nicht derart, daß die im Menschen beginnenden Entwicklungen nicht bereits beim Tier in mannigfachen Vorstufen vorbereitet wären. Was in dieser Beziehung von den psychischen Funktionen

1 W. Wundt, Die Sprache II, 2, S. 635f. Die anderen Zitate auf den darauffolgenden Seiten. 
überhaupt gilt, das gilt auch von den Ausdrucksbewegungen, die zu jenen als ihre natürlichen Komplemente gehören, und die Sprache ist demnach nichts anderes als diejenige Gestaltung der Ausdrucksbewegungen, die der Entwicklungsstufe des menschlichen Bewußtseins adäquat ist. Dieses menschliche Bewußtsein läßt sich ohne Sprache gerade so wenig denken, wie sich Sprache ohne menschliches Bewußtsein denken läßt. Darum sind beide miteinander und durcheinander geworden, und die Frage, ob die Vernunft oder die Sprache das Frühere sei, hat ebensowenig einen Sinn wie die berühmte Streitfrage, ob das Ei oder die Henne früher sei."

Man erkennt in diesen Sätzen eine einfache und klar a ufgebaute Axiomatik, die streng formuliert in drei Schritten zu entwickeln wäre. Obenan steht das Parallelenaxiom von der durchgehenden Bindung wahrnehmbarer Körperbewegungen an alle seelischen Regungen. Im zweiten Schritt wird der Entwicklungsgedanke aufgenommen und die Konsequenz gezogen, daß uns die ganze Mannigfaltigkeit des Seelischen vom niedersten Tier bis zum Menschen an der wahrnehmbaren Mannigfaltigkeit der Ausdrucksbewegungen lesbar vor Augen steht. Der dritte Schritt endlich wird vorbereitet durch die noch nicht zitierte Annahme, daß aus dem Ganzen der Ausdrucksbewegungen die Lautsprache als ein relativ selbständiger Sektor hervorgeht. „Hiernach dürfen wir annehmen, daß sich die Lautsprache ursprünglich mit und an der Gebärdensprache entwickelt und daß sie sich erst allmählich unter dem Einfluß dauernden Zusammenlebens von ihr gelöst und verselbständigt hat." Also nur im Vorbeigehen sozusagen und um die relative Verselbständigung der Lautsprache zu erklären, wird der Einfluß der Gemeinschaft in die Sprachtheorie eingeführt. Dann wird die Menschensprache in toto ausdrücklich noch einmal unter das Parallelenaxiom gestellt. Auch in ihrer höchsten Ausgestaltung ist und bleibt sie, was sie war, nämlich ein gesetzmäßiger Ausfluß und damit, wenn man so will, ein Halt und eine Stütze des individuellen Seelenlebens.

Dies letztere steht freilich nicht gerade im besten Einklang mit Wundts Auffassung von der ,Volksseele“" und der ausdrücklichen Abhebung der Völkerpsychologie von der Individualpsychologie. Allein bei genauerem Zusehen ergibt sich, daß diese Unterscheidung nicht reinlich zu Ende gedacht ist. Der wunderliche Begriff einer Gemeinschaftsseele tritt wie anderwärts der "Gesamtwille" und die ,Gesamtpersönlichkeit" nur im Programm, nur in der Einleitung zur Völkerpsychologie auf, um bei der Ausführung so gut wie vollkommen ohne Verwendung zu bleiben. Wundt ist faktisch nicht über die Erlebnispsychologie hinausgekommen; das geht im Grunde schon aus der Tatsache hervor, daß er genau nach dem Muster der Einzelseele einen Träger für die ",gemeinsamen geistigen Erzeugnisse" sucht, um sie dann doch wieder restlos in die Einzelobjekte einzubetten. Es wird ein Kriterium für den Fortschritt in den konstituierenden Begriffen sein, daß solche zweifelhaften Konzeptionen wie die Volksseele 
überflüssig werden ohne Vernachlässigung der Tatbestände, die zu ihrer Bildung gedrängt haben. Was die Sprachtheorie angeht, so bilden die angeführten Axiome das Fundament der Wundtschen Lehre. Wir schreiten zur Kritik.

Zögernd nur da und dort einmal, aber ohne rechten Ernst und rechtes Vertrauen auf die Beantwortbarkeit, hat man zu Wundts Zeiten die Frage nach dem Sinn eines Ganzen gestellt. Hier wäre sie durchaus am Platze gewesen; denn solch ein konstitutives Axiom wie das von der durchgehenden Bindung alles Seelischen an wahrnehmbare Ausdrucksbewegungen müßte sich vor der Frage: wozu das Ganze? verantworten lassen. Man beachte scharf, daß nicht etwa von der Hypothese des psycho-physischen Parallelismus, sondern von einer viel weiter gehenden und spezielleren Bindung des Seelischen an körperliche Vorgänge die Rede ist. Dem psychophysischen Parallelenaxiom wäre ja durch äußerlich unwahrnehmbare Vorgänge im Nervensystem oder sonstwo im Körper genau so gut wie durch wahrnehmbare Genüge geleistet. Nein, man müßte schon beide Begriffsmomente, das von der Wahrnehmbarkeit und das von der Ausdrucksfunktion der Körperbewegungen bis zur Unbrauchbarkeit des ganzen Begriffs verallgemeinern, verwässern, um das konstitutive Axiom der Wundtschen Sprachtheorie als eine Konsequenz der psychophysischen Parallelitätsannahme zu begreifen. „Vorgänge des Bewußtseins nach außen kundgeben" - wem kundgeben? Doch wohl nicht nur dem forschenden Psychologen, der mit raffiniert erdachten Instrumenten beobachtet, sondern allen Artgenossen, die darauf vorbereitet und dafür ausgerüstet sind, von den Kundgaben Notiz zu nehmen. Und hier liegt der Angelpunkt einer fruchtbaren Kritik. Zu einer Kundgabe im spezifischen und einzig brauchbaren Sinn des Wortes wird irgendeine Körperbewegung erst in Relation zu einem wirklich vorhandenen oder mindestens fingierten Kundnehmer; Kundgabe und Kundnahme sind nur als korrelative Begriffe definierbar. Wer Pointen liebt, könnte die These vertreten, daß Wundts und vor ihm Darwins Theorie der Ausdrucksbewegungen unabgeschlossen und unbefriedigend bleiben mußten aus mangelnder Einsicht in diesen logischen Sachverhalt. Verstöße gegen die Logik aber sind in der Regel sachlich begründet, und in unserem Falle liegen die Dinge so, daß man mit den Mitteln einer Betrachtungsweise nur vom Individuum aus etwas leisten wollte, was sie grundsätzlich nicht zu leisten vermag.

2. Obwohl es hier nur darauf ankommt, diesen allgemeinen Satz an einem exemplarischen Falle einsichtig zu machen, so sei es mir doch gestattet, in abstraktem Beweisgang zu zeigen, wie auch Darwin nach einer vielversprechenden Problemstellung auf dieselbe Sandbank geraten ist. Der Anfang ist einwandfrei. Denn wenn irgendein erster, allgemeiner Satz über die Körperbewegungen der Tiere und des Menschen schlechthin 
vonnöten ist, um die Semasiologie im weitesten Sinne des Wortes zu konstituieren, so ist es der von Darwin stillschweigend vorausgesetzte Satz von ihrer lebenswichtigen, lebenserhaltenden Leistung. Daß gewisse Bewegungen, z. B. dem Aufsuchen, Ergreifen und Verzehren der Nahrung, andere wieder anderen Lebensbedürfnissen direkt Genüge leisten, ist eine Auffassung, die der Psychologe nicht erst zu begründen braucht. Im Gegensatz dazu kann nach Darwin beim Großteil aller Ausdrucks. bewegungen von einer solch direkten Bedürfniserfüllung keine Rede sein. Wo steckt also ihre Ratio? Das ist das Darwinsche Problem. „Der ganze Gegenstand mußte von einem neuen Gesichtspunkt aus betrachtet werden, und eine jede Ausdrucksform verlangte eine rationelle Erklärung ${ }^{1}$ " Die gesuchte Ratio läßt sich in dem Satze aussprechen, die Ausdrucksbewegungen seien Rudimente ehemaliger Zwecktätigkeiten. Wenn der Zornige seine Muskeln strafft, die Fäuste ballt und mit den Zähnen knirscht, so ist das Ganze ein schwacher Nachklang aus der Zeit des Kämpfens mit Faust und Gebiß. Analoge Vermutungen werden an allen ïbrigen Gebärden erprobt und erst dort, wo sie offenkundig versagen, zwei Hilfsannahmen in die Theorie eingeführt. Einiges wie das Zusammenfahren und die ungeordneten Bewegungen beim Schreck oder das Zittern sieht aus wie sinnlose Entladungserscheinungen, wie Überflutungen des Bewegungsapparates mit Impulsen aus einer Hochspannung im Zentralnervensystem. Andere Ausdrücke könnten, meint Darwin, auch sekundär als Kontrastphänomene entstanden sein.

Nun, die Kritik hat längst schon die Tragweite dieser Ideen auf ein bescheidenes Maß reduziert. Wir stellen die Frage, warum diese ganze Theorienbildung nach einem schönen Anlauf so hoffnungslos unabgeschlossen und zerfasert steckengeblieben ist, und geben die Antwort: weil auch sie an entscheidender Stelle den notwendigen Schritt vom Individuum zur Gemeinschaft nicht vollzogen hat. Rein logisch betrachtet ist die Alternative Darwins unvollständig; denn wenn die geballte Faust nicht mehr zuschlägt, so kann die Bewegung immer noch einen Zweck erfüllen, vorausgesetzt, daß der andere, dem sie gilt, als Wahrnehmender darauf reagiert. Wer weiß, ob nicht viele Ausdrucksbewegungen gerade um solcher spezifischen Effekte auf wahrnehmende Artgenossen willen allererst entstanden sind? Aber selbst dann, wenn sie wirklich, wie es Darwin für einige plausibel machen konnte, ursprünglich eine andere Funktion besaßen, so wären sie heute als rein semantische Bewegungen nicht funktionslos geworden, sondern hätten nur einen Funktionswechsel durchgemacht. Die außerordentlich fein differenzierte Gesichtsmimik des Menschen z. B. wäre als Sammelsurium völlig zwecklos gewordener Be-

1 Ch. Darwin, Der Ausdruck der Gemütsbewegungen bei dem Menschen und den Tieren. 
wegungen gewiß nicht auf ihre heutige Entfaltungshöhe gelangt. Aber diese naheliegende und doch so weittragende Ergänzung oder Modifikation der Darwinschen Idee setzt eben voraus, daß man den anderen, den spezifischen Empfänger, den Adressaten sozusagen der Ausdrucksbewegungen, regelrecht erst in die Theorie aufnimmt. Ohne ihn wäre nichts von all dem, was sich im Anschluß an Seelenregungen im Körper abspielt, im echten Wortsinn eine Kundgabe; mit ihm erst kann der Grundbegriff der semantischen Körperbewegung definiert und so das Gebiet der Semantik abgesteckt werden.

3. Wer physikalische Modelle bevorzugt, um seine Begriffe zu klären, mag sich irgendein Zweiersystem von Sender und Empfänger wählen, um daran die wichtigen Begriffe der Einstellung und der Steuerung durchzudenken. Ein Empfänger braucht selbst nicht rein passiv, d. h. nicht stromlos zu sein; was der Sender bewirkt, kann eine Steuerung des Eigengeschehens im Empfänger sein. Eine Vorbedingung dazu ist am toten wie am lebenden Aggregate die Einstellung von Sender und Empfängcr aufeinander. Wir wissen gar nichts von einem Innern, einem Zumutesein materieller Systeme. Aber man gebe uns eines von der Art, wie sie die Menschen für die Zwecke ihrer Mitteilungen in die Ferne konstruiert haben im Betrieb zur Untersuchung, und wir wollen an ihm rein mit den Mitteln des Technikers über die Art der Koppelung und die Angelegenheit der Steuerung allerhand wichtige Erkenntnisse gewinnen. Das ungefähr ist ins Extreme gesteigert die Position des reinen Behaviorismus angesichts der Semantik im Tierreich. Es kommt darauf an, zu erfassen, daß sein Unternehmen weder hoffnungslos noch überflüssig genannt. werden darf, und dann Schritt für Schritt den Gang seiner Theorien. bildung $\mathrm{zu}$ verfolgen.

Ein konkreter Fall. Die Imker kennen am Bienenvolk den ,,Schwarmton“", "Heulton", ,Stechton" und haben auch beobachtet, ,daß der ,Flugton" einer reich beladen heimkehrenden Biene ein besonderer ist und namentlich der Abflugton einer zu einer Honigquelle wieder hinausstürzenden Biene ein eigenartiger und für die Fluggenossen verlockender sein dürfte ${ }^{1}$ " Es erhebt sich also die Frage, ob hier eine Semantik durch Töne vorliegt. Exakte Bestimmungen ergaben, daß der Flugton der an der Ausbeutung ergiebiger Fundstellen arbeitenden Bienen in der Tat um etwa einen ganzen Ton höher war als der ihrer weniger erfolgreichen Genossen. Vielleicht werden die Nestgenossen durch solch höheren Flugton zur Mitarbeit angeworben? Der Versuch hat die Frage im verneinenden Sinne beantwortet, der höhere Flugton dürfte also keine semantische Funktion erfüllen. Man beachte, daß diese Entscheidung ohne irgend-

1 Zitat nach v. Büttel-Reepen bei K. v. Frisch, Die Sprache der Bienen 1923, S. 150. 
welche Annahmen über den seelischen Zustand des Zeichengebers oder Zeichenempfängers getroffen werden konnte, man weiß nicht einmal genau, wie der höhere Flugton zustande kommt, und ob die Bienen überhaupt so etwas wie einen Gehörapparat haben. Es gibt aber andere Verständigungsmittel im Bienenvolk, deren Wirksamkeit exakt bestimmt worden ist. Die ganze Organisation des Sammelgeschäftes beruht nach von Frisch auf drei verschiedenen semantischen Einrichtungen, drei „Ausdrücken der Bienensprache“. Es ist überflüssig, sie hier zu erörtern; das Wichtigste in unserem Zusammenhang ist die Tatsache, daß in dem ganzen Buch von Frisch über die Sprache der Bienen an keiner entscheidenden Stelle irgendein Terminus der Erlebnispsychologie zu finden ist. Nichts von Trieben, Affekten, Empfindungen, nichts von irgendeinem Zumutesein des Zeichengebers und Zeichenempfängers. Das ist reiner Behaviorismus, eine wohlgebaute Lehre vom sinnvollen Verhalten der Bienen beim Einsammeln von Nektar und Blütenstaub und von der sozialen Organisation dieser lebenswichtigen Angelegenheit des Bienenvolkes. Überflüssig, die Frage zu stellen, ob das schon zur Tierpsychologie gehört oder nicht, es bietet jedenfalls einen Zugang zu ihr.

Wir zielen auf Prinzipienfragen der Sprachtheorie und durch sie hindurch auf eine Neuorientierung der Psychologie ab. Es sei hier aber zwischendurch eine Bemerkung zu der Frage nach dem Ursprung der Sprache vorgebracht. Nicht zu dem spezifisch Menschlichen an unserer Sprache, sondern zu dem weiten Bereich der vormenschlichen semantischen Einrichtungen, aus dem sie vermutlich herausgewachsen ist. Hätte es seine Richtigkeit mit dem Wundtschen Parallelenaxiom, dann wäre ein weiteres Fragen nach dem Ursprung des Semantischen abgeschnitten, denn es wäre ja irgendwie wesensgesetzlich den psychischen Erscheinungen mitgegeben, und man könnte höchstens weiter nach deren Ursprung forschen. Die neue Auffassung dagegen, welche den Begriff der Ausdrucksbewegungen viel enger und spezifischer faßt, gestattet und fordert wieder die Frage nach ihrem Ursprung. Eine Frage, die nicht mehr den Vorteil genießt, Unterschlupf zu finden bei einem axiomatischen Satz, sondern empirisch beantwortet sein will. Von der Korrelation der Begriffe Kundgabe und Kundnahme aus empfiehlt sich die Hypothese, da $B$ die semantischen Einrichtungen von vornherein im Dienste eines geordneten Gemeinschaftslebens stehen und überall dort auftreten, wo die Einstellung der Mitglieder einer echten Gemeinschaft aufeinander und die wechselseitige Steuerung ihres Benehmens über den Wirkungsbereich des einfachsten Wahrnehmungskontaktes hinaus erreicht werden soll. Liegt eine Gemeinschaftsaufgabe ganz im Bereich des gemeinsamen Wahrnehmungsfeldes zweier Individuen, dann bedarf es keiner besonderen semantischen Einrichtung, um eine Konkordanz ihrer Tätigkeiten zu erreichen; diese Tätigkeiten vermögen sich gegenseitig selbst zu steuern, wenn anders sie 
wahrgenommen und verstanden werden. So greifen die Tätigkeiten von Menschen und Tieren in ungezählten Modifikationen wortlos und gestenlos ineinander. Transzendiert aber die Aufgabe in irgendeiner Richtung diesen Bereich, dann bedarf es eigener, vermittelnder Einrichtungen, bedarf es eines Kontaktes höherer Ordnung, um die Steuerung weiter zu ermöglichen. Es ist z. B. ein relativ einfacher Ersatz der gemeinsamen Wahrnehmungssituation, wenn unter den Bienen die Finderin einer neu aufgeblühten honigreichen Blütenart in den Stock zurückgekehrt, Genossen, die müßig herumsitzen, zum Ausfliegen anregt und ihnen den spezifischen Duft der Blütenart mitgibt, nach dem sie nun das Flugfeld absuchen. Ich glaube, wir kommen mit diesem Leitgedanken dem Ursprung der semantischen Einrichtungen viel näher als durch die Axiome Wundts.

Darwins Idee war im Vordersatz richtig und im Nachsatz falsch. Um ein Gemeinschaftsleben, das diesen Namen verdient, d. h. über die Zufallsscharung von Einsiedlern hinaus zu Gemeinschaftsleistungen organisiert ist, allererst zu ermöglichen, war die gegenseitige Einstellung, das Verstehen, und die Steuerung vonnöten. Der Fortschritt zu Kontakten höherer Ordnung dürfte von dieser Basis aus erfolgt sein, und so mag man es zum methodischen Prinzip erheben, die spezifischen Gebärden einzeln daraufhin zu untersuchen, ob und wie sie wohl aus prosemantischen primären Zwecktätigkeiten entstanden sein mögen. Allein sie darum als rudimentäre Zweckgebilde aufzufassen, das wäre kaum klüger und berechtigter, als wenn jemand das Telegramm als rudimentären Brief charakterisieren wollte. Es steckt ein eminent progressiver Ent wicklungswert in den Gebärden. Man kann ihn nur so treffen, daß man von vornherein nicht vom isolierten Individuum, sondern von der Gemeinschaft, nicht vom Einer-, sondern vom Zweiersystem ausgeht. Die Theorie wird beim Übergang vom physikalischen Modell zum lebenden Zweiersystem eine Reihe zusammengehöriger, spezifischer Grundeigenschaften an ihm finden. Ich nenne im Vorbeigehen die mehr oder minder großen Spielräume im Geben und Empfangen, genauer gesagt, Verwerten der Steuerimpulse je nach dem Eigenbedarf der beteiligten Individuen; ich nenne weiter, ohne darauf einzugehen, den entscheidenden Schritt von der unmittelbar verständlichen, naturhaften zur symbolischen Gebärde.

4. Schon die Biologie sieht sich veranlaßt, ihre Untersuchungen über das Individuum hinaus auf die Faktoren des Lebensraumes und der Tiergemeinschaften auszudehnen. Man schlage etwa das Werk von Hesse-Doflein "Tierbau und Tierleben" auf; im Vorwort des zweiten Bandes wird treffend der Standpunktwechsel charakterisiert, der dazu notwendig ist. Wurde im ersten Band das Individuum, als lebensfähige Einheit geschildert", so muß nun eine zweite Betrachtung folgen, worin „,die Gesamtheit der Einflüsse, die während des individuellen Lebens auf 
eine Tierart einwil cen", zur Würde jener Rahmeneinheit erhoben wird. Und es sind in der Tat neue Probleme, die aus dem neuen Aspekte entspringen. Wenn die Psychologie den analogen Schritt vollzieht, dann liegt darin mehr beschlossen als für die Biologie, denn die Erlebnisse sind Gegenstände der inneren, das Benehmen ist, wie es scheint, ein Gegenstand der äußeren Wahrnehmung. Kein Wunder, daß der Behaviorismus mit dem Gebaren und den Ansprüchen einer neuen Wissenschaft aufgetreten ist. Ich bin der Meinung, daß dieser Anspruch in einem präzisen Sinn begründet ist, aber den Verzicht, das Ganze der Psychologie auszumachen, in sich schließt. Und das Gebiet der Sprache, das wir zur Illustration gewählt haben, ist wie kaum ein anderes geeignet, uns darüber einen klärenden Aufschluß zu bieten.

Zum Ganzen der Sprache gehören sinnlich wahrnehmbare Zeichen und ihre Bedeutungen. Man kann diese Zeichen für sich zum Gegenstand einer Wissenschaft machen und gelangt so zur Konstitution der Phonetik. An ihr und ihrem Verhältnis zum Ganzen der Sprachwissenschaft ist paradigmatisch vorgebildet und einfach abzulesen, was uns zur Würdigung des Behaviorismus im Rahmen der Psychologie zu erfassen vonnöten ist. Erstens das scheinbar paradoxe Doppelgesicht einer Abkehr und Zukehr zum Sinn der Zeichen. Die Phonetik muß prinzipiell die sprachliche Bedeutung ihrer Gebilde außer Betracht lassen (einklammern würde Husserl sagen), um sie rein für sich zu erforschen und doch stets darauf sehen, daß etwas zum Einklammern da ist, damit sie nicht abirrt auf das Gebiet der sprachlich irrelevanten Laute. Gewiß wird ihr niemand verwehren, den ganzen Umkreis des Hörbaren abzustecken und, wo es Vorteil bringt, zur Klärung ihres speziellen Gegenstandes heranzuziehen. Aber zu dem, was sie eigentlich sein will und leisten soll, wird sie doch nur durch die besondere Auswahl derjenigen Laute, die in der Sprache als sinnvolle Zeichen fungieren. Das Analoge gilt für den Behaviorismus. Er mag sich drehen und wenden, wie er will, es ist ihm wesensgesetzlich vorgeschrieben, aus all dem, was man an Verhaltungsweisen der Tiere und des Menschen mit den Sinnen wahrnehmen kann, die ,sinnvollen" auszuwählen, an denen allein das Interesse des Psychologen haftet. Also auch hier muß etwas in der Klammer zurückbleiben, und niemand kann letzten Endes darüber Aufschluß geben, was Sinn eigentlich ist, außer der Erlebnispsychologie. Vor dieser Aufklärung letzten Endes liegt freilich das weite Gebiet der „objektiven" ZweckmäBigkeit, das man einstweilen fiktiv durch ein fort und fort gesetztes „als ob" behandeln kann. Über die endliche philosophische Einlösung dieses Wechsels mag jeder denken, wie er will, dem Psychologen aber ziemt es, darüber im klaren zu sein, daß er schon, um solche Setzungen zu vollziehen, immer wieder Anleihen aus seiner eigenen inneren Erfahrung machen muß. 
Die Erläuterung des Sinnbegriffs sei für später rorb noch etwas zweites, was man wissenschaftstheoretisch unserem Vergleiche entnehmen kann. Der Phonetiker begibt sich, gleichviel, ob er die akustischen Phänomene als solche oder ihre Erzer zung durch den menschlichen Stimmapparat ins Auge faßt, unter die Physiker und Physiologen. Er durchläuft mit ihnen, und muß es tun, die ganze Skala physikalischer Betrachtungen von der Stimmgabel und Lippenpfeife bis zu den komplexen Organstrukturen der Muskulatur und des tierischen und menschlichen Zentralnervensystems. Und darf über all dem doch nie vergessen, erstens, daß die Vollendung seiner Wissenschaft über die Psychologie führt, und zweitens, daß sie im Dienste der Sprachwissenschaft steht. Quod non est in actis, non est in mundo, sagt der Jurist. Die Akten sind in unserem Fall das ,Sprachbewußtsein“, ein Begriff, der freilich erst definiert werden muß. Aber jedenfalls kann man sofort das eine sagen: was nicht gehört oder gesehen (oder im Notfall getastet) werden kann, und zwar von den unbewaffneten Sinnen der naiven Sprachgenossen, das gehört nicht zum Bestande der Sprachzeichen. Ja noch viel weniger gehört zu ihr. Aus der vieldimensionalen und kontinuierlichen Mannigfaltigkeit der mit dem menschlichen Stimmapparat erzeugbaren Laute, aus dem kaum übersehbaren Reich des Möglichen, verwendet jede menschliche Sprache nur eine abzählbare Menge wohl charakterisierter Elemente und Komplexe. Die Musik macht es mit ihrem Material vielleicht nicht ganz so eigenwillig, aber im Prinzip doch ebenso. Und die Prinzipien solch selektiver Bevorzugung sind wieder nur, sei es wie in der Musik aus allgemeinen Gesichtspunkten der Erlebnispsychologie, sei es wie in den einzelnen Sprachen aus dem nur teilweise durchsichtigen historischen Tatbestande, jedenfalls in beiden Fällen nicht ohne Rücksicht auf die Sinnfunktion der Zeichen zu gewinnen. Genau in der gleichen Lage befindet sich die Wissenschaft vom Benehmen der Tiere und der Menschen. Es wäre ein Grundirrtum, zu glauben, die natürlichen oder künstlichen „,Situationen und Reaktionen“ könnten ohne Rücksicht auf den biologischen Sinn des Ganzen jene begriffliche Bestimmung erfahren, die das Ziel der Psychologie vorschreibt. Ein Tier unter variierten Umständen der „Behinderung“ beobachten, heißt schon die Situationen, eine Handlung als Kampf oder Pflegetätigkeit bestimmen, heißt die Reaktionen teleologisch deuten und für die wissenschaftliche Betrachtung auswählen. Wie sich aus dem unüber sehbaren Reich sinnloser Möglichkeiten das System des sinn. vollen Benehmens heraushebt, das ist das spezifische Thema der Benehmenstheorie. Mag das Experiment dabei, und das ist zum Zweck des systematischen UUberblicks und zur Abhebung notwendig, alle Arten und Stufen der Sinnentlehnung vornehmen, man darf es, wenn dies wie in der wohldisziplinierten Phonetik geschieht, darob nicht tadeln. Letzten 
Endes freilic $x_{1}$ miß $B$ eine Theorie des sinnvollen Benehmens herauskommen, wenn anders das Ganze eine Angelegenheit der Psychologie bleiben soll.

5. Die Gelegenheit ist günstig, im Namen dieses Satzes, der ohne weiteres auch auf das Gebiet der Erlebnispsychologie übertragen werden kann, zu einem bestimmten Einwand, der gegen die Psychologie der zwei letzten Menschenalter im Ganzen erhoben worden ist, Stellung zu nehmen. Es war zum guten Teil Pionierarbeit, was sie geleistet hat, und vorauszusehen, daß sie einmal historische Rechenschaft über den Sinn und die Tragweite ihrer Unternehmungen werde ablegen müssen. Vielleicht ist der Zeitpunkt nicht fern, an dem dieser ProzeB in vollem Umfang vor kompetenten Richtern aufgerollt werden kann. Der Einwand, den ich hier im Auge habe, ist leicht zu beantworten.

„Ich fordere das Wort Psychologie für die Wissenschaft vom sinnerfüllten Leben zurück", sagte E. Spranger 1922. Zwei Jahre später zog er ,mit lebhafter Freude“ selbst diesem bösen Wort den Stachel aus: ,Damit ist die Trennung der beiden Psychologien, die sich herausgebildet hatte, überbrückt, und es bleibt nur die Verschiedenheit, die sich aus der Arbeit an verschiedenen Bewußtseinsschichten ergibt" 1 . Ich will die Freude ob solcher Wiederfindung nicht stören, sondern vertiefen. Zwei Psychologien nebeneinander, die eine als die Lehre vom sinnerfüllten Leben und die andere als die Lehre von den an sich sinnlosen Erlebnismaterialien - das wäre in der Tat eine reichlich unbrüderliche Teilung gewesen und keiner der beiden ,Wissenschaften“ auf die Dauer gut bekommen. „Wissenschaft vom sinnerfüllten Leben“ — wann und wo war die Psychologie das nicht mehr?

Ein einigermaßen gerechter Rückblick auf jüngst Vergangenes, von dem man sich zu eigenen Zielen losgelöst hat, ist besonders schwierig. Ich denke aber, über die notwendige Einseitigkeit jeder historischen Phase und den guten Grundsatz, den ich irgendwo einmal bei Harnack gelesen habe, man solle sich vor dem billigen Triumphe hüten, der aus dem Vergleich der eigenen vollkommenen Idee mit der mangelhaften Realisierung einer fremden Idee entspringt, wird man sich schnell einigen und damit imstande sein, einiges Irrelevante abzuscheiden bei dem Urteilsspruch über die Psychologie der verflossenen zwei Menschenalter. Vielleicht trifft ein Vergleich am besten, was zu ihrer Verteidigung gesagt werden muß. Angenommen, ein junger Mediziner käme aus jenen meist öden Stunden, in denen er jeden Knochen und jedes Knöchelchen in die Hand nehmen, betrachten, zeichnen und die lateinischen Namen all seiner Kanten, Furchen und Vorsprünge erlernen muß, zu Spranger, ob denn

1 Das erste aus dem Vorwort zur 3. Aufl. der ,Lebensformen“, das zweite aus der „Psychologie des Jugendalters" S. 10. 
das alles zur Wissenschaft vom „sinnerfüllten menschlicher; Organismus “: gehöre, der Student würde gewiß eine trostreiche jjahende Antwort erhalten. Nur die höchste, dem Anfänger freilich nicht immer begreifliche Akribie hat die Osteologie instand gesetzt, beim Fund eines isolierten Unterkiefers in den Sanden von Mauer bei Heidelberg die begründete Vermutung auszusprechen, daß dieser Knochen weder einem menschenähnlichen Affen, noch einem rezenten Menschen, sondern einem „,homo“, noch primitiver als der Neandertaltypus, angehört hat. So tief führt die Osteologie in die „Struktur"feinheiten des menschlichen Körpers hinein. Man vertausche nun den Mediziner mit einem Psychologen, der irgendwo an den öden Feinheiten psychophysischer Maßmethoden oder an dem Gedächtnisexperiment nach Ebbinghaus und G. E. Müller oder an irgendeiner anderen Statistik der Psychologie matt und irre geworden ist. Wird er eine weniger trostreiche Antwort erhalten, wie steht es z. B. mit dem Sinngehalt der weitausgebauten Lehre von den Empfindungen oder vom mechanischen Gedächtnis? Die Männer von Helmholtz und Fechner bis G. E. Müller glaubten jedenfalls an etwas zu schaffen, was den Vergleich mit der Osteologie auszuhalten vermag; und sie dürften sich nicht getäuscht haben.

Wir wollen der Sache durch einen neuen Vergleich ein anderes, uns schon bekanntes Gesicht abgewinnen. Kunstwerke, Sonaten und Gemälde, die gewiß in ihrer Art zur Sinnfüllung unseres Lebens beitragen, sind auf Töne und Farben gebaut und fordern vom Psychologen eine Theorie der Farben und Töne. Ungefähr so wie die Sprache vom Linguisten die Phonetik fordert. Daß in der reinen Empfindungslehre die ganze Sinnfülle des Kunstwerkes und der Wahrnehmungswelt überhaupt zunächst einmal ausgeschaltet (,eingeklammert") wird, ist keine Entgleisung, sondern wissenschaftliche Notwendigkeit. Was würde man von einem Phonetiker sagen, der die analoge Ausschaltung des sprachlichen Bedeutungsgehaltes nicht reinlich zu vollziehen vermöchte? Man erlasse mir die Durchführung einer zweiten Parallele auf dem Gedächtnisgebiet; das sogenannte rein assoziative Gedächtnis soweit als möglich isoliert zu untersuchen war kein verfehltes, sondern ein notwendiges und fruchtbares Unternehmen, ohne das wir heute nicht imstande wären, die Eigenart des geordneten Denkverlaufes beim Menschen wissenschaftlich zu begreifen. Denken ist freilich etwas anderes als das Reproduzieren sinnloser Silben. Aber es ist gar nicht abzusehen, wie wir diesen Unterschied wissenschaftlich je hätten erfassen sollen ohne den Versuch einer möglichst reinlichen Isolierung der beiden stets verflochtenen, aber wechselnd dominierenden Momente blinder Assoziationen und ihrer einsichtigen Beherrschung und Verwertung. Aber darin stehe ich auf Sprangers Seite, daß ohne die wissenschaftliche Erforschung des zweiten Momentes mit den Erlebnissen des Gedächtnisexperimentes kaum etwas Rechtes an- 
zufangen wäre, und wundere mich einigermaßen, daß ihm 1922 entweder die Existenz oder die Idee der Denkpsychologie noch verborgen sein konnte.

6. Doch überlassen wir das Vergangene dem Historiker. Wir haben den Behaviorismus gerechtfertigt und kritisiert, nun gilt es den dritten Aspekt des Gegenstandes der Psychologie ebenso exemplarisch an der Sprache zu würdigen. Ein Beispiel: Angenommen, ein Zeuge vor Gericht macht eine Aussage gegen seine UUberzeugung, trifft aber damit exakt den objektiven Tatbestand. Er hat, wenn es unter Eid geschah, einen Meineid begangen und ist strafbar, obwohl er Richtiges gesagt hat. Es kommt auch umgekehrt vor, daß jemand nach bestem Wissen etwas Unrichtiges aussagt, also einen Falscheid begeht, und dafür unstrafbar bleibt. Daraus ist rein formal, relationstheoretisch, die Unabhängigkeit von zwei Sinndimensionen, denen ein und derselbe Aussagesatz anger hört, zu entnehmen. Er gibt erstens eine UUberzeugung des Sprechers kund und bringt zweitens einen Sachverhalt zur Darstellung. Eine Kundgabe kann echt oder unecht sein, die Darstellung ist richtig oder unrichtig. Im lebendigen Sprachverkehr kommt es dem Sprecher oder Hörer bald mehr auf das eine, bald auf das andere an; der vollendete wissenschaftliche Satz erfüllt seine Leistung rein in der Sinndimension der Darstellung; im Gefüge eines lyrischen Gedichtes dagegen kann die direkte oder indirekte Kundgabe eines grammatisch betrachtet schlich. ten Aussagesatzes durchaus dominieren:

Úber allen Gipfeln ist Ruh'

In allen Wipfeln spürest du

Kaum einen Hauch ....

Der Begriff und die Kriterien der Wahrheit sind wesensgesetzlich aus der Darstellungsfunktion zu entnehmen und umgekehrt bestimmt das Ideal der treffenden und richtigen Darstellung weitgehend die Produktion sprachlicher Gebilde bis in die Wortwahl und Struktur der Sätze hinein. Die Sprache ist also, soweit dies zutrifft, einem bestimmten Gebiet des „objektiven Geistes", dem Gebiet der Erkenntnis, der Wissen. schaft, der Logik verhaftet, verwachsen. Das ist gewiß keine neue und keine strittige Erkenntnis; sie war den Griechen, die das eine und das andere mit demselben Wort hóros bezeichneten, sie war Aristoteles, dem Schöpfer der Logik, geläufig und ist gegen alle ,Kritiker" der Sprache in besonnenem Ausmaß aufrechtzuerhalten. Es erhebt sich die Frage, welche Konsequenzen sich daraus für die Psychologie der Sprache ergeben. Ich beantworte sie dahin, daß noch einmal ein neuer Ansatz möglich und nötig wird und bringe dazu vorerst nur den kritischen Teil des Beweises von der Unzulänglichkeit jeder Sprachtheorie, die ohne ihn auszukommen versucht. Das Positive, was ich zu den Problemen einer Kantstudien XXXI. 
Konstitution der Psychologie vom objektiven Geiste her zu sagen habe, soll dann im dritten Abschnitt folgen.

Wir schlagen noch einmal Wundt auf und finden im zweiten Band (2. Aufl., S. 258) in der Satzlehre, wo nach dem in einer reinen Kundgabetheorie einzig berechtigten Kundgabe-, oder wie Wundt sagt, Ausrufungssatz der Übergang zum Aussagesatz gesucht wird, die ebenso treffende wie unerwartete Feststellung: ,Seinem psychischen Inhalt nach ist der Aussagesatz auf das Tatsächliche und Objektive gerichtet" (dort nicht gesperrt). Nun, ich denke, das mußte früher kommen und Platz haben in den axiomatischen Grundlagen der Sprachtheorie. Jedes Wort, das als Name fungiert, ist ,aufs Objektive gerichtet", d. h. dem bezeichneten Gegenstande zugeordnet. Und gerade darin ist die Möglichkeit, daß es so etwas wie Darstellungssätze gibt, vorbereitet, ja liegt nach alter Auffassung der Keim des spezifisch Menschlichen an unserer Sprache beschlossen. Wenn Platon die Frage stellt, ob die Wortbedeutungen $\varphi u ́ \sigma \in \mathfrak{l}$ oder $\theta \hat{\sigma} \sigma \in \mathfrak{l}$ bestehen, wenn Herder sich um die seelischen Situationen des Urmenschen, aus denen heraus die Menschensprache geboren wurde, bemüht, ja selbst in der Erzählung der Genesis, wo Adam ,einem jeglichen Vieh und Vogel unter dem Himmel und Tier auf dem Felde seinen Namen" gibt, stets hat man die Nennfunktion der Wörter in diesen Ursprungsspekulationen vor Augen. Es ist richtig, die Problemstellung Wundts und Darwins faßt tiefer an, indem sie das Gesamtgebiet der menschlichen und tierischen Gebärden zum Gegenstand wählt und die Menschensprache auf breitester vergleichender Grundlage als einen Sektor des Ganzen verstehen will. Ist nur die Frage, ob die allgemeinsten Begriffe und Leitsätze einer solch umfassenden Theorie der Gebärden auch das Eigenartige an der Menschensprache zu erfassen und zu bestimmen vermögen. Nach den Gesetzen der Logik ist es keineswegs ausgeschlossen, daß man beim Fortschritt der theoretischen Bewältigung eines Gesamtgebietes an bestimmter Stelle zur Aufnahme neuer Axiome gezwungen ist. Ich behaupte, dies trifft für die Sprachtheorie zu. Vorsichtiger und logisch exakter formuliert, wir können nur beweisen, daß die bis hierher entwickelte Axiomatik für die Menschensprache nicht ausreicht. Ob und wie weit etwa die Verhaftung an die Logik, die wir in der Menschensprache antreffen, auch in die vormenschlichen semantischen Einrichtungen hinabreicht, mag als eine offene Frage bestehen bleiben.

Überblicken wir noch einmal den ersten und den zweiten Schritt unserer eigenen Theorie. Erstens: wo immer ein echtes, d.h. sich selbst regulierendes Gemeinschaftsleben besteht, muß es eine Steuerung des sinnvollen Benehmens der Gemeinschaftsglieder geben. Zweitens: wo die Richtpunkte der Steuerung nicht in der gemeinsamen Wahrnehmungssituation zu finden sind, müssen sie durch einen Kontakt höherer Ordnung vermittelt werden. 
Das zweite Axiom ist der Quellpunkt semantischer Einrichtungen. In dem Beispiel aus dem Bienenleben liegt eine räumliche Transzendenz des Richtpunktes der Steuerung vor. Denn im Bienenstock ist die neuentdeckte Blütenart nicht wahrzunehmen und auf sie sollen doch die Neuangeworbenen das Flugfeld absuchen; also erfolgt ad hoc im Werbetanz ein rein semantischer Akt, die Duftübertragung von der Werbenden auf die Angeworbene. Vielleicht gelingt es einmal, die Möglichkeiten der Transzendenz systematisch aufzustellen, der Philosoph wird neben der räumlichen sofort an die zeitliche Transzendenz und an das, was die Menschensprache in dieser Richtung leistet, denken. Fast wichtiger noch ist es, gleich am Ausgang daran zu erinnern, da $B$ wir es mit lebenden Individuen zu tun haben. Soll der Eigenbedarf und die Eigenstimmung der Individuen bei der gegenseitigen Steuerung ihres Benehmens Berücksichtigung finden, nun, dann müssen sie eben, soweit sie nicht ohne weiteres aus der primären $Z_{\text {wecktätigkeit zu entnehmen }}$ sind, eigens kundgegeben werden. Hier die Stelle der Theorie, wo die Wundtsche Idee in modifizierter Form einzufügen ist. Nicht jede seelische Regung und alle Schwankungen des Zumuteseins haben einen Anspruch darauf, in spezifischen Gesten zum Ausdruck zu gelangen; gefordert wird dies entwicklungstheoretisch nur für jene, die irgendwie kurzerhand das Benehmen anderer Gemeinschaftsglieder zu steuern berufen sind.

Nun der dritte Schritt, der das System der Axiome zum Abschluß bringt: Durch Zuordnung der Zeichen zu den Gegenständen und Sachverhalten gewinnen sie eine neue Sinndimension und damit eine unabsehbare Steigerung ihrer Leistungsfähigkeit als Kommunikationsmittel, das eine durch das andere.

Betrachten wir die Sache noch einmal in statu nascendi an Beispielen aus dem Bienenleben. Den Angeworbenen realiter mitgegeben wird ein bestimmter Blütenduft. Er mag, wenn nun die Suchenden ihren Instinkten folgend das Flugfeld abstreifen, ähnlich wirksam sein wie bei uns ein mitgenommenes Erkennungszeichen. Genau besehen aber fehlen der ganzen Einrichtung zwei Momente, auf denen der unvergleichliche Freiheitsgrad und der so gut wie unbegrenzte Anwendungsbereich der menschensprachlichen Bezeichnungen beruhen. Nämlich erstens die Entstofflichung der Zeichen. Denn es ist und bleibt ja der reale Duftstoff der Blüten, welcher die Kommunikation der Bienen bestreitet, während die Kennzeichen im Bereich der menschlichen Namengebung einen Verkehr ohne Stoffproben ermöglichen. Um nun den Bienen und Ameisen möglichst weit entgegenzukommen, vielleicht bedarf im Grenzfall die Empfangende bei derartigem Verkehr nicht mehr des Stoffes, als was zur einmaligen Reizung ihres Geruchssinnes nötig ist; vielleicht behält sie den Eindruck gedächtnismäßig und bleibt auf ihn eingestellt während des Suchens im Flugfeld. Das wäre an sich eine bemerkenswerte Leistung, aber noch njcht das Entscheidende. Erst dann, wenn sie imstande wäre, ihren Gedächtniseindruck anderen Genossen weiter zu vermitteln, ohne wieder etwas von der alten Stoffprobe zu 
benötigen, erst mit dieser Unabhängigkeit wäre im ersten Punkt die Vergleichsbasis mit der Menschensprache erreicht.

Dazu das zweite. Daß gerade Düfte und das Geruchsorgan den Verkehr der Bienen vermitteln, während sich unser Sprechen im Sektor des Hörbaren vollzieht, wäre kein Grund, einen Niveauunterschied zu konstatieren. Übrigens dürfte in der Semantik der Bienen, ähnlich wie bei den Ameisen, auch der Tastsinn eine Rolle spielen, und der Tastsinn böte gewiß annähernd ähnliche Möglichkeiten wie unser Gehörssinn in Verbindung mit dem Kehlkopf. Wozu außer einer gewissen Mannigfaltigkeit die Selbsterzeugung der Kommunikationsmittel gehört. Beides wäre prinzipiell auch in einer Geruchssprache möglich, ja, mit einem einzigen Eigenduft zum mindesten arbeitet sogar die Semantik der Bienen. Wenn sich nämlich eine Finderin an reicher Nahrungsquelle vollgesaugt hat, beduftet sie den Fundort, und es ist exakt bewiesen, daß die Stockgenossen aus einiger Entfernung von diesem Lokalzeichen angelockt werden. Ein selbstproduziertes Lokalzeichen also wird der Fundstelle angeheftet, so ungefähr wie der famose Rötelstrich von den Räubern Ali Babas. Wir wollen als Deuter der Dinge auch hier nicht kleinlich mäkeln an dem Vergleich, sondern die Leistung möglichst hoch einschätzen. Ein geschickter Anwalt und Vermenschlicher der Bienensprache wird nach solchem Zugeständnis einen großen Logiker zum Zeugen aufrufen. Hat nicht J. St. Mill den Kreidestrich der Räuber in der menschlichen Logik als Beispiel verwertet, um die Leistung der Eigennamen zu charakterisieren? Also erreicht die Bienensprache das Niveau der menschlichen Eigennamen? Nein, das wäre ein übereilter Schluß. Der besonnene Gegner einer vorschnellen Vermenschlichung wird von der doppelten Gleichung, Gleichstellung, die hier behauptet wird (Beduften $=$ Rötelstrich $=$ Name) nicht die erste, sondern die zweite, selbst gegen J.St. Mill, wenn es sein müßte, in Zweifel ziehen. Das naheliegende erste Argument, es sei doch immer dasselbe Erkennungszeichen, was die Bienen an jedem neuen Fundort anbringen, ist, was die Prinzipien anlangt, von geringem Gewicht. Wenn ihrer Sprache nur das eine übrigbliebe, eine angemessene Mannigfaltigkeit in die selbstgeschaffenen Ortszeichen zu bringen, das wäre kein belangreiches Manko; auf dem Gebiet der Tastzeichen der Ameisen besteht nach den Angaben der besten Kenner eine recht beträchtliche Mannigfaltigkeit, wenn nicht gerade von Ortszeichen, so doch von Klopfzeichen, die sich die Tiere gegenseitig auf Brust und Kopf versetzen. Aber das andere ist bestreitbar, nämlich, dab in dem Punkte, worauf es hier ankommt, Kennzeichen von der Art des Kreidestrichs den Eigennamen der menschlichen Sprache gleichzustellen sind. Man braucht nur der Frage nachzugehen, warum solche Erkennungszeichen der Natur der Sache nach nur angeheftet an Objekte als Zeichen fungieren, also nicht ablösbar sind, um wieder in das rechte Geleise zu kommen. Unsere Eigennamen fungieren ja auch ohne physische Anheftung. Erst wenn bewiesen wäre, daß solch unangehef tete, selbstgeschaffene Gegenstandszeichen im Verkehr der Bienen oder irgendwelcher anderer Tiere vorkommen, wäre für sie die Gleichstellung mit den Namen unserer Sprache berechtigt. Das ist das zweite.

Noch einmal beides zusammengehalten, die Entstofflichung der Verkehrsmittel, genauer gesagt der Schritt von der Stoffprobe zum echten Zeichen und eine prinzipielle Ablösbarkeit von den Dingen, als deren Zeichen es fungiert. Erst beide in eins böten die Gewähr dafür, daß eine gegebene Semantik, die wir nur von außen her beurteilen können, auf unserer dritten Entwicklungsstufe steht. Weder die Ablösung allein, wenn der Charakter 
einer Stoffprobe erhalten bleibt, noch die Selbsterzøugung allein, wenn die prinzipielle Ablösbarkeit fehlt, beweisen, daß Zeichen von der Dignität unserer Namen vorliegen, beweisen, daß zwischen Sender und Empfänger rein ideelle, d.h. kraft reiner Zuordnung fungierende Gegenstandszeichen ausgetauscht werden oder ausgetauscht werden könnten. Auf diese Möglichkeit kommt es an. Das eingeschlagene Beweisverfahren ist ein Indizienbeweis, der wie jeder andere seiner Art geschlossen sein muß, um bündig zu sein; der Arzt kennt aus seinem Erfahrungsbereich analoge Fälle, wo zwei Symptome nur kombiniert eine Beweiskraft besitzen. Was die Sache angeht, so kann man sagen: wo beide Symptome vorliegen, da ist ein Entwicklungsschritt vollzogen, der mit dem Übergang vom primitiven Tauschverkehr der Sachgüter zum Papiergeld verglichen werden darf. Oder noch einmal anders ausgedrückt, G. Simmel hat einmal, um ganz allgemein die Eigenart der menschlich geistigen Stufe im biologischen Entwicklungsgang zu charakterisieren, von der Wendung zur Idee gesprochen. Damit ist ziemlich exakt das tertium unseres Vergleiches getroffen. Die Zuordnung der Namen zum Genannten ist ebenso wie die Zuordnung der Assignaten zu ihren ökonomischen Werten eine rein ideelle Relation, während man bei der Goldmünze, richtiger beim Goldbarren, wie beim reellen Duftaustausch der Bienen trotz ihrer semantischen Funktion vom Stoffwert des Kommunikationsmittels noch nicht derart frei geworden ist, daß seine Ersatzmöglichkeit durch ein, kraft reiner Zuordnung, in Kurs gesetztes Zeichen für dieselbe Gemeinschaft garantiert erscheint.

Ein Schluß aus Symptomen ist stets ein umständliches Verfahren. Aber er ist in der Tierpsychologie notwendig, und wir haben auf diesem Wege objektive Kriterien für das Bestehen der dritten Entwicklungsstufe gewonnen.

Gehen wir zur Menschensprache selbst über, so ist die Struktur, der Sinn und die Art ihrer Darstellungsfunktion viel einfacher und reiner durch einen Vergleich mit anderen Arten der Darstellung, die in Kunst, Wissenschaft und sonstwo anzutreffen sind, begrifflich zu erfassen. Die Sprache ist wohl die erste und ist sicher die universellste von allen, die der Menschengeist erschaffen hat. Es ist, wenn wir von da zurückblicken, beim gegenwärtigen Stand unserer Kenntnisse müßig, zu überlegen, ob eine andere species auf Erden dem Menschlichen in diesem Punkt nähergekommen ist als die Ameisen und Bienen. Trotzdem weder beim Haushund noch bei den menschenähnlichen Affen, sei es im Bereich der Laute und Gebärden, sei es sonst am sinnvollen Verhalten, eine echte Darstellungsfunktion nachgewiesen ist, muß die Frage ihres Vorkommens noch einmal ausdrücklich als eine offene und rein empirische Frage bezeichnet werden. Und für die Psychologie liegen die Dinge dann so: überall dort, wo eine Darstellungsfunktion nicht nachzuweisen ist, genügen unsere zwei ersten Axiome zu einer Theorie der semantischen Einrichtungen. Das dritte aber wird gefordert durch die neue Sinndimension der Darstellung.

7. Was ist nun gewonnen? Es ging um die Axiome der Sprachtheorie im weitesten Sinn des Wortes Sprache, um eine Grundlegung also der Semasiologie. Und zwar so wie der vergleichende Psychologe sie hand- 
lich vonnöten hat, der über die menschlichen Verhältnisse hinaus die ganze reiche Semantik im Tierreich mit begreifen will, sich aber von vornherein auf den Sektor der Sprache einstellt. Nicht alles, was in der Sphäre des Menschlichen die Funktion eines Zeichens erfüllt, nicht alles, was in irgendeinem Geltungssystem etwas anderes als sich selbst zu vertreten berufen ist, gehört zur Sprache. Eine Theorie der Zeichen, von diesem höchsten Gesichtspunkt her entwickelt, muß anders vorgehen und wird schließlich auch im Bestand der historischen Sprachen noch manchen Abglanz und viele Einmengungen aus sprachfremden Zeichenfunktionen nachweisen, z. B. Überreste des magischen Denkens und eine Ladung der Wörter mit moralischen, religiösen, juristischen Funktionen. Auch über sie hat eine ausgeführte Sprachpsychologie Rechenschaft zu geben. Allein hier stand das alles nicht in Frage, hier mußte jenes Minimum psychologischer Ansätze gefunden werden, ohne die auch nicht die erste Absteckung des Gebietes stattfinden kann. Ich bin allerdings der Meinung, daß die drei Sinndimensionen der Kundgabe, Auslösung und Darstellung den Kosmos der „reinen Sprache“ restlos konstituieren. Aber nicht dies, da $\beta$ sie ausreichend, sondern das andere, daß sie unent behrlich sind im Begriffssystem der Sprachpsychologie, ist der Obersatz unserer Deduktion.

Der Untersatz stellt fest, daß alle drei Aspekte der Psychologie erforderlich sind, um die Grundbegriffe, Kundgabe, Kundnahme und Darstellung psychologisch zu definieren. Das ist ein kurzer und mißverstehbarer Ausdruck: psychologisch definieren. Er will nichts anderes treffen, als was wir erst in polemischer Wendung gegen Wundt und Darwin und dann am Bestande der menschlichen Sprache durchgeführt haben, nämlich die Gewinnung und Aufzeigung von Tatbeständen, an denen die Begriffsbildung durch einfache, ideierende Abstraktion zu vollziehen war. Dies logische Verfahren als solches kann und braucht hier keine Rechtfertigung zu erfahren, es ist jedem Empiriker durchaus geläufig und wird selbst in deduktiven Wissenschaften nicht verschmäht, wie wenn der Mathematiker z. B. aus illustrierenden Exemplaren eine Strukturerkenntnis gewinnt. Dem theoretischen Physiker vollends und allen anderen, die im Bereich der Realwissenschaften Grundbegriffe gewinnen müssen, ist dies Verfahren unentbehrlich.

Der Schlußsatz unserer Deduktion stellt fest, daß für einiges, was zur Psychologie gehört, die drei Aspekte unentbehrlich sind, und überläßt es vorerst der Kraft von Analogieschlüssen, wieweit hinaus über die Sprache das Ergebnis als gesichert zu betrachten ist.

Der nervus probandi liegt naturgemäß an drei Stellen. Um mit dem letzten zu beginnen, so mußte gezeigt werden, daß der Begriff der Darstellungsfunktion an der Sprache nur von dem zu gewinnen ist, der sie als Instrument des Erkennens, in letzter Linie als Instrument 
der Logik betrachtet. Zu den aufschlußreichsten Untersuchungen, die man als reiner Theoretiker an der Sprache anstellen kann, führt die konsequente Verfolgung der einfachen Frage, wie denn die Sprache im. stande ist, mit hörbaren Lauten so gut wie alles, woran und worüber wir zu denken vermögen, in ihrer Art zur Darstellung zu bringen. In dem Begriff symbolische Darstellung kreuzen und verschlingen sich erkenntnistheoretische, logische und psychologische Probleme, ohne eine Auflösung zu finden, bevor man erkannt hat, daß zu jeder systematischen und produktiven Darstellung ein Darstellungsfeld gehört, und daß die Sprache mehrere Darstellungsfelder übereinander von der einfachen, aber fast bedeutungslosen Lautmalerei bis hinauf zur Kohärenz der Begriffe in ihrem Dienste verwendet. Auf Begriffe, auf das Invarianzprinzip, auf die Verwendung einer abzählbaren, verhältnismäßig kleinen Anzahl von symbolischen Zeichen ist die Sprache, ganz anders als z. B. die Malerei, ihrem Wesen nach angelegt. Doch das alles wird hier nur flüchtig und nebenbei erwähnt, um anzudeuten, welcher Reichtum von Problemen aus dem dritten Aspekt erwächst.

Der erste in unserer Aufzählung ist derjenige der inneren Wahrnehmung; und wollten wir ihn streichen, so wäre mit ihm ,die Sprache des Herzens" gestrichen und das Moment der Kundgabe von Erlebnissen aus der ganzen Semasiologie verbannt.

Der zweite Aspekt ist notwendig, um die gemeinschaftsbildende und gemeinschaftstragende Funktion semantischer Einrichtungen von Grund auf zu begreifen. Vielleicht entstehen noch einmal Zweifel und die Notwendigkeit, auf das präziseste zu entscheiden, ob und warum der Erlebnisaspekt allein mit diesem Tatbestand nicht fertig zu werden vermag. Wir werden zunächst unumwunden zugeben, daß mit einer genügenden Dosis menschenartiger Reflexion im Ansatz alles zu bewältigen wäre. Das Ich und das Nichtich, das Du und die Gemeinschaft - vom philosophisch vielfach reflektierten und überlegenen Denken kann man alles Schritt für Schritt dialektisch erobert und in das solipsistisch ausgestaltete Koordinationssystem des menschenartigen Bewußtseins hineingebaut ausdenken. Die Frage ist nur, ob die Berechtigung und Notwendigkeit besteht, solche Endleistungen des philosophischen Denkens an den Ausgang der genetischen Reihe zu rücken oder nicht. Der behavioristische Ansatz bietet den unüberschätzbaren Vorteil, daß das direkt Wahrnehmbare, die Steuerung des Benehmens der Gemeinschaftsglieder, als das Erstbestimmte und alle übrigen vorerst unauflösbaren Faktoren wie mit unbestimmten Zahlzeichen versehen in der Rechnung erscheinen. Nicht damit fährt man am besten bei dem Aufbau der Theorien einer Realwissenschaft, daß man das einstweilen Unentscheidbare, mag es biegen oder brechen, doch zur Entscheidung bringt, sondern damit, daß man mit Unbekanntem in der Rechnung fehlerfrei zu operieren 
und sich das Schritt für Schritt zu erweiternde Feld des Bestimmbaren nicht überflüssig und vorzeitig zu verbauen versteht. Und dies ist in unserem Fall der Sinn der Behauptung von der Unentbehrlichkeit des Schrittes vom Einer- zum Zweiersystem. Ohne unerträgliche Belastung der Hypothesen kann man die Grundtatsachen der tierischen Semantik nicht solipsistisch bewältigen, während alles unerhört einfach wird für denjenigen, der sich zu dem vorgeschlagenen Standpunktswechsel entschließt. Und so ist mit der Rückkehr zum genetisch ersten unser Rundgang beschlossen.

Merkwürdig genug, daß dieser Sachverhalt hier zum erstenmal begrifflich fixiert werden mußte. Wer sich in der Geschichte der Sprachtheorie umsieht, findet immer wieder Versuche, das Ganze aus einem einzigen Aspekte zu bewältigen, z. B. Logiker, die alles und jedes, was es in der Sprache gibt, als Darstellung zu kennzeichnen unternehmen. Ich nenne Bolzano, dem Husserl, auf rein Logistisches eingestellt, nicht scharf genug entgegengetreten ist'. Die Autorität des Aristoteles, der genau gesehen hat, da $\beta$ nicht jede „Rede“" ein Urteil ist, nicht jeder Sprachsinn dem Kriterium von wahr und falsch untersteht, würde allein schon genügen, der restlosen Logisierung der Sprache zu mißtrauen. Entscheidend dagegen spricht der Tatbestand der tierischen Semantik und vieles aus den Ergebnissen der vergleichenden Sprachwissenschaft. Wenn der indogermanische Imperativ z. B. aus einer älteren Schicht in die neuere Formenwelt flektierender Sprachen übernommen worden ist, so ist er uns ein Zeuge für das höhere Alter der Auslösungsfunktion auch in der menschlichen Sprache; ebenso der Vokativ und für die Kundgabe der uralte Bestand von Interjektionen. Ausdenken kann man sich natürlich einen Zustand des restlos reflektierten Sprechens, in welchem der schlichte Satz „Die Donau ist aus den Ufern getreten“ drei Urteile enthielte: 1. Ich glaube an das Gesagte, 2. ich will dir die Überzeugung daran einflößen, 3. es ist so. Es blieben dann immer noch drei Dimensionen, weil die drei Urteile unabhängig voneinander wahr oder falsch soin können. Aber daß dieser Grenzfall restlos reflektierten Sprechens als die Norm und zugleich als der ursprüngliche betrachtet werden dürfe, wird deshalb wohl im Ernste niemand vertreten. - Wundt, der einseitige Kundgabetheoretiker, wird, wie wir gesehen haben, an der entscheidenden Stelle seinem Prinzip untreu. Marty legt den Akzent auf die Auslösungsfunktion, kennt aber sehr gut auch die Kundgabe und hat zur begrifflichen Klärung dieses Begriffes die ersten Beiträge geliefert. Daß er die Eigendimensionen der Darstellung verkennt, daß er die Zuordnung der Sprachzeichen zu den Gegenständen nur als ein implizites Sinnmoment behandelt, hängt mit der Eigenart seiner Psychologie zusammen. Nach ihm müßte jede Intention eines Sprechers letzten Endes auf die Auslösung und jedes Verstehen des Hörers durch die Kundgabe hindurchgehen. Wer vorurteilslos eine wissenschaftliche Darstellung selbst produziert oder die eines anderen verstehend aufnimmt, wird die direkte Richtung auf die Objekte in aller wünschenswerten Klarheit finden. - Am nächsten kommen meiner eigenen Theorie die Bemühungen Meinongs. Es war mir eine große Freude, als er mir 1919 brieflich ,unsere Übereinstimmung" bestätigte. „,Statt ,Kundgabe" sage ich ,Ausdruck' und

1 Vgl. dazu: K. Bühler, Kritische Musterung der neueren Theorien des Satzes, Indogerm. Jahrb. 6 (1919). 
statt ,Vorstellung' rede ich von ,Bedeutung‘. Die Lösung des Bedeutens vorn Ausdrücken habe auch ich gelegentlich hervorgehoben, glaube aber, daß sie durch Ihre Darlegung in weit helleres Licht tritt." (Brief vom 26. August 1919.) .... Ähnlich wie Meinong haben auch schon die Engländer, vor allem $\mathrm{Hob}$ bes und J.St. Mill, und hat auch Frege der Sache nach eine Zweiheit irn Sprachsinn erkannt (Frege spricht von Sinn und Bedeutung), aber nie ist das ganze „Dreiersystem von Koordinaten“ aufgestellt worden. -- Phänomenologisch gehört das, was in der Kundgabe und Auslösung an Zeichenfunktionen vorliegt, unter den Oberbegriff der Anzeichen, während die Daystellung mit Ordnungszeichen operiert.

\section{Die Synthesis der drei Aspekte.}

1. Die Behavioristen und die geisteswissenschaftlichen Psychologen haben begonnen, je eine eigene Terminologie auszubauen, man wird, die Begriffe der älteren Erlebnispsychologie dazu gerechnet, in ein und derselben Wissenschaft bald drei Sprachen sprechen. Innerhalb gewisser Grenzen liegt dies unvermeidbar in der Natur der Dinge, wenn anders der Satz gilt, daß jeder der drei Aspekte möglich und keiner entbehrlich ist. Das Erstgegebene der Selbstbeobachtung, das am Benehmen unmittelbar durch äußere Wahrnehmung Erfaßte und der Gehalt oder die Struktur der Gebilde des objektiven Geistes, verlangen jedes nach seiner Art ein anderes Koordinatensystem für ihre erste Bestimmung. Darüber werden wir nicht hinwegkommen. Um dies noch einmal an der Sprache zu erläutern: Die Sprachzeichen an sich sind Schallphänomene und andere Massenbewegungen, die mit den Mitteln des Physikers und Physiologen bestimmt werden müssen; ohne sie wäre die Phonetik hilflos. Auf der anderen Seite, was die Zeichen kundzugeben und was zu steuern sie berufen sind, die Erlebnisse des Sprechers und die des Hörers, Gedanken, Gefühle, Willensvorgänge an sich erfordern die Bestimmungsmittel der sogenannten inneren Wahrnehmung; die Sprachpsychologie wäre zur Sterilität verdammt, wenn ihr diese Erkenntnisquelle verschlossen würde. Und noch einmal anders, es gäbe keine wissenschaftliche Grammatik und überhaupt keine vollendete Sprachwissenschaft ohne den dritten Aspekt, unter dem man die Sprache betrachten kann, und auch von da gibt es einen Zugang zur Psychologie mit naturgemäß noch einmal anderen Grundbestimmungen vom Ausgangsgegenstand her.

Es entsteht die Frage, ob und wie trotz dieser Dreispältigkeit am Ausgang eine Einheit am Ende, eine einheitliche Wissenschaft erwartet werden darf. Erlebnis, Benehmen und Werk sind weitgehend unabhängig variabel und gehören doch irgendwie zusammen, konstituieren eine höhere Einheit. Wenn die Alltagserfahrung lehrt, daß oft schon ein heiteres Werk auf düsterem, verzweifeltem Erlebnisgrunde entstanden ist, daß Gesinnung und Benehmen manchmal diametral auseinander gehen $\mathbf{u}$. dgl. m., so kann dies alles für die Theorie nur ein Anreiz 
sein, die Gründe und Grenzen sowohl der erwarteten Konkordanz wie der unerwarteten Diskordanz tiefer zu erfassen und exakter zu bestimmen. Ausgeschlossen muß in Zukunft jeder Versuch bleiben, einen der drei Aspekte zu dem schlechthin orthoskopischen zu erheben. Wenn die Psychologie als die Theorie eines irgendwie in sich geschlossenen Systems von Erlebnissen zu vollenden wäre, gäbe es kein psychophysisches Problem, keine Annahmen über das Unbewußte, keine Psychoanalyse, und mindestens das eine oder andere von den Dreien wird doch wohl jeder Erlebnispsychologe für unvermeidbar halten. Über die Unvollendbarkeit und Selbstauflösung der einseitigen Benehmenstheorie habe ich an anderem Ort aus dem konkreten Problemgebiet der Instinkte heraus ausführlich gesprochen ${ }^{1}$. Und ebensowenig wird es gelingen, die Psychologie einseitig als eine Theorie des, ,subjektiven Geistes" zu vollenden. Von da her allein sind weder die Erlebnisse noch das Benehmen restlos zu begreifen. Die Lösung der Krise wird also eine Synthesis sein müssen.

Angenommen, der Geograph erhält von einem unbekannten und schwer zugänglichen Gelände drei photographische Aspekte, die von verschiedenen, geographisch bekannten Standorten aufgenommen sind, so wird er über die Methode einer Synthesis dieser Aspekte nicht in Zweifel sein. Eine neue Darstellungsart, die geographische Karte zu gewinnen, ist sein Ziel; in sie wird er nach diesem oder jenem Utbersetzungsverfahren die Daten der Bilder eintragen. Gelingt dies aber aus irgendeinem Grunde nicht sofort, dann könnte er immerhin vorerst in eines oder das andere der Bilder selbst schon Orientierungslinien, z. B. Nord-Südrichtung, etwas von den Längen- und Breitenwerten, Maßstäbe u. dgl. m., das heißt summarisch ausgedrückt, Daten aus dem Fond seiner übrigen Kenntnisse anbringen und es damit wissenschaftlich exakter lesbar und wertvoller machen. Vielleicht ist dies letztere ein methodisches Gleichnis für die nächsten Ziele, und die Gewinnung der Karte ein Gleichnis für das Endziel einer Synthesis der Aspekte in der Psychologie. Jedenfalls finden wir allenthalben Bilder mit fremdaspektlichen Eintragungen, z. B. Schilderungen des sichtbaren Benehmens von Mensch und Tieren mit erlebnispsychologischen Interpretationen ausgestattet, Erlebnisanalysen von Affekt- und Willensverläufen, die am sichtbaren Benehmen ihre Stütze finden, Leistungsanalysen, die immer wieder das Erlebnis schildern, nicht nur soweit es von dem objektiven Gebilde, sondern auch, soweit es von subjektiven Zusatzeinflüssen bestimmt wurde. Puristische Forderungen und Scheidungsversuche müssen im Namen der erkenntnistheoretischen Sauberkeit erhoben und können vom Forscher, der sich hilft, wie's geht, vorerst doch nur in den seltensten Fällen reinlich erfüllt werden.

${ }^{1}$ Vgl. K. Bühler, Die Instinkte des Menschen. Ber. über den IX. Kongr. f. Psych. 1926. 
Für den Fortschritt und die Vereinheitlichung der Theorie von höchster Tragweite wäre es nun, wenn etwas von dem Begriffssystem, in das einst die Daten aller drei Aspekte nach einem durchsichtigen Übersetzungs. verfahren eingetragen werden können, greifbar hervorträte. Die philosophischen Bemühungen um die Neuorientierung der Psychologie sollten sich vor allem um ein solches Begriffssystem konzentrieren. Wer das weite Reich der psychologischen Forschung von heute durchmustert, wird aus allen Provinzen brauchbare Beiträge und konvergierende Bestrebungen dazu finden. Vom Gesamtverhalten der Amöben bis zum wissenschaftlichen Denken der Menschen ist gewiß ein kaum überschätzbarer Abstand. Und doch wird das eine und das andere nach den besten modernen Beobachtern unter die zwei gemeinsamen Begriffe des Ganzheitsgeregelten und des sinnvollen Geschehens zu bringen sein. Da haben wir den Strukturbegriff und den Sinnbegriff, mit einem Worte gesagt, es ist die teleologische Betrachtung, zu der uns ebenso die Eigenbestrebungen jedes Aspektes wie die Bedürfnisse einer übergreifenden, einheitlichen Theorie hinführen. Wir haben den Begriff der Steuerung aus dem Wortschatz des Physikers entlehnt, um die zweckvolle gegenseitige Beeinflussung des Verhaltens der Mitglieder tierischer und menschlicher Gemeinschaften auf eine Formel zu bringen, die kraft ihrer Herkunft wenigstens den oberflächlichsten Einwänden mechanistisch gesinnter Denker entrückt ist; es gibt Steuerungen auch an toten Systemen, man kann ihr Vorhandensein und ihre Richtpunkte, auch ohne von vornherein bestimmte Annahmen über den Steuermann zu treffen, bestimmen. Und nichts hindert, diesen Begriff in gleicher Weise vom Benehmen und vom Erleben zu gebrauchen. Vielleicht ist der Gegenstand der Psychologie einigermaßen exakt durch diesen Begriff zu charakterisieren. Die Steuerungen im Gesamthaushalt der Individuen selbst, samt ihren Bezügen zu dem Gemeinschaftsleben und den ideellen Richtpunkten am Sternenhimmel der Werte, das gibt in der Tat eine brauchbare Umschreibung, die allen drei Aspekten gerecht wird. Von da aus wäre leicht auch die Tatsache unterzubringen, daß innerhalb jedes Aspektes die Mituntersuchung des Eigengeschehens der gesteuerten Systeme selbst notwendig wird, und daß diese Untersuchungen es sind, die den Psychologen bald zur Aufstellung des Assoziationsgesetzes, bald zu Anleihen bei dem Physiker und Physiologen veranlassen. Ein solcher Gedankengang läßt sich grob, er läßt sich auch sehr subtil zu Ende denken ${ }^{1}$. Weitere Voraussetzung einer gegenseitigen Steuerung der Individuen ist die Einstellung aufeinander und das ,Verstehen“ des fremden Benehmens. Es ist gewiß mehr als ein Zufall, da $B$ dasselbe Wort „,Verstehen“ in der Methodendiskussion der Gegen-

1 Ich glaube, E. Becher meint mit der „Führerrolle des Seelischen“ im Organismus dasselbe. 
wart an hervorragender Stelle vorkommt; wir werden uns noch mit ihm beschäftigen.

Noch einmal anders gewendet. An dem, was von der Sprache den Sinnen zugänglich ist, wird ganz deutlich, daß es dem Psychologen letzten Endes nur als Zeichen für jenes andere, dem es verhaftet oder zugeordnet ist, und zwar gerade um seiner Zeichenfunktion willen, ein Gegenstand der Untersuchung wird. Von den anderen physischen Dingen, die in Endsätzen der Psychologie vorkommen können, von Werkzeugen, Sachgütern, Kunstwerken usw. gilt Analoges. Und was die Erlebnisse angeht, so trifft eine ähnliche Bestimmung, nämlich das Moment der Intentionalität zum mindesten eine wichtige Seite ihrer Natur. Ich will ein paar Sätze, die ich an anderem Orte geschrieben habe, wiederholen ${ }^{1}$. „Die psychischen Phänomene unterscheiden sich von allen physischen durch nichts so sehr als dadurch, daß ihnen etwas gegenständlich innewohnt (Brentano). Es ist das unvergängliche Verdienst Franz Brentanos, das Merkmal der Intentionalität, des Hinweisens, Gerichtet-, Bezogenseins der Erlebnisse, jenes Merkmal, das kraft einer Art Stammesvernunft den fruchtbarsten psychologischen Klassifikationsversuchen seit Aristoteles häufig unerkannt oder verschleiert zugrunde lag, begrifflich scharf erfaßt und gebührend gewürdigt zu haben." Die punktmäßige, sozusagen statische Intentionalität jedes Einzelerlebnisses für sich betrachtet, wäre eine unverständliche Kuriosität; wenn wir darin aber mehr, nämlich eine dynamische, eine Ablaufszuordnung erblicken, dann gewinnt die Intention die natürliche Funktion eines Steuerhebels, durch den Erlebnisse in uns in Konkordanz mit den Struktur- und Daseinsgesetzen der Gegenstände gebracht werden können. Ein Gedanke, den ich denke, ist mein Gedanke, er steht im Erlebnisverband mit Affekten und Strebungen, die als Ganzes gesehen, nicht noch einmal vorkommen. Aber die gegenstandsgerechte Steuerung, die sachliche Bestimmung meines Denkverlaufes ist, wenn alles klappt, von solcher Art, daß wir mit Spinoza unter gehörigen Vorbehalten voraussagen können: ordo idearum idem est ac ordo rerum. Ein Wort über die connexio der beiden sei uns vorbehalten.

Der allgemeine wissenschaftstheoretische Ertrag solcher Überlegungen liegt darin, da B wir durch sie aus der lebendigen Forschung heraus Schritt für Schritt zu der Entwicklung eines übergreifenden Begriffssystems und zu einem Vollzug der geforderten Synthesis der Aspekte gelangen. Mag man fortfahren, die Theorie der Farben und Töne, der sinnlichen Gefühle, der Gesetze des Einprägens und Vergessens im Rahmen des Erlebnisaspektes zu vollenden. Die Forschung ist damit noch lange nicht am Ende, ganz zu schweigen von der deskriptiven Bestimmung der sog. komplexen oder höheren Erlebnisse im Koordinatensystem der Selbstbeobachtung.

1 K. Bühler, Die geistige Entwicklung des Kindes, 4. Aufl., S. 436. 
Die Wendung der Denkpsychologie ins Dynamische und die Eroberung des wichtigen Begriffs der psychischen Operationen, wie sie vor allem von Selz gefördert worden ist, hat einiges zum Abschluß gebracht und neue Perspektiven eröffnet. Man darf aber im Namen einer Verlaufsbetrachtung die ältere statische Analyse nicht für überflüssig erklären. Mögen die Behavioristen fortfahren, in großzügiger, vergleichender Betrachtung das sinnlich wahrnehmbare Verhalten der Tiere und des Menschen als Phonetiker sozusagen exakt aufzunehmen; sie werden gewiß Benehmensgesetze finden, die dem Vergleich etwa mit den Assoziationsregeln an Gehalt und Exaktheit gewachsen sind. Das alles ist ebenso unentbehrlich und ebenso unvollendbar im Sinne einer geschlossenen Wissenschaft wie etwa die Erfolge der Interpretationsmethode der geisteswissenschaftlichen Psychologen. Das übergreifende Darstellungssystem aber fordert von seinen Begriffen das eine, daß sie die unmittelbaren Daten der Selbstbeobachtung und der äußeren Wahrnehmung, wie sie im Dienste psychologischer Forschung aufgenommen werden, in einer spezifischen Art in sich aufnehmen. So nämlich, daß die Erlebnisse so gut wie die Elemente des Benehmens und die physischen Dinge im Bereich des objektiven Geistes als Konstituenten oder Träger von Sinngebilden im System der Endsätze unserer Wissenschaft erscheinen. Wir haben Spranger nicht widersprochen, wo er die Psychologie als die Lehre vom sinnerfüllten Leben bezeichnete; nur ist Sorge dafür zu tragen, daß sich unsere Wissenschaft von den anderen, die es auch mit dem ,Leben“ und gewiß nicht nur mit seinen sinnleeren oder sinnwidrigen Phasen, Momenten, Erscheinungsformen zu tun haben, mit wünschenswerter Schärfe abhebt, und daß der Sinnbegriff selbst samt der ganzen Sippe von Begriffen, die mit ihm verwandt sind, die höchst erreichbare logische Klärung erfährt. Ein nahezu uferloses Debattieren darüber ist in Gang gekommen, ich wähle das, was Spranger bietet, als Leitfaden, um zu den Grundfragen Stellung zu nehmen.

2. Das Schlagwort von der ,verstehenden Psychologie" spielt in den theoretischen Diskussionen der Gegenwart eine große Rolle. Wer ihm nachgeht, sieht sich schließlich vor zwei verschiedene Tatbestände geführt, nämlich zu dem, was man Einfühlung, und zu dem, was man Strukturgesetz genannt hat. Es gibt angeblich ein einfühlendes und ein strukturgesetzliches Verstehen, und beides kann zu einem oder dem psychologischen Forschungsverfahren kat' '̇̌oxńv verfeinert werden. Das einfühlende ist jedem von uns aus dem seelischen Verkehr mit anderen Menschen praktisch vollkommen geläufig. Man versetzt sich selbst fiktiv in die Lage des anderen, um ihn zu verstehen. Das Bild müßte für viele Fälle noch intimer sein, bald in die Haut, d. h. in die Sinne, bald in die Muskeln, bald in das Wesen des anderen versucht man sich zu versetzen; wie und wieweit es gelingt, mag unerörtert bleiben. Tatsache ist, daß der also Versetzte, fiktiv Verwandelte oder Eingestellte dann an sich selbst dies 
und das abzulesen oder zu vermuten vermag, wie es dem anderen wohl zu Mute ist, und warum er sich gerade so und nicht anders benimmt. Die Aufgabe, ein fremdes Erleben zu erfassen oder ein fremdes Gebaren zu begreifen, wird durch die Versetzung in eine Aufgabe der Selbsterkenntnis transformiert und, wo es gelingt, sie dann zu lösen, spricht man von einfühlendem Verstehen. Es wäre möglich, schon von hier aus ein Wissenschaftsideal aufzustellen, das den Namen ,,verstehende“ Psychologie für sich in Anspruch nehmen könnte. Wer etwa die psychische Realität in den Erlebnissen als solchen beschlossen denkt (im Sinn der Wundtschen Aktualitätstheorie) und von da aus mit Mach und anderen Positivisten der Wissenschaft überhaupt die Aufgabe stellt, Beobachtungen vorauszusagen, der könnte dies zum besonderen Charakteristikum der Psychologie erheben, daß sie systematisch und eindeutig zu solchem Verstehen anleitet, um Beobachtungen, die an anderen gemacht werden können, vorauszusagen.

Vielleicht hat gerade diese Denkweise vielen Psychiatern von heute, die das möglichst weitgehende Einfühlen in die abnormen Seelenzustände ihrer Kranken erstreben, die Parole einer verstehenden Psychologie besonders empfohlen; vielleicht wertet mancher die Technik des Miterlebens auch deshalb so hoch, weil er darin eine ähnliche Erkenntnishilfe wie in dem Nachzeichnen eines körperlichen Objektes auf dem Papier oder dem Nachkonstruieren einer Maschine im Modell erblickt. Ich glaube, dies letztere kann man nur von einer interpretierenden und darstellenden Wiedergabe, wie sie z. B. der Schauspieler erstrebt, nicht aber von dem viel einfacheren, resonanzartigen Miterleben erwarten. Aber wie dem auch sei, das einfühlende Verstehen mag den Gesichtskreis der Erlebnispsychologie erweitern, es wird auch an bestimmter Stelle im. Rahmen einer vorurteilsfreien Verhaltenstheorie vorkommen, aber eine besondere Erkenntnisart darf man in ihm nicht erblicken. Denn mit dem Hineinversetzen allein ist ja noch gar nichts erreicht; es mag mit irgendeinem Transformierungsverfahren der naturwissenschaftlichen Experimentiertechnik verglichen werden, die entscheidenden Feststellungen werden dem wissenschaftlichen Beobachter weder dort noch hier erspart. Geübte Techniker des Verfahrens mögen in komplexen Fällen, z. B. einem psychisch Erkrankten gegenüber, wechselnde Einfühlungen ausprobieren, ungefähr so, wie ein Klavierspieler zu einem gesungenen Lied die Tonart und passende Begleitung durch probierende Griffe auf seinem Instrumente aufsucht, bis der Einklang erzielt ist. Das ist eine Angelegenheit der Diagnose, nicht eine besondere Forschungs- oder Erkenntnisart der Psychologie. Ich stimme darin, soweit ich sehen kann, mit Spranger überein. Daß die Tatsache der Einfühlung selbst in ihren Arten und Stufen wichtige, deskriptive und vergleichend psychologische Probleme enthält, steht natürlich auf einem anderen Blatt. 
$\mathrm{Zu}$ einem vielbesprochenen Methodenproblem dagegen ist die andere Art, das sog. strukturgesetzliche Verstehen, ausgewachsen. Ich zitiere Spranger :

„Das eigentümliche, geisteswissenschaftliche Erkenntnisverfahren, das wir Verstehen nennen, und das nicht etwa mit Sympathisieren oder seelischem Gleichklang verwechselt werden darf, ist nicht auf die Auffassung von Personaleinheiten beschränkt. Es ist auch, wie wir sofort sehen werden, nicht einfach mit ,Nacherleben" gleichzusetzen. Verstehen in allgemeinster Bedeutung heißt: geistige Zusammenhänge in der Form objektiv gültiger Erkenntnis als sinnvoll auffassen. Wir verstehen nur sinnvolle Gebilde. Durch das Merkmal des sinnvollen Zusammenhangs unterseheidet sich die Erkenntnisleistung des Verstehens vom Begreifen und Erklären, z. B. von der Kausalerklärung aus Gesetzen nur äußeren Aufeinanderfolgens. Das Verstehen scheint in den inneren Zusammenhang einzudringen. Es erfaßt immer einen Sinn, indem es otwas Geistiges gleichsam mit seinem Leben durchdringt und ausfüllt und erst auf diesen Totalakten die Erkenntnis des Aktsinnes aufbaut1."

Es empfiehlt sich, schon hier Halt zu machen und den Unterschied von Verstehen und Erklären nach dem ersten begriffsbildenden Merkmalspaare ,äußere Aufeinanderfolge - innerer Zusammenhang“" ordentlich durchzudenken. Durch die hinzugefügte Anmerkung wird jeder in der Philosophiegeschichte Bewanderte eindeutig belehrt, wovon die Rede sein soll. „Sobald wir zu den ,echten“ Kausalgesetzen des Auseinanderfolgens übergehen, ist schon eine leise Annäherung an das Verstehen erreicht, insofern dann die Wirkung als wesensgesetzlich in der Ursache vorgebildet gedacht wird." Es handelt sich also um jene Uneinsichtigkeit, jenen synthetischen Charakter des Kausalprinzips, der die Denker nach Descartes in beiden Lagern des Rationalismus und des Empirismus bis zu Kant hin so lebhaft beschäftigt hat, und darum, daß nun mit dem Erkenntnisverfahren des Verstehens einsichtige Sätze gewonnen werden sollen. Ich glaube nicht, daß Hume oder Kant eine rechtes Vertrauen in die Aussicht auf solch, ,echte" Kausalgesetze auf irgendeinem Gebiete gesetzt hätten. Nun, es steht nicht geschrieben, daß sie für alle Zeiten Recht behalten müssen; vielleicht gelingt es der Strukturbetrachtung wirklich einmal, für dies oder jenes Gebiet das wesensgesetzliche Auseinander von Tatsachen, von Daseinsbeständen einsichtig zu machen. Dazu wird aber weit mehr gehören, als was bis heute z. B. irgendwo in der Psychologie geleistet ist. Wenn wir, woran ich nicht zweifle, das Auseinander von Erlebnisschritten in vielen Formen faktisch erleben, z. B. das Hervorgehen des Willensentschlusses aus den Motiven, der Handlung aus dem Entschluß, der Urteilsentscheidung aus den Gründen oder primitiver noch der Tätigkeit aus dem ungehemmten Triebbegehren, so ist mit diesem faktischen Erlebniszusammenhang noch keineswegs jenes Ideal

1 Psychologie des Jugendalters, 1924, S. 3. 
der Einsicht in die wesensgesetzliche Notwendigkeit des Eintretens des zweiten Erlebnisschrittes nach dem ersten oder anders gesagt, die Einsicht in die vollständige Daseinsbestimmtheit des zweiten durch den ersten erreicht. Aber das nur nebenbei.

Fruchtbarer wird die Diskussion, wenn wir das in den mathematischen Naturwissenschaften Erreich te mit dem für die Psychologie Erstrebten vergleichen. Einige Zeilen weiter schreibt Spranger: „Sinnvoll ist... eine Ordnung oder ein Zusammenhang von Gliedern, die ein Wertganzes bilden, auf ein Wertganzes bezogen sind oder ein Wertganzes bewirken helfen." Lassen wir vorerst noch den ,Sinn" und den „Wert" aus dem Spiel, um nur das Verhältnis eines Ganzen zu seinen konstitutiven Momenten ins Auge zu fassen, so gewinnen wir den allgemeinsten Begriff des Strukturgesetzes und die Parallele zu den mathematischen Naturwissenschaften. Ein Strukturgesetz des ebenen, geradlinigen Dreiecks ist z. B. der Satz, daß die Summe seiner Innenwinkel $180^{\circ}$ beträgt; er bestimmt das Verhältnis eines Ganzen zu seinen konstitutiven Momenten und ist, wie alle echten Strukturgesetze, einsichtig zu machen. Wenn also ein Vorbild des Verstehens als einer Erkenntnisart, die ,in den inneren Zusammenhang eindringt" gesucht werden muß, so ist es (und darin stimmen wir einer uralten Auffassung bei) in der Mathematik zu finden. Nun wissen wir, wie fruchtbar die Anwendung mathematischer Erkenntnisse in den Naturwissenschaften geworden ist. Kepler z. B. hat durch seine denkwürdige Konzeption ubi materia, ibi geometria gewisse einsichtige Sätze der Geometrie auf die Planetenbewegungen anzuwenden gelehrt. Die Problemlage in der Psychologie ist heute eine ähnliche, wie sie zu Keplers und Galileis Zeiten für die Physik bestand, es gilt Grundideen von ähnlicher Fruchtbarkeit für die Forschung, es gilt allgemeinste Modelle, strukturgesetzlich einsichtige Modelle zu konzipieren. Mit Mathematik allein vermag (vorerst zum mindesten) die Psychologie nicht allzuviel auszurichten, Spranger empfiehlt ihr die Sinnidee: Das Gebiet des Geistigen und Seelischen ist sinndurchwaltet. Dagegen ist nichts einzuwenden, auch sind die Modelle Sprangers, z. B. seine Lebensformen fast durchgehend glücklich gegriffen. Angenommen nun die Struktur solcher Modelle ist einsichtig erkannt, so bleibt immer noch die Frage, ob wir nach solchem Verstehen der Induktion enthoben sind. Und diese Frage ist, wenn anders zwischen Modell und Wirklichkeit im Bereich des Seelischen genau so unterschieden werden muß, wie im Bereich der Physik, zu verneinen. So unentbehrlich die geometrischen Konzeptionen Keplers gewesen sein mögen, der Beweis für die Gültigkeit der Bewegungsgesetze der Planeten mußte durch die astronomische Induktion erbracht werden, und auch die Leistung Newtons hat daran prinzipiell nichts geändert. Kein moderner Erkenntnistheoretiker verwechselt die an glücklich erdachten Modellen abgelesenen Strukturgesetze mit den induktiv 
bewiesenen Sätzen der Physik. Ich behaupte, für die Psychologie gelte dasselbe.

3. Zuvor etwas Logisches. Wie steht es mit den Begriffen ,Sinn"- und „Wertganzes"? Das althochdeutsche Wort ,sinnan" bedeutet, wohin gehen, auf etwas abzielen' (vgl. germ. sinpa ,Reise', woher auch ,Gesinde' gleich Reisegefolgschaft, Kriegsgefolgschaft). Wenn wir sagen ,im Sinne des Uhrzeigers' oder an Linien Sinn und Gegensinn, nach denen man sie ablaufen kann, unterscheiden, so treffen wir damit das Etymon des Wortes noch sehr genau. Es empfiehlt sich, in seine Definition als Terminus technicus keine anderen Merkmale als die der Zweckhaftigkeit und Zweckgerechtigkeit aufzunehmen. Wenn ein Hund eine Lokomotive anbellt, so dürfte dies eine zweck h af te aber keine zweckmä Bige Tätigkeit sein; wenn es im Bereiche der organischen Angepaßtheiten solche geben sollte, die der (utrierten) Darwinschen Idee entsprechen, so wären sie als zweckgerecht (zweckmäßig), aber nicht als zweckhaltig zu bezeichnen. Es ist wünschenswert für Gebilde und Tätigkeiten, die beiden Bedingungen zugleich genügen, einen eigenen Namen zu haben, und so mag man für sie die Worte Sinn und sinnvoll reservieren. Das ist ein terminologischer Vorschlag, den man nach Brauchbarkeitserwägungen annehmen oder verwerfen mag; er trifft den herrschenden Sprachgebrauch, soweit ich sehen kann, so exakt als möglich. Aber wie dem auch sei, jedenfalls muß es zu Unzuträglichkeiten führen, wenn maan übersieht oder es dann und wann vergißt, daß die Prädikate ,werthaft, wertbestimmt, wertgerecht" nur einem kleinen Teil der zweckhaft-zweckmäßigen Ganzheiten zukommen. Spranger definiert: ,Sinn hat, was in ein Wertganzes als konstituierendes Glied eingeordnet ist" und bringt sofort eine Reihe von Beispielen, an denen man durch eine einfache philologische Interpretation entnehmen kann, daß er in Wirklichkeit nicht das Moment der Wertbestimmtheit, sondern nur das des Zweckhaft-zweckmäßigen im Auge hat, wo er von Sinn und Sinnverständnis, spricht. Wir wollen zwei von diesen Beispielen analysieren.

„In einem sprachlichen Satz hat jedes Wort einen bestimmten Sinn, und der ganze Satz wieder seinen bestimmten Sinn in dem Zusammenhang einer Erkenntnis oder Kundgabe, also unter dem Gesichtspunkt eines theoretischen Wertes (S. 4)." Mich dünkt, einen Satz unter theoretischem Wertgesichtspunkt beurteilen, heißt ihn als wahr oder falsch beurteilen, und das ist mehr als seinen Sinn erfassen, ist mehr, als ihn verstehen. Ganz schlicht und naiv ausgedrückt heißt einen Satz verstehen, soviel wie wissen oder erfassen, was damit, gemeint" ist, heißt den Sprachzweck, nicht aber seinen Wahrheitswert erkennen. Spranger führt zwei Dimensionen des Sprachsinns, nämlich Kundgabe und ,Erkenntnis" an; das letztere nenne ich die Darstellungsfunktion, und dann gibt es noch eine dritte Dimension, die ebenso verstanden werden will, 
nämlich die Auslösungsfunktion. Damit ist der Bereich des Sprachsinnes vollständig abgesteckt, Sprachsinn gleich Sprachzweck. Die Unterscheidung von zweckhaft und zweckgerecht gestattet uns an jeder konkreten Sprachäußerung, und zwar für jede der drei Sinndimensionen die faktische Intention des Sprechers als den ,,subjektiven" Sprachsinn von dem „objektiven" Sprachsinn, d. h. dem, was der gewählte Ausdruck nach den Regeln des Sprachgebrauchs bedeutet, zu sondern. Auch die Tatsache, daß das Verständnis beim nächstliegenden, dem unmittelbar oder wörtlich Ausgedrückten stehenbleiben oder in die Tiefe dringen kann, soweit es gelingen mag, und zwar im Erfassen des subjektiven oder des objektiven Sprachsinnes, wird ohne weiteres begreiflich, wenn das Verstehen auf den Sprachzweck abzielt; denn die Unterordnung näherer unter fernere Ziele gehört ja zu den allgemeinen Eigenschaften komplexer Zweckmittelverhältnisse. Und dies alles können wir theoretisch ins reine bringen ohne jeden Appell an die ,Wertgesichtspunkte" von wahr und falsch.

Eines bleibt richtig, nämlich, daß der Begriff und die Kriterien der Wahrheit wesensgesetzlich aus der Darstellungsfunktion entspringen. Und wenn Spranger nur behaupten wollte, daß jeder Darstellungssatz (Aussagesatz) unter dem theoretischen Wertgesichtspunkt betrachtet werden kann, oder wenn er behaupten wollte, daB sprachlich darstellende Menschen sich in der Regel vom Kompaß der Wahrheit leiten lassen, so wäre dagegen nichts einzuwenden. Aber weder das eine noch das andere gehört zu dem Vorgang des schlichten Sinnerfassens.

Ein zweites Musterbeispiel: „In einer Maschine haben die Teile einen Sinn, der durch die Gesamtleistung der Maschine bedingt ist." So ist es in der Tat kraft der Zweckbedingungen, denen der Bau der Maschine. genügt. Und der Teilzweck einer Komponente dieses $Z_{\text {weckgebildes wird }}$ „,verstanden" aus dem Gesamtzweck und den technischen Bedingungen seiner Verwirklichung. Mit Wert oder Unwert hat dies Zweckverstehen nichts zu tun, ,Leistung“ ist zunächst ein völlig wertfreier Zweckbegriff. Ob eine Maschine Mehl erzeugt oder Straßenstaub aufwirbelt, ob etwas Wertvolles, Wertloses oder Wertwidriges durch sie verwirklicht wird und werden soll, ist für die Art und den Grad ihrer Zweckhaftigkeit und der Zweckmäßigkeit ihrer Struktur vollkommen irrelevant. Unbestritten bleibt auch hier der Satz, daB man Werkzeuge und Maschinen unter einem spezifischen Wertgesichtspunkt, nämlich dem der Ökonomie ihrer Leistung, betrachten kann. Wenn es darauf ankäme, ließe sich sogar der Begriff und die Kriterien der Ökonomie an ihnen ablesen. Unbestritten bleibt auch der Erfahrungssatz, daß Maschinen in der Regel der Verwirklichung. ökonomischer Werte dienen und dazu konstruiert worden sind. Aber zum schlichten Sinnverständnis einer Maschine bedarf es solcher Wertbetrachtungen durchaus nicht.

Im Anschluß daran noch eine andere Überlegung. Wer an den also. 
durchdachten Beispielen die Behauptung nachprüft, das Verstehen dringe in den ,,inneren Zusammenhang“" ein und sei darum eine vollkommenere Erkenntnisart als die Kausalerklärung ,aus Gesetzen nur äußeren Aufeinanderfolgens", dem erwachen auch dazu allerhand $\mathrm{Be}$ denken. Worin unterscheidet sich vom Laienverständnis einer Maschine das Verständnis des Fachmannes und zuhöchst das Verständnis des Konstrukteurs? Der Konstrukteur hat sie, wenn er ganz gründlich vorging, durchgerechnet, bevor sie gebaut wurde, und dabei gewiß nicht gespart mit der Verwertung von Kausalerkenntnis. Sollte nicht gerade dadurch sein Verständnis vertieft worden sein? Uns Laien geht, wenn er, der Konstrukteur, allgemein verständlich zu erzählen anfängt, von den Schwierigkeiten, und wie er sie überwunden hat, da und dort ein Licht auf, dem Fachmann die höchst erreichbare theoretische Einsicht, wenn er die Berechnungen und Motivationen nachprüft, dem Praktiker, wenn er beim Gebrauch der Maschine Gelegenheit hat, die starken und schwachen Seiten ihrer Konstruktion kennenzulernen. Mich dünkt, was man so gemeinhin mit einem Wort das ,Verständnis" einer Maschine nennt, sei demnach eine vielseitige und unter Umständen sehr verwickelte Angelegenheit, die auf keinen Fall ohne Physik und mit reiner Sinneinsicht befriedigend erledigt werden kann. Mit dem Sprachverständnis ist es nicht anders. Wer sich als Anfänger um das Sinnerfassen eines fremdsprachlichen Satzes mit dem Wörterbuch in der Hand bemüht hat, weiß davon zu berichten, daß es Stufen des Verstehens gibt und welches gewichtige Wort dabei die Übung mitspricht. Was an echter Struktureinsicht beim Verstehen eines Satzes aufblitzt, verteilt sich bei genauerem Zusehen auf das sachlich-logische und das grammatische Gebiet. Ich habe das charakteristische Aufblitzen als Aha-Erlebnis bezeichnet; die Denkpsychologie hat auch sonst über den komplexen Vorgang noch mancherlei eruiert ${ }^{1}$. Man darf dabei nie aus dem Auge verlieren, daß solche flüchtigen Struktureinsichten in der Regel unablösbar verwoben sind in die durchaus uneinsichtigen Assoziations- und Suggestivwirkungen, wie sie im lebendigen Sprachverkehr im Vordergrund stehen, und vor allem das Kundgabeverständnis bestreiten. Die reibungslose Geläufigkeit ihres Eintretens kann leicht vom Erlebenden selbst und noch mehr von einem einfühlenden Fremdbeobachter mit Struktureinsicht verwechselt werden; ich habe ausdrücklich vor solcher Konfundierung mit der Deutung bestimmter Affenversuche gewarnt und glaube diese Warnung ist hier noch einmal angebracht ${ }^{2}$.

$1 \mathrm{~K}$. Bühler, Über das Sprachverständnis vom Standpunkt der Normalpsychologie. Ber. über den III. Kongr. f. Psych. 1909, S. 94-130. Dort die ältere Literatur. Die vollständigste neue Ưbersicht bei $\mathrm{A}$. Willwoll, Begriffsbildung. Psych. Monogr. 1 (Hirzel in Leipzig) 1926.

2 Vgl. Die geistige Entwicklung des Kindes, 4. Aufl., S. $20 \mathrm{f}$. 
Echte Wertstrukturen, wie sie Spranger letzten Endes vorschweben, gibt es gewiB. Die Logik belehrt uns z. B., daB in einem korrekten Syllogismus die Wahrheit der Konklusio einsichtig aus der Wahrheit der Prämissen hervorgeht; größere Wahrheitsgefüge von Sätzen zu bieten, erstrebt ja jede Theorie, jede Wissenschaft, die sich dem Ideal eines geschlossenen Systems annähert. Ästhetische Qualitäten tragen, erhöhen sich gegenseitig und interferieren auf noch andere Art am Kunstwerk, das Gebiet der Sachgüter wird eigene, und wieder andere Ganzheitskonstitutionen das Reich des Sittlichen aufweisen. Daran zweifle ich nicht, und einiges davon in Projektion auf die wertverhaftete Persönlichkeit offenbaren uns die Lebensformen Sprangers. Nur wird man streng darauf sehen müssen, daß der Aufbau der Begriffe in einer allgemeinen Lehre von den Strukturen, diesem interessanten, im Grunde schon von Husserl und Stumpf vorgeahnten, in der Gestaltpsychologie oder Komplextheorie der Psychologen und in anderen Wissenschaften ungefähr gleichzeitig lebendig gewordenen Unternehmen, mit peinlicher Sauberkeit erfolgt. Es geht nicht an, die Begriffe Struktur, Sinn und Wert in eins zusammenzuwerfen. Der Begriff der Ganzheit mit ihren konstitutiven Momenten ist der weiteste und ihm ist das einsichtige Erkennen zugeordnet; Zweckganzheiten $=$ Sinngebilde, die einem Sinnverstehen zugänglich sind, können nach dem logischen Gesetze von der Umfangsverengerung eines Begriffes bei Bereicherung seines Inhaltes nur ein Teilgebiet der Strukturen sein. Und noch einmal enger wird der Bezirk, wenn man aus dem Bereich der Sinngebilde nur die werthaften und wertgerechten herausholt, z. B. aus dem Bereich der sinnvollen Sätze die wahren und wissenschaftlich wertvollen. Zweck und Wert gehören irgendwie zusammen, aber gewiß nicht so, daß alles Zweckvolle auch als wertvoll betrachtet werden darf.

4. Struktur, Sinn und Wert, die Namen bezeichnen drei Problemgebiete der theoretischen Psychologie, die innerlich zusammenhängen und doch unterschieden werden müssen. Wenn wir den aristotelischen Satz: „Das Ganze ist vor den Teilen“ als prägnante Formel für das, worum es in dem Gestaltproblem der Psychologen geht, aufnehmen, so brauchen wir uns damit noch nicht vorbehaltlos der ganzen aristotelischen Metaphysik zu verschreiben. Es ist z. B. fraglich, ob der Satz auch für die Physik gilt; was man als physische Gestalten beschrieben hat, sind nichts als Gleichgewichtszustände. Nehmen wir an, die Steuerungen im Organismus erfolgen weitgehend unter Ausnutzung von Gleichgewichtslagen, dann wird die Ausführbarkeit der Regulierungen im weiten Bereich physikalisch einfach verständlich, nicht mehr, aber auch nicht weniger. Wir begreifen damit, daß am Benehmen so gut wie an Erlebnissen und an physischen Werken der Tiere und des Menschen Ganzheitscharaktere zum Vorschein kommen, respektive ihnen aufgeprägt werden können. Und 
soweit dies gilt, soweit wir mit dieser physikalisch orientierten Forschung vorzudringen vermögen, soweit wird der Problem]zomplex der Gestalten ohne Rezeption des Zweckbegriffes eine Aufhellung erfahren können.

Um es noch einmal anders zu sagen, die Ausfübrung von Steuerungen und Prägungen wird vereinfacht, wo sie Gleichgewichtsgesetze ausnutzen kann. Ein angestoßenes Pendel wird, gleichviel wie stark und in welcher Richtung es angestoßen wurde, in einer bestimmten Lage wieder zur Ruhe kommen. Der Konstrukteur einer Maschine stattet sie an allen Ecken und Enden mit ,Toleranzen“", zu deutsch mit Freiheitsgraden aus, damit in deren Bereich sich die vorauszusehenden Störungseinflüsse ohne Schaden für das Ganze ausschwingen können; es gibt faktisch keine Maschine ohne solche Freiheitsgrade. Weiter, wenn der Uhrmacher ein Pendel als Teil in sein Werk einsetzt, nutzt er eine andere Konstanzeigenschaft dieses Teilsystems zur Steuerung des Ganzen aus. Es gibt an einfachen und verwickelten physischen Systemen mancherlei Konstanzmomente; wer außer den grob-sinnlich faßbaren die übersinnlich kleinen und großen, die schnellen und die langsamen Ausgleiche mit in Rechnung stellt, wird die Überzeugung gewinnen, daß nicht nur Maschinen, sondern auch das Werk unserer Hände sie in der mannigfachsten Weise ausnutzt, um in einfacher Art Steuerungen des physischen Geschehens zu erzielen und vorbestimmte Gebilde zu schaffen. Und was wir derart im Bereich der Technik finden, dürfen wir wohl auch im Bereiche der organischen Steuerungen als verwirklicht und ausgenutzt annehmen. Köhler und Wertheimer haben im Zuge der psychologischen Gestaltforschung einiges von den unabsehbaren Steuerungsmöglichkeiten, die in lebenden Systemen beschlossen liegen, in das rechte Licht gerückt. Das ist das Verdienst ihrer Ganzheitsbetrachtungen.

Es gibt physikalische Systeme, für deren Gang jene Grundeigenschaft ,phänomenaler" Gestalten, die schon E. Mach und dann von Ehrenfels zuerst an optischen Formen und an der Melodie hervorgehoben haben, nämlich die Transponierbarkeit, eharakteristisch ist. Überall, wo gewisse Proportionen bei Veränderung der absoluten Bestimmtheiten, zwischen denen sie bestehen, konstant bleiben, liegt eine proportionsgerechte Transposition vor. Schon den ersten an der Psychophysik geschulten Erforschern der phänomenalen Gestalten lag nun der Gedanke nahe, eine einfache psychophysische Parallele zu ziehen. Ich will ein paar Sätze zitieren, die ich selbst im Jahre 1913 veröffentlicht habe: ,,Die Leistungen des anschaulichen Proportionsvergleiches, die wir beschrieben und quantitativ bestimmt haben, physiologisch verständlich zu machen, ist die Aufgabe einer Theorie der Proportionswahrnehmung. Welche Bedingungen muß ein Apparat erfüllen, der imstande sein soll, ähnliche Leistungen zu vollbringen? Es gibt viele physikalische Modelle, an denen dies demonstriert werden kann. Die Wheatstonesche Brücke z. B. ist ein Proportionsinstrument, denn sie gestattet, zwei elektrische Widerstände daraufhin zu vergleichen, ob sie der gerade eingesteilten Proportion entsprechen oder nicht ... Die einfachsten Modelle sind Hebelapparate; man denke an Vergrößerungseinrichtungen zur mechanischen 
Karl Bühler.

Reproduktion von Zeichnungen in beliebigem Maßstab oder an das Nächst liegende - die Wage. Sind die Wagebalken gleich lang, dann werden aufgelegte Körper auf die Gleichheit ihres Gewichtes geprüft. Sind sie nicht gleich lang auf die bestimmte, gerade eingestellte Proportion ... Wir nennen denjenigen physiologischen ProzeB, der dem Einstellen der Wagebalken auf ein gewisses Längenverhältnis äquivalent ist, die Proportionseinstellung" usw. ${ }^{1}$. Diese Sätze sind sieben Jahre vor Köhlers Buch „Die physischen Gestalten", und zwar als die entscheidenden Überlegungen zur Gewinnung einer ,.Theorie der Proportionswahrnehmung“" veröffentlicht; ich habe sie zitiert, um einer beginnenden Legendenbildung über den Ursprung der psychophysischen Parallelitätsannahme zur ,Erklärung" der phänomenalen Gestalten aus einer einzigen Quelle (Frankfurt, Berlin) entgegenzutreten. Im übrigen ist diese Parallelitätsannahme, die Wertheimer ganz allgemein in dem Satze ,denn was innen, das ist außen" formuliert hat, keineswegs zwingend, und alle Bemühungen, die seither unternommen worden sind, für diese oder jene Eigenschaften der Wahrnehmungsgestalten bestimmte Eigenschaften des nervösen Geschehens verantwortlich zu machen, sind über vage Vermutungen nicht hinausgekommen ${ }^{2}$.

Der Gang einer Pendeluhr ist gleichförmig kraft der bekannten Systembedingungen, ihre Steuerung beruht auf einem physikalischen Konstanzmoment. Beim Schießen mit einer Kugelflinte dagegen oder beim Werfen einer Kugel in ein Loch in der Erde, wie es die Kinder zu tun pflegen, gibt es außer Treffern auch Nieten, weil hier das Ziel nicht so einfach in die Systembedingungen eingebaut ist. Doch kann der SchieBende, wenn das Ziel stillhält, sein Glück öfters versuchen oder das Kind der Kugel nachlaufen und sie von der Stelle aus, wo sie liegenblieb, von neuem werfen, bis sie endlich doch ins Loch gelangt. Ein Ganzheitstheoretiker gerät bei Fällen, die dem zweiten oder dritten Beispiel ähnlich sind, nicht in Verlegenheit, sondern fast einfach das mehrmalige Schießen oder das wiederholte Werfen als eine Ganzheit von Geschehnissen auf, wonach es evident wird, daß auch hier der Effekt durch die Systembedingungen garantiert ist, und erklärt uns triumphierend: „Nun gibt es in der Biologie und Psychologie kein Zweckproblem mehr. Mechanismus und Vitalismus sind abgeschafft. Das lebende System erreicht seine Effekte genau so wie das tote, nämlich kraft seiner physischen oder, von der anderen Seite gesehen, psychischen Systembedingungen." Leibniz hat sich, abgesehen vom Parallelismus, ähnlich ausgedrückt, aber für nötig befunden, das Prinzip der prästabilierten Harmonie und einen allmächtigen, zwecksetzenden Schöpfungsakt als Quellpunkt der Zweckordnung in der Welt anzusetzen. Ein moderner Ganzheitstheoretiker ist vielleicht mit einer Amöbe am Ausgang zufrieden oder glaubt, selbst der Schritt vom toten zum lebenden System sei nun begreifbar geworden.

Mich dünkt, es gehöre mit zur philosophischen Besinnung bei der Neuorientierung der Psychologie, den Blick aufs Ganze zu schärfen, auf daß

1 K. Bühler, Die Gestaltwahrnehmungen, 1913, S. 288ff.

2 Vgl. dazu besonders E. Becher in Ztschr. f. Psych. 87 (1921), S. 1 ff. 
nicht ein integrierender Teil ihres Gegenstandes übersehen bleibt und wir die einseitige Formel der Assoziationstheorie durch die kaum minder einseitige von dem systembedingten Geschehen und den systembedingten Gebilden eintauschen. Die Befreiung, das Aufatmen in der neuen Luft des Ganzheitsgedenkens wirkt erfrischend; er wird seine historische Mission um so vollkommener erfüllen, je reiner wir ihn denken und je weniger wir ihn mit unerfüllbaren Leistungshoffnungen belasten. Zu seiner Reinheit gehört die logisch fundierte Einsicht, daß Ganzheiten ohne Teile in jenes Gebiet der Gegenstandstheorie gehören, wo vom hölzernen Eisen die Rede ist, und daß, soweit unsere Blicke reichen, Form ohne Stoff keine Realität konstituiert. Wer z. B. im Namen einer ganzheitstheoretischen Wahrnehmungslehre, den Empfindungsbegriff, streichen will, muß angeben können, welch anderen Stoff er an Stelle des gestrichenen einzuführen gedenkt, um seine Ganzheiten existenzfähig zu machen, oder er weiß nicht, was er sagt. Wenn die Psychologie in der üblichen Art eine Lehre von den Tönen und Geräuschen entwickelt, dabei auf die Attribute, oder wie man auch sagt, die Dimen. sionen der Tonhöhe, Tonstärke usw. achtet, das System der Töne nach diesen Dimensionen entwickelt, die bekannten Entstehungsfragen erledigt usw., dann geht sie sinnvoll und korrekt vor; sie baut systematisch an der Erkenntnis des Stoffes im Sektor des Hörbaren. Der Wert ihrer Ergebnisse ist unabhängig von der Frage, ob solch ungeformter Stoff vorkommt oder nicht. Er kommt nicht vor, der bestisolierte Ton im Bewußtsein eines Menschen wird sich immer irgendwie aus der Stille abheben und etwas von den anderen Komplexfähigkeiten, Gestaltfähigkeiten, die in reicheren Ganzheiten zu voller Entfaltung gelangen, an sich tragen sowohl als statisches Phänomenon wie als Konstituens eines Erlebnisverlaufes. Wozu dieser Satz aus dem Abc der Wahrnehmungslehre, nachdem wir begriffen haben, daß einige ihn vergessen hatten, seit Jahren in ungezählten Varianten wiederholt wird, ist mir nie ganz verständlich geworden. Das Feld der Tonkomplexe und Tongestalten harrt der Erforschung. Daß man darauf auch als altmodischer Theoretiker etwas Erkleckliches leisten kann, hat sooben Stumpf durch sein gehaltreiches Buch über ,Die Sprachlaute“" (Springer 1926) bewiesen. Man vollende die Gestaltuntersuchungen, dann wird am Schlusse jedermann selbst beurteilen können, wieviel am Begriffssystem und den Sätzen der alten Tonpsychologie wirklich zu ändern war. Daß das Ganze, die Wahrnehmungstheorie des Akustischen, nicht ohne einen Stoffteil, nicht ohne den Begriff der Tonempfindungen vollendet werden kann, ist eine axiomatische Erkenntnis, die 2000 Jahre nach Aristoteles jm Kreise von Philosophen keiner näheren Erläuterung bedarf ${ }^{1}$.

Die Fruchtbarkeit des Strukturgedankens in der Psychologie weit hinaus über den Bereich der phänomenalen optischen Gestalten, an denen er den Experimentatoren zum ,Erlebnis“" geworden ist, vermag heute noch niemand in vollem Maße abzuschätzen. Es sei mir gestattet, mit seiner Hilfe an einer eigenen Jugendleistung Wahres und Falsches zu scheiden, und damit einen Stein, an dem sich auch wohlwollende Kritiker der Denkpsychologie gestoßen haben, aus dem Wege zu räumen.

1 Zur Entschuldigung für diese Sätze möchte ich den philosophischen Leser bitten, meinen Artikel „Die ,neue Psychologie“ Kofflas", Ztschr. f. Psych. Bd. 99 (1926), S. 145 ff. nachzulesen. 
Die Rücksicht auf Prägnanz und das Selbstgefühl des Autors verlangen gleichmäßig einen Ausgang vom Richtigen und Entwicklungsfähigen. Vor 20 Jahren konzipierte ich den Begriff der ,Psychischen Gegenstandsordnung" und wollte damit zweierlei treffen, nämlich erstens den phänomenologischen Tatbestand, daß Gegenstände im aktuellen Denken sehr häufig nur indirekt, d. h. durch den Platz, den sie in irgendeiner bewußten Ordnung einnehmen, präsent und bestimmt sind. Fin Darstellungsschema, so drücke ich das jetzt genauer aus, ein Schema räumlicher, zeitlicher, sprachsyntaktischer oder sonstiger Natur und Provenienz und in ihm ein markierter Platz, an den das Gedachte hingehört, ist im Bewußtsein gegeben und präsentiert das Gedachte. Wir operieren im raschen und flüchtigen Denken, besonders wo es sich um abstrakte Gegenstände handelt, sehr sicher, erfolgreich und ökonomisch mit derartigen symbolischen oder erscheinungstreuen, aber detailarmen Präsentationen, wir können an ihnen die Relationen zu anderen Gegenständen derselben Ordnung nicht nur unmittelbar ablesen, sondern auch über den Bereich des Ablesbaren hinaus noch richtig entnehmen. Das ist der Tatbestand, den ich damals mit den Worten "Psychische Gegenstandsordnung", „Platzbestimmtheiten“ u. dgl. m. begrifflich erfassen wollte. Er gehört, wie der philosophisch Orientierte leicht selbst ergänzen wird, zu den grundlegenden Voraussetzungen für die Möglichkeit des abstrakt sprachlichen und jedes anderen, sagen wir einmal kurz,symbolischen' Denkens. Wäre statt der kurzsichtigen Kritik der sensualistischen Psychologie von damals das fruchtbare Moment dieses Ansatzes aufgegriffen worden, so wären wir rascher über die unrichtige Annahme ,rein unanschaulicher Gedanken hinweg und geradeswegs zu einer Strukturtheorie des Denkens geführt worden. Denn jenes Úbergreifen des Denkens über die anschaulichen Präsente hinaus kraft der Platzbestimmtheiten in einer Ordnung ist ja nichts anderes als ein besonderer Fall von Strukturbestimmtheit im Bereich des Phänomenalen. Man muB freilich ein ganzes Knäuel von Problemen erst auflösen, vor allem den Symbolbegriff exakt definieren, um diese Dinge vollständig ins Reine zu

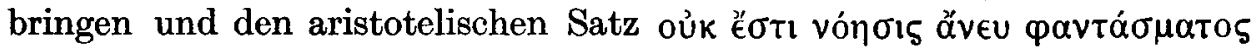
richtig zu interpretieren. Davon mehr in einer ausgeführten Theorie der Sprache.

Die Rede von der psychischen Gegenstandsordnung sollte aber zweitens auch den Hauptcharakterzug des Erlebnisverlaufes im sach gemäßen Denken treffen, und diese Angelegenheit ist seitdem durch O. Selz zu einer geschlossenen Theorie, einer Komplextheorie des Denkverlaufes ausgestaltet worden. Es soll meiner Wertschätzung dieser Theorie keinen Eintrag tun, wenn ich sie im folgenden zunächst einmal der Einfachheit halber zu denen rechne, die den Sinnbegriff durch den Strukturbegriff restlos ersetzen wollen, wovor Selz durch seine Anerkennung. 
einer größeren Mannigfaltigkeit psychischer Grundoperationen eigentlich hätte bewahrt bleiben müssen.

5. Der Begriff der Steuerung ist mir selbst aus der Sprachtheorie erwachsen; ich will versuchen, mit seiner Hilfe logisch klarzulegen, daß und warum der Sinnbegriff sein eigenes Bürgerrecht in der Psychologie besitzt, daß und warum die Zweckprobleme durch Strukturannahmen allein nicht zu lösen sind. Diese Ửberlegungen richten sich gegen den Physi kalismus jüngsten Gepräges in der Psychologie. Tatsachenmaterial zu unserem Beweisverfahren könnte aus allen Distrikten der Psychologie erbracht werden. Wer z. B. über den von Jennings bündig gemachten Nachweis, daß das einfache physikalische Modell der Tropismentheorie nicht einmal das Verhalten der Amöben, geschweige denn das der höheren Tiere zu erklären vermag, nachdenkt, wird schon von hier aus auf die entscheidenden Punkte hingelenkt. Wenn ein mit menschlichen Ruderern besetztes Boot einem Ziel entgegenfährt, geschieht das entweder ohne oder mit einem eigenen Steuermann, ohne oder mit einer reinlichen Zerlegung der Gesamttätigkeit in die zwei Komponenten eines Gesteuerten und eines steuernden Geschehens, das von einer Zentralstelle ausgeht. Aber vorhanden und wirksam ist unter allen Umständen die Führung, das zentrale Steuerungsmoment. Auch das Benehmen der Tiere erweist sich fast durchgehend als zentral gesteuert und zeigt so viele Freiheitsgrade, daß zwischen Zielsetzung (Zielaufnahme) und Ausführung von vornherein theoretisch unterschieden werden muB. Doch ist es methodisch richtiger, in dieser Angelegenheit rom Menschen auszugehen, sei es vom Einzelnen und seinen Zielen, sei es von Gemeinschaftszielen und wie sie gesetzt werden.

Auf einem Ozeandampfer wird das Steuerrad von untergeordneten Funktionären bedient; es ist nichts gegen eine Strukturbetrachtung einzuwenden, welche die Tätigkeit des Steuermatrosen nach einem rein physikalischen Modell begreift, sie etwa der regulierenden Funktion eines Uhrenpendels gleichstellt. Die moderne Technik wird, wenn es lohnt, den lebenden Menschen am Steuerrad durch einen toten Maschinenteil vollkommen ersetzen; daß das Geschehen vorher durch menschliche Sinnesorgane und eine gewisse erlernte Kunstfertigkeit, jetzt durch einen reinen Automaten hindurchläuft, ist für den praktischen Endeffekt und die Theorie, die ihn zu begreifen hat, irrelevant. Die Rechnung von allen entbehrlichen Posten zu entlasten, dahin zielt ja die fortschreitende technische Praxis im Gleichschritt mit der fortschreitenden wissenschaftlichen Theorie. Also setzen wir in unsere Bilanz die Tätigkeit des Matrosen als ein systembedingtes Geschehen ein, weil ess uns nur als solches interessiert. Nun, der Appetit kommt mit dem Essen. Wie wäre es, läßt sich der Kapitän des Schiffes nach demselben Rezept verspeisen? Ist sein für die Theorie relevantes Tun und Unterlassen auch ein system- 
bedingtes Geschehen? Die energische Theorie kennt keine Grenzen mehr, sie bezwingt auch den Reeder samt der ganzen Schiffahrtsgesellschaft und die Wirtschaftsbedingungen zwischen zwei Kontinenten. Ist es nicht buchstäblich wahr: auf der einen Seite des Wassers der Waren- und Menschenüberfluß, auf der anderen der entsprechende Hunger, daß es ein systembedingtes Geschehen ist, wenn unternehmende Kaufleute einen Transportdienst eröffnen, und ergibt sich nicht eins aus dem anderen bis hinunter zum letzten Matrosen, genau so systembedingt wie einst das Sonnensystem und alles auf Erden entstanden ist?

Auch Spinoza hat einst die Menschen samt ihrem Willen und dem wirren Getriebe ihrer Leidenschaften in seine Rechnung eingestellt, ac si quaestio de lineis, planis, aut de corporibus esset. Nun, die Verwandtschaft der mo. dernen Strukturtheorie mit dem alten Spinozismus ist in vielen Einzelzügen so groß, daß die entscheidende philosophische Auseinandersetzung mit ihr kaum ein neues Blatt in der Ideengeschichte erfordern wird. Man denke in diesem Zusammenhang noch einmal an den ebenfalls spinozistischen Satz ,denn was innen, das ist außen" (Wertheimer). Der erkenntnistheoretisch gerichtete Psy. chologe von heute wird kaum anerkennen, daß durch dies Diktum alle wohlerwogenen Bedenken, die seit Stumpfs berühmter Rede (1896) gegen die naivste Form der Zweiseitenlehre vorgebracht wurden, entkräftet sind. Ich unterstrich den Ausdruck ,naivste Form", weil die Tendenz zu einem ganz naiven, aristotelischen und voraristotelischen Realismus, in der Wahrnehmungslehre, für die das Wertheimersche Diktum gesprochen worden ist, seither bei Koffka in einem ernst gemeinten Anlauf gegen das Johannes Müllersche Prinzip von den spezifischen Sinnesenergien deutlich zum Vorschein kam. Die Sinnesdaten sollen nicht mehr als Zeichen, sondern über

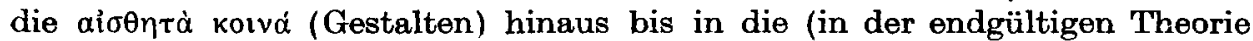
den Gestalten gleichzusetzenden) Sinnesqualitäten hinein als Realbestimmungen der Dinge angesehen werden. So ungefähr, wenn überhaupt eine erkenntnistheoretische Besinnung dahintersteckt, läuft hier der Hase ${ }^{1}$. Dazu methodisch die Verehrung der reinen Empirie bis zum anstandslosen Nebeneinanderstellen verschiedener Logiken und einem Spielen mit dem Gedanken, daß die Wahrnehmungen, so wie sie eigenen Strukturgesetzen unterliegen, auch eigne Erkenntnisse bieten, die nicht den Prinzipien der hergebrachten Logik unterstehen. In diesen zwei Tendenzen zum naiven Realismus und dem grundsätzlichen erkenntnistheoretischen Relativismus, der aus einem unbedingten Glauben an die alleinseligmachende Erfahrung entspringt, unterscheidet sich der neue Versuch vom historischen Spinozismus. Ist nur die Frage, ob zum Vorteil oder Nachteil der psychologia nuova. Wer die außerordentliche Einfachheit des Rationalismus mit seiner Entwertung der Sinneserkenntnis preisgibt, verpflichtet seine Theorie zum Aufschluß über manches, was jener als Scheinprobleme beiseite schiebt; das darf als ein Vorzug gewertet werden. Er verliert aber häufig zu seinem

1 Vielleicht kommt ein Zug aus dem Machschen Denken darin zum Vorschein; doch wie verträgt er sich mit dem Parallelismus? Wenn die Sinnesdaten selbst die Elemente der Wirklichkeit sind, braucht man kein physisches Gegenbild für sie. Das wäre eine Verballhornung des Machschen Gedankens ähnlich derjenigen, wie sie den Leibnizschen Seelenmonaden widerfahren ist, als man ihnen physische Monaden als Pendant beigegeben hat. 
Nachteil nicht nur den (vielleicht trügerischen) rationalen Halt in allen Sinnfragen, sondern geradezu das Organ für sie.

Wie Spinoza über Zweckbetrachtungen der Tierpsychologie gedacht hat, weiß ich nicht, die Zielsetzungen des Menschen jedenfalls hat er als eigenes Problem nicht vergessen und beiseite geschoben. Und wenn er auch über dem Prinzip der Selbsterhaltung (in suo esse perseverare) die höheren Zielsetzungen der Menschen äußerst einfach aus der adäquaten Erkenntnis eines einzigen Endzieles und Endwertes, worauf unser Dasein eingestellt und abgestimmt ist, und worin das Streben zur Ruhe kommt, determiniert, so hat er doch jedenfalls gerade durch diese Gegenüberstellung von zwei Determinationsstufen etwas von dem wahren Sachverhalt getroffen. Die Ziele und ihre Motivationen steigen nicht nur aus zwei, sondern aus vielen eigengesetzlich verschiedenen Schichten des menschlichen Wesens auf; zwischen der Affektlage des Augenblicks und der reinen Ewigkeitsorientierung Spinozas liegt noch mancherlei an Schichten und Systemen. Die erste Frage ist, welche von ihnen im gegebenen Fall aktuell wird und das Geschehen bestimmt. Es gibt nicht nur eine Kollision von Pflichten, sondern eine fast unübersehbare Mannigfaltigkeit von Unterstützungen und Interferenzen, wo mehr als eine Schicht aktuell wird. Vielleicht ist der Psychologe überhaupt nicht oder wenigstens nicht allein berufen, zwischen Determinismus und Indeterminismus in der Willenslehre eine Entscheidung zu treffen, jedenfalls aber darf er nicht blind an dem Tatbestand vorbeigehen, daß es sein besonderes Bewenden hat mit dem Auftreten und dem Sichzueigenmachen von Zielen, von Zwecken. Wer ein Fragezeichen hinter dem Satz anbringt, daß auch dieser Matrose durch einen toten Automaten prinzipiell ersetzbar wäre, braucht sich durch kein physikalistisches Diktum das Vertrauen auf das eigene Denkvermögen erschüttern zu lassen.

Angenommen nun, ein Zweck ist gesetzt, steht dann von vornherein fest, daß die Steuerung des Geschehens in seinem Sinne die Angelegenheit bereits fix und fertig realisierter Systembedingungen ist? Gleichviel, wovon man bei der Betrachtung ausgeht, ob von einem faktisch gesteuerten Geschehen, um zuzusehen, ob darin noch systemfremde Zusatzeinflüsse vorkommen, oder von den faktisch am Anfang gegebenen Systembedingungen, um zuzusehen, ob sie allein die Erreichung des Zieles garantieren, so wird man bei allen komplexeren, schwierigeren Leistungen des Menschen die erste Frage zu bejahen und die zweite zu verneinen haben. Wenn für jeden Zweck sofort auch ein System von Bedingungen aktualisiert werden könnte, das die Ausführung auch nur einigermaßen garantiert, dann gäbe es wohl nicht so viele Entgleisungen aus innerer Unzulänglichkeit und so viele Menschen, welche die bekannte Straße zur Hölle wandern, die mit guten Vorsätzen gepflastert ist. Aber vielleicht sind viele Entgleisungen so zu erklären, døß der Ausführende 
Karl Bühler.

in den Bannkreis eines zielfremden Systems hineingezogen wird wie ein Komet aus einem in ein anderes Sonnensystem. GewiB, gerade das ist unsere Auffassung. Es gibt so viele einander fremde und vielfach widersprechende Einzelsysteme im Menschen, daß es zum Hauptproblem der Strukturbetrachtung wird, wie ein Nachen auf ferne und fernste Ziele durch sie hindurchgesteuert werden kann. Die Antwort in der Sprache des Physikers lautet: es muß außer dem freien auch ein gezwungenes, außer der systembedingten auch systemfremde Steuerungen geben, wo immer etwas Derartiges zustande kommen soll. Wer den Gang einer Uhr von Zeit zu Zeit durch Einstellung der Zeiger mit der Hand reguliert, führt eine systemfremde Steuerung durch. Wer sich in eine Kuranstalt begibt, sich dies oder das durch äußere oder innere Zwangsbedingungen ablistet, sich durch erfolgreiche Abwendung von dem und jenem in seinem Wesen befreit, begeht ähnlich gewaltsame Eingriffe. Minder drastische kommen in allen komplexeren Willenstätigkeiten vor. Wenn der Mensch nicht die Fähigkeit zu wirksamer Abwendung (Abstraktion) und zu Sperrungen (Hemmungen) aller Art, wie sie in den experimentellen Untersuchungen deutlich genug hervorgetreten und jedem aus Erfahrung an sich selbst und an anderen bekannt sind, besäße, wie sollte ihm das Kunststück gelingen, anders wie ein Komet in der Welt zu leben?

Außerdem gibt es noch so etwas wie „Einstellungen“, ein Begriff, mit dem auch die Strukturmonisten ausgiebig zu operieren gezwungen sind. Einstellung ist soviel wie das Aktualisieren, die Bereitstellung eines Bedingungssystems für diesen oder jenen Zweck. Der Begriff wäre überflüssig, wenn er nicht eine der Möglichkeiten systemfremder Steuerungen bezeichnen sollte. Es gibt in allem Erleben, Benehmen und Schaffen Verschiedenes; es gibt Phasen, die den Charakter der freien Erfüllung, des Ausklingens im festen Rahmen gegebener Systembedingungen tragen, es gibt andere, die den Charakter einer systemfremden Steuerung des Geschehens tragen, mag nun die Führung letzten Endes doch in uns selbst oder mag sie außerhalb liegen, und es gibt noch einmal andere Phasen und Wendepunkte, die den Charakter von Zwecksetzungen haben. Was soll angesichts dieses Reichtums die einseitige Formel des Strukturmonismus? Sie erweist sich, wenn man ihren universellen Geltungsanspruch mit den paar Anläufen, die bestehenden Strukturen am Menschen und den Tieren faktisch aufzuweisen und exakt zu bestimmen, vergleicht, nicht als ein wohlfundierter Glaubenssatz.

Eine beliebte Antithese der Strukturmonisten ist folgende: Die Assoziationspsychologie und die Maschinentheorie der Biologen konnten sich bestimmte Erfolge eines Geschehens nur auf Grundlage starrer Bindungen vorstellen. Wie die Glieder einer Kette, wie die Zahnräder einer Maschine immer nur eins ans andere gebunden sind, so sollte es im Erlebnisverlauf mit den Assoziationen, im organischen Geschehen mit den Einzelprozessen 
sein. Der Strukturgedanke dagegen zeigt auch physische Modelle, in denen ein Geschehen ebenso sicher ohne solch starre Einzelbindungen zu bestimmten Erfolgen führt. Das war ein befreiender Gedanke, ich will es noch einmal anerkennen. Aber jene Antithese ist nicht scharf, denn es gibt erstens keine materiellen Maschinen mit nichts als starren Bindungen, d.h. ohne Freiheitsgrade, und es gibt zweitens keine materiellen oder psychischen Strukturen ohne irgendwelchen Halt an festen Bindungen. Das Pendel mit seinem Strukturmoment der Gleichförmigkeit ist in die festen Fügungen der Zahnräder: der Uhr eingebaut und zwingt ihnen den eigenen gleichförmigen Gang auf. Wo irgendein Techniker eine Maschine konstruiert, muß er beide Momente in einem Gebilde vereinigen. Und im lebenden Organismus mit seinen zentralen Steuerungen muß außerdem noch eine Instanz vorhanden sein, deren Funktionen den Konstrukteur der Maschine oder den Maschinisten mehr oder minder weitgehend ersetzen. Ohne das Indienststellen bald dieser, bald jener Systembedingungen und ohne das systemfremde Steuern wäre der Organismus trotz seiner Strukturen letzten Endes doch nicht mehr als eine tote Maschine. Anders gesagt, er wäre nicht das Ganze aus Maschine und Maschinisten. Und die Psychologie als solche wäre keine selbständige, abschließbare Wissenschaft ohne die Funktion des Maschinisten im Organismus.

6. Genug vom Physikalismus. Es hängt mit der Stellung der Psychologie im System der Wissenschaften zusammen, daß ihr von Physikern vor einem halben Jahrhundert die ersten experimentellen Methoden bereitgestellt werden konnten, und daß sie nun selbst in einer neuen Rezeption das wichtige Denkschema der Struktur an Modellen der Physik zur letzten Klarheit zu bringen vermochte, während sie auf der anderen Seite mit demselben Recht von den Geisteswissenschaften beansprucht und ,,zurückgefordert" wird. Der Strukturbegriff ist wichtig, aber nicht imstande, den Bedarf der Psychologie an Kategorien allein zu decken. Schon die biologischen Wissenschaften brauchen mehr, schon sie müssen sich irgendwie mit dem Tatbestand der organischen ZweckmäBigkeit auseinandersetzen. In der Psychologie wird der von den Biologen ausgestellte Wechsel fällig, das ,,als ob" organischer Zweckbetrachtungen muß einmal irgendwo in barer Münze zur Endverrechnung gelangen und zum mindesten am Menschen wird offenbar, daß es Źweckmäßiges gibt, was den Endgehalt des Zweckhaften, Zweckgeborenen wirklich enthält. Der Abrechnung von da zurück weiter nachzugehen, liegt nicht im Plane dieser Untersuchung. Nur eines sei noch gesagt, man sollte nie vergessen, daß in der Ordnung zwischen Physik und den Geisteswissenschaften das weite Feld des Biologen liegt. Die vollendete Psychologie kann nicht anders als endständig am Stamme der biologischen Wissenschaften gedacht werden. Den Geisteswissenschaften steht sie anders 
gegenüber, als Grundwissenschaft in einem neuen Teilsystem, wenn man so will.

„Psychologia psychologice" heißt es bei Spranger. Wer wollte dem nicht restlos beistimmen? Nur sind wir Sterblichen eben alle an den Leib und die Materie gebunden, es ist der species homo sapiens ein unentrinnbares Gesetz: primum vivere, dann soll sich aus den Lebensnotwendigkeiten und über sie hinaus das Reich der Werte verwirklichen und erfüllen. Es gehört zu den Selbstverständlichkeiten meines Denkens, daß man dies Reich der Werte wie jedes andere Gegenstandsgebiet für sich abstecken und nach den Wesens- oder Strukturgesetzen, die in ihm enthalten sind, erforschen muß. Eine Logik oder Ethik aus der Psychologie ableiten, erscheint mir als ein ebenso sinnwidriges Unternehmen, wie wenn man dies mit der Mathematik versuchen wollte. Nie aber habe ich verstehen können, wie eine Psychologie zustande kommen soll, der es verboten ist, psychophysische Korrelationen in den Endbestand ihrer Sätze einzubauen. „Wie ich . . . aus der Tätigkeit der Geschlechtsdrüsen das tiefe Einsamkeitsgefühl des Jugendlichen oder seinen Radikalismus oder seine Tendenz zum Idealisieren ursächlich erklären soll, ist mir ganz schleierhaft"“1. Mir offen gestanden auch, und wenn nur die Unzulänglichkeit voreiliger Zuordnungen in Frage steht, wie sie aus dem geschickt gewählten Beispiel Sprangers jedem Laien in die Augen springt, dann wäre darüber jedes weitere Wort verschwendet. Aber wie steht es, wenn ich z. B. das Sehen eines farbenblinden Daltonisten exakt bestimmt habe, so daß ich weiß, es ist um eine ganze, genau angebbare Dimension ärmer an Farbennuancen als das Sehen des normalsichtigen Menschen; muß ich dann abbrechen mit meiner Forschung, weil der nächste Schritt weiter mich ins Physiologische führen würde? Hering oder Helmholtz geben mir Aufschluß darüber, was dem Farbenblinden fehlt, und sie tun es doch wohl nur im exakten Ausbau der Korrelationen, die im Groben auch der Laie schon trifft, wenn er mir erklärt, ein vollständig Blinder sehe überhaupt nichts mehr, weil seine Augen operativ entfernt worden sind. Die Schwermut eines Psychopathen verschwindet in vielen Fällen restlos in wenigen Tagen auf ein Jodmedikament, das ihm der Arzt verabreicht, mein eigener Hunger und meine Sättigung steigen gesetzmäßig aus dem Chemismus des Körpers auf, Kretschmer bringt bestimmte Temperaments- und Charakterzüge psychopathischer und gesunder Menschen in Korrelation zu ihrer Körperkonstitution. Spranger kann nicht im Ernste annehmen, daß die psychologische Forschung mit verbundenen Augen an all dem vorübergeht. Wenn er sich ein anderes Thema gestellt hat, warum muß denn der Nachbar als wissenschaftlich minderwertig charakterisiert werden? Raum für alle hat das große Haus

1 Spranger, Psychologie des Jugendalters, S. 24. 
der Psychologie; mag der eine in den Mansarden sein Fernrohr auf den Sternenhimmel der Werte richten, die Kellerräume der Psychophysik können zum mindesten das eine für sich in Anspruch nehmen, daß ihre Mauern in der kausalen Ordnung der Dinge das Ganze zu tragen berufen sind. Der Vergleich trifft nicht alle, aber doch eine sehr wichtige Gruppe von Entstehungsbedingungen der Erlebnisse. Die Sache ist nicht damit erledigt, daß man eine eigentliche und eine uneigentliche Psychologie unterscheidet. „Wohl verstanden: wir halten jene physiologischen Feststellungen nicht für gleichgültig oder wertlos. Sie sind von der größten Wichtigkeit für die Physiologie und interessant auch für die physiologische Psychologie. Aber in der eigentlichen Psychologie helfen sie uns keinen Schritt weiter" (Jugendps. S. 24). Nein, etwas, was nur interessant ist, aber keinen Schritt weiterhilft in einer Wissenschaft, muß über Bord geworfen werden. Oder - es stimmt etwas nicht in den Grundbegriffen oder in den Ansprüchen dieser ,eigentlichen' Psychologie. Davon mehr S. $518 \mathrm{f}$.

Es sei zunächst an einem Beispiel gezeigt, daß man als durchaus moderner Denker und von den Geisteswissenschaften her auch zu einem anderen Ansatz gelangen kann wie Spranger. Ich wähle den kurzen, gedankenreichen Essay von M. Freyer ,Theorie des objektiven Geistes" (1923), wo in zwei Kapiteln der ,,seelische Kreislauf des Verstehens" (S. 60 bis 69) und ,Der Prozeß des Schaffens“ (S. 69-87) phänomenologisch gezeichnet wird. Wenn wir statt lebender Mitwesen ihre Werke vor uns haben, so gehört zum Verstehen dieser ,Geräte des Lebens" zunächst einmal das Anmerken, daß sie von einem anderen geschaffen sind, und dann durch alle Stufen des eindringenden Verstehens so etwas wie ein Nachschaffen. „Es kann nun gefragt werden, was denn psychologisch vor sich gehe, wenn geistgeladene Materie und verstehende Seele mit positiver Wirkung zusammentreffen, und wie zumal in den Fällen vollkommenen Verstehens der subjektive Geist den Anschluß an den objektiven bewirke. Diese Fragen könnten nur in tiefgründigen und sehr umfangreichen psychologischen Untersuchungen gelöst werden. Denn es handelt sich in ihnen ... um eine Psychologie aller derjenigen Verhaltungsweisen, in denen wir auf Dinge der Kultur, tätig oder leidend, bewußt oder unbewußt bezogen sind, in denen wir unsere Geräte benutzen, unsere Zeichen verwenden, von unseren Gebilden umgeben sind, unsere Organisationsformen erfüllen, im Stile unserer Bildung leben." Es ist das weite Feld der Kulturpsychologie, das sich hier auftut.

Und das Pendant dazu wäre eine Psychologie des Schaffens an den Werken der Kultur. Freyer sieht sehr wohl, „dali der Sinngehalt des objektiven Gebildes das gerade Gegenstück zum Kraftgehalt des produzierenden Lebens sein kann“, aber nicht sein muß, ,daß nicht nur aus der Fülle, sondern auch aus Mangel, nicht nur aus Überfluß, sondern 
auch aus Sehnsucht, nicht nur aus geradem Willen, sondern auch aus allerhand Umdeutungen und Fragwürdigkeiten heraus Werke geboren werden können". Trotzdem gelten zwei kategorische Sätze von jedem Schaffen, als erster der Satz von der „Bündigkeit" (mit Simmel). „,Das Objektive selbst, ehe es eigentlich da ist, wirkt im Schaffensprozeß mit, es schafft sich selbst ebensosehr, wie es geschaffen wird", sobald es nämlich anfängt, und in dem Maße, wie es eine Struktur erhält. Dann ist es so wie bei jeder Struktur, daß das Ganze seine Teile fordert und sich selbst in ihnen ausgliedert. Der z weite ist der Satz von dem „,Opfer charakter" des Schaffensprozesses. Während sonst in Lebensvorgängen subjektive Kraft an Gegenstände gewendet wird, um sie selbst oder dies und das an ihnen zu genießen, von ihnen zurückzuhalten, soll gerade dies zum Charakter des reinen Schaffens gehören, daß das Subjekt opferhaft sein Bestes an das Objekt gibt ohne Rücksicht und Aussicht auf eine entsprechende Rückwirkung von dorther.

Úber das zweite ließe sich wohl mancherlei sagen; der Satz ist, wie er dasteht, nicht voll aufrechtzuerhalten. Und seine durchaus treffende Ergänzung aus der Sphäre des Gemeinschaftslebens allein genügt noch nicht. Freyer schreibt: „Der schaffende Geist scheint allerdings die eigentliche Richtung des Lebens zu verraten: er scheint ins Objektive hinein zu handeln, ohne einen Nutzen zurückzuholen. Es wird aber zurückgeholt, nur nicht von ihm, sondern von anderen. Das Werk bedeutet die große Erfindung des Lebens, daß das Subjekt (lies: Objekt) Akkumulator und Reservoir von Geist sein kann: unter der Bedingung, daß durch es hindurch gezielt wird auf das Subjekt, daß es in einem höchsten und reinsten Sinn auf Wirkung geschaffen ist. Kultur (als Inbegriff aller menschlichen Werke) ist der Versuch der Menschheit, auf dem Umweg übers Objekt einen übervitalen Sinn ihres Lebens zu finden.“ Dazu hätte ich als Psychologe noch zweierlei hinzuzufügen, erstens, daß der unmittelbare Lohn, mit dem das Werk den Schaffenden beglückt, jene höchste Art der Freude ist, die ich als Schaffensfreude charakterisiert, von der Freude des Genießens und von der Funktionslust abgegrenzt habe. Sie folgt freilich nicht dem vollendeten Werke nach, sondern muß ihrer ganzen biologischen Funktion nach vor seiner Vollendung liegen, nämlich in der Konzeption und im Hochgefühl des Könnens. Wenn wir das mit der „List der Natur“ in diesem Sachverhalt zu Ende denken, dann müssen wir auch den subjektiven Motor aufdecken, den sie eingesetzt hat, um die opfervolle Hingabe an das Werk nicht nur in denen, die uns als die erfolgreichen Neuleister vor Augen stehen, sondern schon in dem zartesten Kindesalter und in den primitivsten unserer Mitmenschen, die wir kennen ${ }^{1}$.

1 Näheres darüber bringt „Die geistige Entwicklung des Kindes“" in dem Abschnitt ,Genießen, Spielen, Schaffen', 4. Aufl., S. 449-462. 
Das zweite ist die Tatsache, daß die Persönlichkeit des Schaffenden rückwirkend vom Werke geprägt werden kann, wenn auch nicht muß; darin brauchen wir kein subjektives Schaffensmotiv, aber wir müssen doch objektiv einen Lohn, der reichlich lohnet, anerkennen.

Doch das nur zur Ergänzung. Im übrigen halte ich das Schema für richtig und fruchtbar. Eine ausgeführte Psychologie des Schaffens wird in der Tat die zwei Aufgaben haben, ,erstens jene seelischen Ausgangslagen schöpferischer Prozesse zu untersuchen, die durch ein vorläufig ungerichtetes, bereitliegendes chaotisches Plus an Kraft charakterisiert sind, und $\mathrm{z}$ weitens zu ergründen, wie aus jenem Fonds einer gesteigerten Vitalität nicht Akte des Lebens, nicht Handlungen, nicht Leidenschaften, sondern solche Prozesse gespeist werden, die von der Wurzel an eine andere Richtung haben, die opferhaften, nämlich formschaffenden Charakters sind". Die radikale Lebensfremdheit besteht für den, der die Schaffensfreude als Faktor einsetzen darf, nicht mehr und das ,von der Wurzel an verschieden" auch nicht, wenn anders in jedem vollmenschlichen Tun das Schaffensmoment enthalten ist; aber wie dieses Moment zur Reinheit eines beherrschenden Prinzips über alle Lebensopfer, die es fordert, aufblühen kann, ist in der Tat ein allgemeines Problem der Psychologie des Schaffens. Auch das Schema des Wechselspiels bei der Ausführung des Werkes, des Wechselspiels zwischen Setzen und Rückempfangen neuer Forderungen und Anregungen vom halbfertigen Gebilde her, wobei der anfangs große Spielraum von Möglichkeiten Schritt für Schritt verengert wird, und die Parallelen zwischen Schaffen und Verstehen (S. 75ff.) sind vorzüglich und präzis gesehen. Es wird die von Freyer selbst geforderte psychologische Einzelarbeit an all dem unmittelbar ansetzen können und die geeigneten ersten Leitlinien haben. Die Prinzipien, welche Selz erarbeitet hat, ergänzen sich mit denen von Freyer aufs beste. Die philosophische Besinnung auf Ziel, Methode und Kategorien der Psychologie ist hier so weit fortgeschritten, daß ein beherrschter und exgiebiger Fortschritt der Einzeluntersuchungen auf der erreichten Grundlage garantiert erscheint.

7. Höher und konkreter zugleich sind die Ziele Sprangers, der ausgeführte Teile einer geisteswissenschaftlichen Psychologie selbst vorgelegt hat. Sein Geschick in der Aufstellung von Modellen zur Charakterlehre und in der Jugendpsychologie in Ehren, aber die philosophischen Beiträge zur Methodologie und zum Kategoriensystem der Psychologie fordern die Kritik heraus; ich nehme das Thema „Struktur, Sinn und Wert" aus dem offenbar nur flüchtig skizzierten ersten Abschnitt seiner Jugendpsychologie noch einmal auf und will die Kritik zu Ende führen.

Voraus der Satz: die Konzeption eines überindividuellen, objektiven Geistes als einer in die Individuen eingreifenden und doch wieder nur von ihnen getragenen Realität ist so, wie sie dasteht und mit den Denk- 
mitteln Sprangers, schlechterdings unausdenkbar. Ich lasse mir einen persönlichen Gott, ohne dessen Willen kein Sperling vom Dache fällt, ich lasse mir den Spinozistischen Pantheismus oder auch einen anderen gefallen, wenn er einigermaßen widerspruchsfrei gedacht ist. Aber Sprangers objektiver Geist dürfte wohl in Ewigkeit nicht fertig werden mit den Widersprüchen, die ihm sein Entdecker einstweilen noch mitgegeben hat. Merkwürdig, die Bemühungen aller anderen modernen Psychologen gehen dahin, die Begriffe „Volksseele“, „Volksgeist" und dergleichen mehr unvollziehbare Erbstücke aus den Zeiten Herders und der Romantik zu eliminieren, nur Spranger fährt mit vollen Segeln noch in diesem Winde. Mag sein, daß ihm die Rickertsche Begriffsbildung mit ihrem erkenntnistheoretischen und anderen überindividuellen Subjekten dabei zum Vorbild dient. Allein es ist doch ein großer Unterschied, ob man solche Subjekte als ideelle Koordinatenausgangspunkte oder ob man sie als Realitäten setzt. Spranger setzt sie ungehemmt als Realitäten.

Für den Fortgang der psychologischen Einzelforschung ist dies deshalb nicht belanglos, weil weniger Kritische verhängnisvolle methodische Konsequenzen daraus ziehen. Wer einmal dem lieben Gott in die Karten zu schauen oder im Generalquartier die Pläne einzusehen in der Lage war, wird leicht mit souveräner Verachtung auf die mühsame Arbeit derer herabblicken, die ohne solche Einsichten den Gang der Dinge Schritt für Schritt von außen her begreifen wollen. Man verstehe mich recht, wir werden im Bereich eines zweckbestimmten Geschehens immer wieder versuchen müssen, ,das ganze Objekt mit einem Griff zu packen, aus der Úberzeugung heraus, daß in der Psychologie eben auf den Sinn fürs Ganze alles ankommt" (Vorwort, S. XII). Gewiß, und doch wieder nein, nicht alles; denn auf die Ganzheitsschau muß die induktive Prüfung folgen. Sollte es denn so schwer sein, den Verstrickungen in die gröbsten methodischen Mißgriffe auf unserem Gebiete und der Gefahr von Zweckspekulationen subalterner Geister zu entgehen? Das 18. Jahrhundert müßte jedem Schüler, der sich daran wagt, in krassen Farben vor Augen gestellt werden. Spranger hat heute schon einen Schweif von Nachtretern, deren Produktionen er energisch ablehnen sollte. Das wirksamste Mittel wäre eine klare Erkenntnis von der Rolle der Induktion in der Psychologie.

Aber nicht dies, sondern Sprangers eigene Konzeption des objektiven Geistes steht hier zur Diskussion. Es ist, um noch einmal an das instruktive Beispiel eines Diltheyschen Interpretationsverfahrens (S. $462 f$.) zu erinnern, jene Brücke zu bestimmen und auf ihre Tragfähigkeit zu prüfen, die es gestattet, aus Struktureinsichten an objektiven Gebilden zu Sätzen der Psychologie zu gelangen. Es wird auch Erlebnisstrukturen und Benehmensstrukturen geben; das einfachste wäre, wenn sich Parallelen zwischen den dreien finden ließen, Parallelen also $G \| E$, 
$B\|E, G\| B$. Die Psychologie hat zwar mit ihrem berühmtesten Parallelschema auf dem Gebiet der psychophysischen Korrelationen nicht gerade die besten Erfahrungen gemacht, aber sie wäre wohl trotzdem bereit, die neuen Hypothesen aufzunehmen, wenn sie ihr plausibel begründet und an guten Beispielen erläutert würden. Der unmittelbare Ertrag für sie wäre der, daß gewisse Sätze z. B. aus der Logik oder Ästhetik oder der Wirtschaftslehre oder sonst aus Wissenschaften, die sich mit objektiven Gebilden beschäftigen, nach einer einfachen Úbersetzung in ihren Bestand von Erkenntnissen aufgenommen werden könnten. Dem logischen Satz vom Widerspruch z. B., je nachdem man ihn in der Begriffslehre (Gegenstandslehre) oder in der Urteilslehre formuliert, entsprächen zwei psychologische Sätze von der Unmöglichkeit, widersprechende Merkmale in einem Denkakt zur Einheit eines Gegenstandes zusammenzudenken, und der andere Satz von der Unmöglichkeit, das Ja und Nein, die Zustimmung und Ablehnung in einem Akt ein und derselben Annahme zu gewähren. Nun, kein Besonnener wird zweifeln, daß derartige Übersetzungen nicht nur aus der Logik in die Psychologie des Denkens, sondern auch aus der allgemeinen Wertlehre in die Willenspsychologie usw. unter gehörigen Kautelen prinzipiell möglich sein müssen. Wäre dem anders, so trüge der Mensch nicht das Zeug, ein Bürger in den Wertreichen zu sein, in seinem Wesen. Allein, so wichtig die derart durch einfache Utbersetzung gewonnenen Sätze der Psychologie auch sein mögen, ihre Leistung erschöpft sich darin, das interessante teilweise Zusammenfallen der Grenzen des Sinnvollen und des Erlebbaren abzustecken. Darum ist man mit ihnen noch nicht zufrieden, sondern sucht weitergehende konkretere Entsprechungen, vor allem der Gebiete $G \| E(E \| G)$ auf allgemeine Formeln zu bringen, und Spranger scheut sich nicht, auch sie ,mit einem Griff zu packen`. Er spricht von objektiven und subjektiven Strukturen und supponiert wohl da und dort eine Parallele $G \| E$. Der Hauptzug seines Denkens aber folgt einer Wechselwirkungshypothese $G \rightleftarrows E$. So, glaube ich, muß man seine Auffassung, im ersten Ansatz zum mindesten, symbolisieren, wenn man aus dem theoretischen Abschnitt der ,Psychologie des Jugendalters“ folgende Sätze zusammenstellt (S. 8-16):

„Es gibt übergreifende Sinnzusammenhänge, die das subjektive Leben bedingen, ohne in die subjektive Sinnerfahrung selbst hineinzufallen." „Wir sind in hohem Maße bedingt und geformt durch einen Bestand überindividueller geistiger Gebilde..., die uns gefangennehmen, leiten und beherrschen." „Der objektive Geist ist eine uiberindividuelle Struktur, ein ïberindividueller Sinn- und Wirkungszusammenhang. Er existiert nur, insofern er von lebendigen Individuen erlebt und getragen wird. Aber er ist vor jedem einzelnen Individuum und bedeutet für jedes einzelne einen vorgefundenen Komplex von Lebensbedingungen und richtunggebenden Faktoren.“ „,Gehen wir ... vom Einzelsubjekt aus, so äußert sich in ihm der objektive Geist als 
Erlebnis und darauf aufgebauter Sinndeutung; umgekehrt nennen wir die sinngebenden und sinnschaffenden Akte des Subjekts Leistung. Gehen wir von dem (als identisch vorausgesetzten) objektiven Geist aus, so nennen wir seinen an sich geltenden Sinn den Gehalt, seinen Reflex in der erlebenden Seele seine Wirkung. Ein Subjekt, in dem der objektive Geist mit dem Gehalt, den wir in ihm voraussetzen, noch nicht bewußt geworden ist, hat Erlebnisse, die den Gehalt noch nicht ausschöpfen, es erfährt Wirkungen, deren vollen Sinn es noch nicht versteht. Es leistet vielleicht schon etwas für den objektiven Geist, aber nur triebhaft; es hat also nur eine inadäquate geistige Produktivität und sinnschaffende Kraft." „Der objektive Geist ist ... mit dem subjektiven durch eine Fülle von Lebensbändern verbunden." „Im Erleben des einzelnen selbst ist dieses Ganze niemals adäquat gegenwärtig, sondern immer nur abgeschattet in einzelnen Verbundenheits- oder Kampfbeziehungen. Ferner: in diesen Formen gesellschaftlichen Verbundenseins fließt ein sachlicher Sinngehalt hin und her. Aber auch dieser wird niemals voll erlebt, sondern er verschiebt sich in der Wirkung auf den einzelnen zu eigenartigen Erlebnisweisen, ja, das ursprünglich sinnvolle Objektive kann in diesem Zusammentreffen mit neuen, subjektiven Konstellationen geradezu sinnwidrig werden:

,Vernunft wird Unsinn, Wohltat Plage,

Weh dir, daß du ein Enkel bist."

Es gibt freilich auch Stellen, aus denen man eine Identitätsauffas sung herausinterpretieren könnte, und wieder andere, in denen der beliebte Strukturbegriff auf das Verhältnis $G: E$ angewandt wird.

„Die Einzelseele ist von vornherein verschlungen in den objektiven Geist." "Wichtig ist, daß die individuelle Seelenstruktur selbst eingelagert ist in größere Sinnstrukturen, die vom Naturzusammenhang bis in den objektiv geistigen Zusammenhang der geschichtlich-gesellschaftlichen Welt hinaufreichen." "Schon die Biologie kommt mit der Annahme einer bloß immanenten Teleologie des Einzelorganismus nicht aus; sie muß eine übergreifende Teleologie (übergreifende Sinn- und Zweckzusammenhänge) anerkennen."

Fast beängstigend vollends werden die Verwicklungen durch eine Mitberücksichtigung von $\mathrm{Niveauunterschieden} \mathrm{im} \mathrm{Bereich} \mathrm{des} \mathrm{objek-}$ tiven Geistes.

„Die Stufen des objektiven Geistes erstrecken sich von dem Naturhaften im gebräuchlichen Sinn empor bis in das gesellschaftlich-geschichtliche Menschenleben und wahrscheinlich auch über diese unsere obere Sinngrenze noch hinaus.“ "Genau genommen müßten wir hier noch unterscheiden den objektiven Geist als historisch-gesellschaftliche Wirklichkeit und den normativen Geist als darauf aufgebaute ideale Forderung. Beides ist in der Struktur des überindividuellen Geistes zu einer Lebenseinheit verschmolzen."

Was ist denn das nun wieder, zu einer Lebenseinheit verschmolzen“? Ich weiß nicht, ob es nur mir so geht, mir fällt als Beispiel einer Lebenseinheit von zwei Partnern zuerst die Ehe ein, und nun werde ich wohl vergebens fragen, ob aus dieser Ehe einer bestimmten Wirklichkeit mit einer idealen Forderung auch lebensfähige Kinder hervorgehen. Spranger selbst fühlt es: „Dies Verstehen kompliziertester Geistigkeit (würde) 
nicht gelingen, wenn nicht bei aller fortschreitenden Verwirklichung ewige Grundlinien erhalten blieben, die immer wieder als Koordinaten des Verstehens angelegt werden." Dies ist in der Tat unser dringendstes

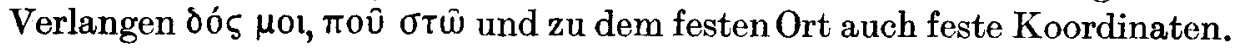
Und hier bewährt sich nun der verehrte Autor als gewiegter Seelenarzt, indem er uns einen Halt im Absoluten empfiehlt.

,Es muß ganz allgemeine und ewige Sinnrichtungen geben, wenn besonders zeitliche Ausprägungen der Sinnzusammenhänge verstanden werden sollen. Diese ideenhaften Richtpunkte sind die beiden - sich gegenseitig fordernden : 1. der totalen Lebenseinheit, 2. der inneren Differenzierung dieser Einheit nach bestimmten Sinnrichtungen, die immer erfüllt werden müssen, wenn überhaupt geistiges Leben sein soll." Einheit alles Lebendigen und des Toten hinzu, das nur als erstarrtes Sinnvolles wirklich ,verstanden" werden kann; zuhöchst der ,,normative Geist, der - bildlich gesprochen - über dem jeweils verwirklichten objektiv-historischen Geist als richtunggebend schwebt. Er ist jedoch, sofern er auf das Verstehen der menschlichen $W$ elt angewandt wird, nicht zu denken nur als ein starrer Fixsternhimmel von Ideen, sondern als ein Organismus von Idealformen oder von ihrerseits individualisierten Entelechien."

Die nüchterne Kritik sollte eines beherzigen, nämlich, daß man die Verdienste Sprangers um die Psychologie am wenigsten verfehlt, wenn man seine Bemühungen etwa mit denen vergleicht, die einst Kepler nach vielen Fehlgriffen zur Konzeption der Ellipsenform der Marsbahn geführt haben. Die ganze Astrologie im Kopfe dieses Mannes ist vergessen, sein Modell ist geblieben. Es ist nun einmal so, daß auch zur induktiven Forschung außer Experimenten Ideen gehören, man denke aus jüngster Zeit an die Massenproduktion von Atommodellen, bis dasjenige gefunden war, das, wie es scheint, vorerst alle Ansprüche der Experimentatoren befriedigt. Ideenreiche Modellerfinder sind voller Bilder; man betrachte die Ausführungen Sprangers als eine Art Entdeckerpsychologie, als einen discours de la méthode oder als regulae ad directionem ingenii. Wir können des Ingeniums im gegenwärtigen Stadium der Psychologie nicht zuviel haben; aber außerdem verlangt der objektive Geist einer Realwissenschaft die induktive Verifizierung der Ideen. Das gilt genau so gut für die Psychologie wie für die Physik. Und bis zum Ansatz geeigneter Prüfungsverfahren sind noch einige Schritte im rein theoretischen Gebiet zurückzulegen. So sei denn zuerst die Frage gestellt, ob aus dem ganzen Bündel von Bildern und Annahmen über das Verhältnis G:E alle gleichberechtigt nebeneinander bestehen können. Dies ist eine Frage der Logik.

Manches wird abgestreift werden müssen. Wie soll man sich z. B. einen Organismus von Idealformen ausdenken? Überhaupt Kausalrelationen zwischen idealen Gegenständen unter sich oder zwischen einem ausdrücklich als ideal und einem ausdrücklich als real charakterisierten. Gegenstande? Das Wort von der Ehe einer Realität mit einer idealen Norm 
war mehr als ein Witz. Man mag über die Lösung des Universalienproblems - und soweit müssen wir zurückgreifen, um die Dinge philosophisch ins Reine zu bringen - denken, wie man will, auf keinen Fall ist die begrifflich fixierte Antithesis real-ideal, wie sie in unserem tradierten Sprachgebrauch lebt, aufrechtzuerhalten, wenn man den idealen Gegenständen als solchen Wirkungsmöglichkeiten zuschreibt. Dies hieße nicht, irgendeine Lösung des Universalienproblems annehmen und andere verwerfen, sondern es hieße den Sinn dieses Problems radikal aufheben. Der Bereich des Wirklichen-Wirkenden wäre ja jedes inneren Haltes und jeder Absteckbarkeit beraubt, wenn er überall und jederzeit Zuflüsse und Direktiven aus dem Nichtwirklichen erhielte. Man mag platonisch denken oder spinozistisch, dann muß eben die Welt des hic et nunc, in der wir leben, eine erkenntnistheoretische Entwertung erfahren. Man mag aristotelisch denken, dann heißt es, sich ehrlich und gründlich mit Form und Stoff und mit dem potentiell Seienden auseinandersetzen. Aber man darf auf keinen Fall Begriffe und Redewendungen aus beiden Systemen promiscue verwenden und es dem Leser überlassen, wie er mit ihrer Vereinigung fertig wird. Mit derartigen philosophischen Kleinigkeiten könnte die nüchterne Kritik an Sprangers bildhaften Ausdrücken noch manche Seite füllen. Sie wäre natürlich gegenstandslos, wenn irgendwo ihr poetischer Charakter oder ihre Geburt aus Ausdrucksnot oder aus dem Streben nach Kürze und rascher Verständlichkeit ausdrücklich anerkannt wäre.

8. Doch nehmen wir einen neuen Anlauf. Vielleicht entgeht uns eine verborgene Begriffsbestimmung real-ideal, die abseits von den großen historischen Versuchen die Formel $G \longleftrightarrow E$, auch wenn eines der Glieder als ideal und das andere als real charakterisiert ist, ausdenkbar macht. Da entsteht dann ein neues Problem, weil Spranger oft in demselben Satz die Prädikate Struktur und Wechselwirkung oder einseitige Kausalität auf ein und dasselbe, eben auf die Relation $G: E$ (E:G) anwendet. Es ist rein logisch, rein gegenstandstheoretisch zu fragen, ob eins im andern möglich ist. Dabei muß der Begriff Struktur in dem weitesten Sinn genommen werden, weil ein allgemeiner Beweis intendiert ist. Was für die Struktur als solche unmöglich ist, ist es auch für Sinnund Wertstrukturen. Es liegt zunächst nichts als die unbestimmte Anweisung vor, zwei in eins zu denken, zwei Kategorien auf dasselbe Verhältnis anzuwenden, ungefähr so, wie wenn die Sprache ein Kompositum „Strukturwechselwirkung" oder ,Wechselwirkungsstruktur" bildet und es der Deutung des Verstehenden, der die Sachen kennt, überläßt, wie er die Bedeutungskomplexion vollziehen will.

Nun von der Sache her kommen nur zwei oder drei Bedeutungskomplexionen solcher Komposita ernstlich in Frage. Erstens zwischen zwei strukturierten Wirklichkeiten, einer objektiven G und einer subjektiven 
$\mathrm{E}$ besteht einseitig oder wechselseitig ein Kausalverhältnis, E ruft G oder G ruft E hervor oder sie bestimmen sich wechselseitig. Es ist zu fragen, ob diese Einwirkung selbst dann überdies noch ein Strukturgeschehen sein kann. Zweitens $\mathbf{G}$ und $\mathbf{E}$ sind die konstitutiven Momente eines Ganzen, sie werden also von diesem Ganzen getragen und bestimmt, kann dann jedes von beiden außerdem noch seine Eigenstruktur besitzen und von ihr bestimmt werden? Diese Fragen sind eine Angelegenheit der Logik.

An beliebigen illustrierenden Beispielen ist eine allgemeine, und zwar negierende Antwort auf sie zu finden. Um Beispiele auf dem rein physischen Gebiet zu wählen, unsere automatischen Abbildungseinrichtungen scheinen auf den ersten Blick darauf angelegt, die Bedingungen des ersten Falles zu erfüllen. Das Bild im Siegelwachs, auf der photographischen Platte, der Phonogrammwalze, im Radioempfänger, ruft hier nicht eine strukturierte Wirklichkeit die andere hervor? Ja und nein, physikalisch nein. Aber wer nach Erhärtung des Wachses sagt, es trägt jetzt die Raumformen, die Züge des Siegelringes und hält sie fest. mag es (physikalisch widerrechtlich) aber in einem funktionellen Sinn ein strukturiertes Gebilde nennen. Nur solch aufgezwungene Formen verraten an physischen Dingen das menschliche Schaffen, gleichviel ob es sich um Bearbeitungsspuren an Feuersteinen oder um eine griechische Statue handelt. Wichtiger aber noch ist, am physischen Modell einsichtig die Erkenntnis zu abstrahieren, daß die Übertragung solcher Formen von einem physischen Geber auf einen physischen Empfänger in irgendeiner Art oder Phase Nichtstrukturiertes voraussetzt. Entweder ist der Empfänger selbst, beziehungsweise das Eigengeschehen in ihm, beliebig bildsam wie das Wachs oder, wenn er latente Prägungen bereits in sich enthält, die nur der Entwicklung harren, wie die belichtete photographische Platte, dann muß der hervorlockende Prozeß, das Entwicklerbad, ein ungeformtes Geschehen auf ihn wirken lassen. Im Idealfall der Resonanz zweier genau gleichgestimmter Stimmgabeln, wo G und E strukturierte Vorgänge sind, spielt das schwingende Zwischenmedium (z. B. die Luft) die Rolle des ungeformten Momentes, und wenn ich sie starr verbinde, das als Ganzes mitgenommene Bindemittel.

Die Anwendung dieser Erkenntnis auf das Verhältnis G:E und E:G führt nur zu negativen, aber heilsamen Ergebnissen. Man wird erst das Nächstliegende einheimsen, um dann zu ganz exakten und allgemeinen Sätzen vorzudringen. Der Bildhauer kommt den Materialforderungen des Holzes oder Marmors in wechselndem Ausmaß entgegen, heißt, er respektiert oder unterdrückt die Materialstrukturen. Ein und dasselbe Milieu weckt selektiv beim einen Menschen diese, bei einem anderen vielleicht die entgegengesetzten Charakterzüge; Kinder im Schoß derselben Familie, manchmal hat man den Eindruck, als wirkten die Einflüsse von außen formlos wie ein Entwicklerbad oder wie das technische 
Verfahren beim Abziehen eines Bildes von der fertiggeritzten Kupferplatte, ein andermal wieder, als präge der Milieucharakter im ganzen oder einzelnen seiner Züge den heranwachsenden Menschen wie ein Siegelwachs. Die tiefer dringende Forschung korrigiert extrem einseitige Auffassungen, biegt sie zusammen und setzt als dritten Faktor die aktive Selbstgestaltung in wechselndem Ausmaß an. Aber wie dem auch sein mag, jedenfalls wird in all diesen und verwandten, zum Teil uralten Gleichnissen die logische Forderung eines unstrukturierten Momentes im ganzen von $\mathrm{G}: \mathrm{E}$ erfüllt.

Und darin liegt einfach ablesbar das erste allgemeine Ergebnis beschlossen: Wer von objektiven und subjektiven Strukturen spricht, setzt zunächst einmal zwei Systeme, um sie dann kausal zu verbinden. Niemand kann ihm diesen Ansatz verwehren, aber jeder muß verlangen, daß die Konsequenzen auch richtig gezogen werden. Soweit die Systeme einander transzendieren, d. h. unabhängig voneinander sind, folgt das Geschehen hier und das Geschehen dort den eigenen Systembedingungen. Wenn man sie in Kontakt bringt, ist Resonanz oder ein aufgezwungenes Systemgeschehen möglich. Der Rezipient kann, sofern er bildsam ist, die aufgezwungenen Systembedingungen sich aneignen und festhalten, dann wird er fernerhin zwanglos nach ihnen reagieren (oder wo es vorkommt auch agieren). Das alles gilt, wo immer die Grundannahme von zwei Systemen zutrifft, und wird durch den Ưbergang von toten zu lebenden Systemen nur weiter und weiter kompliziert, aber nicht aufgehoben. Man kann innerhalb der Strukturannahme auch sofort von einem statt von zwei Systemen ausgehen. $\mathrm{G}$ und $\mathbf{E}$ als die konstitutiven Momente eines einzigen Ganzen, innerhalb dessen das Geschehen systembedingt verläuft, das wäre im Prinzip wie mit den zwei Zinken einer einzigen Stimmgabel. Kann es innerhalb einer solchen Gesamtstruktur noch Teilstrukturen geben? Nun, bei der Stimmgabel nicht, keine der Zinken vermag ihre eigenen Wege zu gehen, und wenn ich die eine von ihnen mit einem Laufgewicht belaste, so belaste und verändere ich damit das ganze System. Aber man kann die Bindung der Komponenten anderer Systeme in verschiedener Weise und in verschiedenem Ausmaße lockern und erhält dann unter Umständen sehr verwickelte Verhältnisse. Gewiß kann man das, nur darf man darüber nicht vergessen, daß damit im Prinzip die Rückkehr zu der ersten Auffassung mit zwei Systemen und allen Arten der Koppelung zwischen ihnen vollzogen ist. Freiheit des einen bedeutet immer die entsprechende Unfreiheit, d. h. Strukturnachgiebigkeit resp. Bildsamkeit des anderen oder den Durchgang des Geschehens durch ein nichtstrukturiertes Medium. Also, wie man es auch anfassen mag, der Gegenstand des Bedeutungskompositums Strukturwechselwirkung oder Wechselwirkungsstruktur muß sich entscheiden, ob er in dieser oder jener Art aus der reinen Sphäre eines $Z$ weiersystems mit zwei Teilstrukturen und 
einer Überstruktur, eines Systems, das rein aus dem Strukturbegriff verstanden werden könnte, an dem nichts Unstrukturiertes mehr wäre, heraustreten will, um dem Vorwurf des hölzernen Eisens zu entgehen.

Man denke nicht, das seien Kümmelspaltereien, denn es steht und fällt mit jener Konstruktion der methodische Anspruch einer reinen Strukturpsychologie, mit Hilfe des Verstehens ganz allein, jenes Verstehens, das ,,anders wie die Kausalerkenntnis in den inneren Zusammenhang" der Dinge eindringt, die Wissenschaft der Psychologie zu vollenden. Mag der objektive Geist sein, was er will, sobald ich objektive und subjektive Strukturen und eine, wenn auch nur relative Unabhängigkeit der beiden voneinander ansetze, brauche ich ein ,unstrukturiertes" Medium zwischen beiden, um sie kausal zusammenzubringen. Die vollständigste Erkenntnis der Strukturen der einen und der anderen Art gibt mir noch keine Erkenntnis dieses Zusammen, wenn ich das Medium vernachlässige. Der Psychologe braucht nicht lange zu suchen, um das Medium und mit ihm die Lücke anzugeben, die im Sprangerschen System klafft, es ist der Körper, an den wir armen Erdgeborenen gebunden sind und mit ihm die Totalität der psychophysischen Korrelationen. Es ist jene uneigentliche Psychologie, über die er stolzen Fluges hinwegsetzt. Jedes Verstehen eines Gebildes, das andere vor uns im Bereiche der menschlichen Kultur geschaffen haben, und jedes eigene Schaffen an physischen $\mathrm{Ob}$ jekten läuft den Weg zurück und hin durch unsere psychophysische Organisation mit Einschluß all der vorerst undurchsichtigen und ,nu r kausal erklärbaren" Synapsen zwischen Reiz und Empfindung, Entschluß und Ausführung, Idee und Verwirklichung und jenen intrapsychischen oder intranervösen Synapsen, die den Gesetzen des Gedächtnisses im weitesten Sinn des Wortes unterstehen. Das ist das Medium zwischen $\mathrm{G}$ und $\mathrm{E}, \mathrm{E}$ und $\mathrm{G}$. Ich betone noch einmal, daß ich nur den überspannten Anspruch der verstehenden Psychologie treffen will, nicht nur Modelle zu bauen, wie die theoretische Physik, Modelle, die der induktiven Prüfung unterliegen, sondern das Ganze der eigentlichen Psychologie mit Struktureinsichten allein aufzubauen.

Sehr beachtenswerte Überlegungen auf gleicher, dem Physiker vollkommen geläufiger Grundlage hat jüngst Fritz Heider auf die Phänomenologie und Psychophysik der Wahrnehmungen angewandt ${ }^{1}$. Er hat uns leider nicht explicite gesagt, wie die Auffassung der Strukturmonisten à la Koffka an ganz bestimmter Stelle in die Enge getrieben, vor ein Entweder-Oder gestellt wird, sondern nur stillschweigend in herkömmlicher Art die psychophysische Korrelation zwischen nervösem, terminalem Vorgang im Gehirn und den phänomenalen Wahrnehmungsstrukturen durch das Zwischenglied noch unstrukturierter Empfindungen, den

1 Fritz Heider, Ding und Medium. Symposion Bd. 1, S. 109-157. 
reinen Empfindungen im Sinne von Helmholtz, J. von Kries, Stumpf und meiner eigenen Annahme in den Gestaltwahrnehmungen hergestellt. Wer den Satz ,,was innen, ist auch außen“ vertritt, kann de m Medium der Empfindungen zwischen einem als strukturiert angenommenen nervösen Geschehen und den Wahrnehmungsgestalten nur durch eine Identitätsannahme entgehen und verstrickt sich damit in alle Paradoxien des Materialismus. Spranger ist davon weltenweit entfernt; doch wird auch er nicht umhin können, irgendwo einmal, wenn sich seine Psychologie zum geschlossenen System abrunden soll, etwas über das Medium zwischen ,objektiven“ und ,subjektiven“ Strukturen zu sagen. Das definitive Wegschieben wäre Vogelstraußpolitik, und den sehr zweifelhaften Ausweg durch die Telepathie oder dergleichen mehr haben wir kein Recht seinem für uns äußerst wertvollen konstruktiven Denken zu supponieren oder vorzuschlagen.

9. Dazu ein Letztes. Auf eine präzise Frage Sprangers wollen wir eine präzise Antwort nicht schuldig bleiben. ,Wird mir die große seelische Veränderung, die beim Utbergang aus dem Kindesalter in das Pubertätsalter vor sich geht, irgendwie psychologisch klarer dadurch, daß bestimmte Drüsen eine verstärkte Tätigkeit entfalten? Diese Erklärung leistet ebensoviel wie die Behauptung, Sokrates sitze deshalb im Gefängnis, weil er seine Beinmuskeln bewegt habe und auf die Art hingekommen sei." (S. 3f.) Alle Achtung vor der Parade! Daß man in beiden Vergleichsfällen auf dieselbe Art entgleisen kann, ist durchaus treffend gesagt. Aber wie wäre es mit dem ernstgemeinten Vorschlag, einmal bei frühzeitig kastrierten Eunuchen oder bei solchen, die in der körperlichsexuellen Entwicklung entscheidend zurückgeblieben sind, nach den seelischen Pubertätsphänomenen Umschau zu halten? Der greifbare Temperaments- und Charakterunterschied zwischen einem Stier und seinem Bruder, dem Ochsen, wird wohl kaum größer sein als wir ihn unter analogen Verhältnissen beim Menschen zu erwarten haben. Als erste Antwort auf die Frage,,woher denn zwischen Brüdern der gewaltige Unterschied?" dürfte der Hinweis auf die Tätigkeit bestimmter Drüsen doch wohl den Anspruch haben, etwas freundlicher behandelt zu werden als der Hinweis des aus der Rolle gefallenen Schülers auf die Beinmuskeln des Sokrates. „Warum"? Die Frage ist so vieldeutig wie das Leben selbst, auf das sie abzielt; es kommt darauf an, ob eine von beiden entbehrlich ist, die Frage, warum in einem System seelischer Veränderungen das eine hier und das andere dort auf seinem Platz steht, und die andere Frage, warum im heranwachsenden Menschen, sei es generell, sei es hic et nunc gerade diese Systembedingungen eingetreten sind. Selbst wenn es so wäre, daß die Reifung der Keimdrüsen mit all ihren Folge- und Begleiterscheinungen, mit der gewaltigen Umprägung des ganzen Körpers und des ganzen physiologischen „Benehmens" sozusagen 
nur wie Grott im Bilde Michel Angelos mit der Fingerspitze die schlummernde Seele Adams zum Erwachen riefe, selbst dann wäre die zweite Warumfrage unerläßlich, weil Adam ohne Gott und der junge Mensch ohne Keimdrüsenentwicklung in alle Ewigkeit unaufgerüttelt blieben. Aber ist es denn so, ist abgesehen von dem Anstoß die Pubertätsentwicklung ein rein innerlich bedingtes und innerlich gesteuertes Geschehen, ungefähr so wie es sich in einer fensterlosen Leibnizschen Monade abspielen müßte? Ich habe eine größere Vorstellung von der Wechselwirkung zwischen Leib und Seele und glaube, durch das Erfahrungsmaterial jedes nachdenkenden Neurologen könnte eine solche Fingerspitzenannahme ad absurdum geführt werden. Doch es geht um ein sehr wichtiges Prinzip und wir müssen etwas weiter ausholen.

Wir bieten dem verehrten Gegner die denkbar größten Chancen, indem wir von den Instinkten und einem von ihm selbst gewählten Beispiel ausgehen. Spranger schreibt:

„Demgemäß ist die primitivste Form, in der der objektive Geist in den Zusammenhang der Individualstruktur hineinreicht, der Instinkt. Von ihrn gilt, was wir über die inadäquaten subjektiven Sinnerlebnisse sagten. Denn die subjektive Erlebnisseite deckt sich nicht mit der objektiven Leistung und dem Sinngehalt.“ ,Im Sexualinstinkt liegt nichts von dem subjektiven Willen der Arterhaltung. Mit einem Wort: die subjektive Teleologie deckt sich nicht mit der objektiven Leistung und dem Sinngehalt." Man könnte daher, wie Hegel von einer ,List der Vernunft" gesprochen hat, schon von einer ,List der Natur“ reden. Sie gliedert die subjektive Teleologie des Einzelwesens ihrer übergreifenden Teleologie ein. „Der Instinkt steht hier nur an Stelle eines Beispiels. Die seelische Ausstattung des Einzelwesens ist ganz allgemein von Anfang an so, daß über seine individuelle Struktur sich eine noch umfassendere überindividuelle Struktur hinüberwölbt, deren Sinn nicht unmittelbar erlebt wird, sondern erst im Anschluß an das Wissen um überindividuelle Zusammenhänge, also gleichsam auf einer höheren Stufe, erlebt werden kann. Alle im engeren Sinn biologischen Bedingtheiten der Seele gehören hierher." (14)

Dazu das Beispiel : ,Hätte die Psychologie nur die Aufgabe zu beschreiben, was im individuellen Bewußtsein selbst erlebt wird, so würde die Antwort auf die Frage ,Weshalb spielt das Kind ?' einfach lauten: ,Weil es ihm Freude macht." Denn darin erschöpft sich der rein subjektive (erlebte) Sinn des Spieles. U̇̉ber die besondere Form und Richtung des Spieltriebes gäbe es keine weitere ,Theorie'. Sobald wir aber, etwa im Sinn der Theorie von Karl Groos, sagen: Das Kind spielt, um sich in dem Vollzug künftiger lebenswichtiger Tätigkeiten zu üben, gehen wir weit über das hinaus, was beim Spiel wirklich erlebt wird. Dieses, um - zu' zällt noch nicht in die Seele des Kindes hinein. Hier liegt ein ,übergreifender Sinnzusammenhang' vor, übergreifend zunächst nur über den unmittelbar erlebten Sinn. Und diese Deutung ist aus dem Wissen um überindividuelle, um geistige Zusammenhänge hinzugefügt." (8)

Nun, wer die etwa zweitausendjährige Geschichte des Instinktproblems überschaut, wird in diesen Sätzen kaum etwas Revolutionäres finden und die Bemerkung Sprangers von ,,diesem bisher nicht beach . 
teten Sachverhalt" unter die Regel subsummieren, daß immer wieder uraltes Gedankengut wie neu und morgenfrisch im subjektiven Geiste eines Forschers aufblühen kann; vielleicht liegt darin auch eine List der. Weltvernunft beschlossen. Jedenfalls haben sich die Stoiker in Abwehr der überspannten pythagoreischen, epikureischen Vermenschlichung des tierischen Verhaltens (in der Art des Plutarch etwa) schon Moment für Moment genau so ausgedrückt wie Spranger ${ }^{1}$. Akkurat um dies Problem, ob die subjektive mit der objektiven Zweckmäßigkeit sich decke, geht dort die Diskussion und die Stoiker halten es mit Spranger, sie denken sich das Tier gleichsam von der Natur, d. h. der Weltvernunft „verwaltet" und Triebe ins tierische Wesen gelegt, die es ohne Einsicht zum Nützlichen führen und vom Schädlichen fernhalten. Statt umständlich die Kirchenväter und Schopenhauer als weitere Zeugen für Spranger aufzurufen, ist es wohl richtiger, einfach zu sagen, es sei fast ein Gemeingut des biologischen Denkens, jenes Problem, von dem er ausgeht. Nur daß die Modernen aller Richtungen von der gemeinsamen Frage aus jene Wege wandeln, die er vermeidet, nämlich die Hebel, die Ansatzstellen im Individuum zu suchen, die der objektive Geist braucht, um seine Ziele zu verwirklichen. Es ist wahr, man tut das in verschiedener Art, die Engländer Stout, Shand, Mc Dougall als Erlebnispsychologen, Lloyd Morgan und die Behavioristen mehr im Gedankenzuge der Psychophysik, ich habe in einem Sammelreferat versucht zu beweisen, daß sie gegenseitig aufeinander angewiesen sind, und wüßte auch für das, was Spranger vorschwebt, noch einen Platz im System anzugeben. Nur nicht gerade so, daß sein Unternehmen als der Königsweg erscheint; er müßte mehr und Köstlicheres in seiner Pfanne haben, um all das übrige als die uneigentliche Psychologie der Instinkte beiseite schieben zu dürfen.

Was bringt er denn faktisch und was wäre von dem dritten Aspekt, den er empfiehlt, im besten Fall zu erwarten? In dem von mir nachgedruckten Texte steht wieder einmal, über die individuelle sei eine umfassendere überindividuelle Struktur hinübergewölbt. Aus der Einsicht in das Objektive, das Gewölbe, soll nach seiner Auffassung more geometrico (oder ethico) unsere wissenschaftliche Erkenntnis der Instinkte fließen. Vermutungen, Fragestellungen, Modelle können in der Tat und müssen so gewonnen werden, daß wir uns fiktiv in den "Haushalt der Natur" versenken, daß wir mit einem ,als ob" in unseren Hypothesen operieren. Aber solche Schemata bleiben, um mit Kant zu sprechen, vollkommen leer, solange nicht das $D a \beta$ und das Wie, und zwar in ganz kommuner, kausaler Forschung erschlossen worden sind. Für Spranger scheint in diesen Dingen Kant umsonst gelebt zu haben. Wir brauchen aber nicht

1 Vgl. A. Dyroff, Die Tierpsychologie des Plutarchus von Chäronea. Progr. d. J. neven Gymnasiums in Würzburg 1877. Ders., Zur stoischen Tierpsych., Blätter f. Gymnasialschulwesen 33 und 34, 1897. 
einmal Kant, sondern nur die Logik und jene einfache Erkenntnis, daß zwischen dem systembedingten subjektiven Geschehen und irgendeinem unabhängigen ,,darübergewölbten“ strukturierten $G$, dem es zugeordnet sein mag, ein unstrukturiertes Moment oder Medium vorhanden sein muß. Das Gegenteil wäre ein Ungedanke, der vor dem Forum der Logik nicht bestehen kann.

Da ist z. B. das Spiel des Kindes. Was Spranger sagt, ist vollkommen die Meinung von K. Groos und all derer, die sich die Groossche Idee zu eigen gemacht haben. Der biologische Sinn des Spielens wird getroffen, wenn wir es als Vorübung künftiger lebenswichtiger Fähigkeiten (Fertigkeiten) betrachten. Groos kam durch ausgedehnte Studien an Tieren auf diese Idee. Sie ist nun da als Hypothese, was weiter? Welch nächsten Schritt der verstehenden Psychologie kann uns Spranger vorschlagen, um aus der Idee eine vollendete ,Theorie" zu machen? Die Wissenschaft brauchte zu ihrem Glück nicht darauf zu warten, sondern ließ sich das bekannte Wechselspiel von verifizierenden Beobachtungen und neuen Ideen, ließ sich eine waschechte Induktion gefallen und ist nicht schlecht damit gefahren. Es gehörte fürs erste eine große Materialkenntnis aus dem weiten Bereich des Benehmens junger Tiere und junger Menschen dazu, um grundsätzlich zu sondern, was und wo vorgeübt wird und was und wo nicht. Der objektive Geist scheint seine Launen zu haben, die jungen Ameisen und Bienen z. B. sehen einem äußerst komplizierten Leben entgegen, und doch fällt es ihnen gar nicht ein, sich brav wie junge Hunde und Katzen und das menschliche Kind in die Vorübungsschule des Spieles zu begeben. An jungen Hühnern wird noch niemand Vorübungen zum Eierlegen oder Brüten und Behüten der Küchlein gefunden haben, während das Pflegespiel an Puppen zu den konstantesten Frscheinungen in der menschlichen Kinderstube gehören. Warum das eine und das andere nicht? Ich fürchte, der objektive Geist wird schweigen wie eine Sphinx, wenn wir ihn mit dieser indiskreten Frage direkt angehen wollten; er hat aber bereitwillig geantwortet, als man ihm bescheiden auf ja und nein eine induktiv gewonnene Vermutung vorlegte.

Schon Groos hat sie formuliert, und sie ist seither wahrscheinlicher, zum mindesten aber nicht unwahrscheinlicher geworden, nämlich, daß den Instinkten ein relativ starres Moment im Bereiche der vererbten Anlagen entspricht, und daß das Spielen als Komplement zu weitgehend plastischen, d.h. mit einem Spielraum für individuell erworbene Variationen ausgestatteten Erbanlagen von der Natur eingerichtet worden ist. Das Fragen, d. h. Vermuten für neue Ansätze der Induktion ging weiter, ich will mich kurz fassen. Angenommen, der objektive Geist hat sich im Bereich des tierischen und menschlichen Gesamtverhaltens jene drei Sphären des Instinktes, der Dressur und des Intellektes geschaffen, die wir im ersten Abschnitt objektiv charakterisieren konnten, so vermögen 
wir ihm nachzurechnen, daß die Spielvorübungen wie das Übungsprinzip überhaupt zur Dressur gehörten; die bekannten Tatsachen stimmen, soweit ich sehen kann, mit der Idee überein.

Und nun die Wendung ins Subjektive, die Spranger mit der auffallend oberflächlichen Wendung ,das Kind spielt, weil es ihm Freude macht' beiseiteschiebt. Ich selbst bin verantwortlich für den Ansatz der Theorie im Subjektiven und ich muß es Spranger sagen, daß mich dies „Schwamm drüber" von seiner Seite außerordentlich befremdet hat. Er selbst braucht doch eine subjektive Struktur für die Spieltätigkeit. Auf der einen Seite steht das ,,du sollst dich vorüben“ des objektiven Geistes, von dem das Kind nichts weiß, auf der anderen Seite sehen wir es vom Morgen bis zum Abend den Befehl vollziehen, und dazwischen wird uns die Warumfrage verboten. Die Stoiker haben die Triebe im Tiere angesetzt, und Kant hat, wo auf der einen Seite der kategorische Imperativ, auf der anderen seine Ausführung im konkreten Fall in Frage steht, die ,Achtung vor dem Gesetz" in die Brust des Menschen gesenkt, und nur ausgerechnet das spielende Kind soll eines leistungsfähigen Motors für die Tätigkeiten, die sein Leben erfüllen, entbehren oder die Theorie soll an ihm als etwas ,Uneigentlichem' vorübergehen. Das verstehe, wer kann. Der nackte Begriff der Lust oder Freude allein böte freilich eine magere Erkenntnis. Aber wie wäre es mit einer spezifischen Lust, genauer gesagt, mit einem spezifischen Verhältnis der Lust zur Tätigkeit, wie wäre es, wenn die Natur an all den Stellen, wo sie einen Ưbungsfortschritt des Kindes im Dienste seiner Ausstattung mit später lebenswichtigen Fertigkeiten die geeigneten Tätigkeiten mit Funktionslust ausgestattet und dadurch ihre oft endlosen Wiederholungen unter probierendem Variieren garantiert hätte? Dieser Begriff der Funktionslust samt seiner Abhebung von der Lust des Genießens auf der einen und von der Schaffensfreude auf der anderen Seite bildet das Kernstück meiner Theorie des Kinderspieles ${ }^{1}$. Wer nicht nur sie, sondern die ganze auf das Subjektive abzielende Warumfrage beiseiteschiebt und doch noch von subjektiven Strukturen im Verhältnis zu objektiven spricht, muß erstens angeben, mit welchem Denkinhalt wir den Ausdruck subjektive Struktur der Spieltätigkeit füllen sollen, und $\mathrm{zweitens}$ mit irgendeinem Sterbenswörtchen verraten, wie es denn der objektive Geist anstellt, um das seiner unbewußte Subjekt zur Ausführung der Befehle zu veranlassen. Sonst spüren wir bei dem Wort „List der Natur“ zwar den Kitzel wie vor einem angestaunten Geheimnis, aber nie die intellektuelle Hochachtung einer fortschreitenden Einsicht.

Ein weiteres Gebiet, auf dem exemplarisch die unaufhebbare Verflechtung der beiden Warumfragen leicht demonstriert werden kann,

1 K. Bühler, Die geistige Entwicklung des Kindes; besonders § 36 . 
ist die Lehre von den Sinnesdaten, von den Empfindungen. Wer z. B. wie E. Hering die Phänomenologie der Farben mit peinlicher Sorgfalt von ihrer Psychophysik getrennt hat, ist prinzipiell über den Vorwurf einer methodischen Konfundierung erhaben und muß doch auf Schritt und Tritt von der gegenseitigen sachlichen Aufhellung der beiden Gebiete Gebrauch machen. Daß Rot und Grün, Gelb und Blau im Gegensatz stehen, ist zunächst einmal ein Satz der Phänomenologie; aber er stellt der Psychophysik Probleme und wird letzten Endes ohne ihre Hilfe nicht begreifbar usw.

Doch lassen wir das, um Spranger auf das Gebiet zu folgen, wo er zu Hause ist. Wenn der Historiker Charakter, Leistung und Schicksal eines Helden zum Thema nimmt, folgt er der methodischen Anweisung Sprangers, daß in jeder Dimension nichts als systembedingte Verläufe zum Vorschein kommen, stets nur die erste, nie die zweite Warumfrage gestellt, nie die „Beinmuskeln des Sokrates" in Bewegung gesetzt werden dürfen? Noch einmal anders gewendet, damit wir nichts versäumen, was die Treffsicherheit des Vergleiches zu erhöhen vermag: Ist es möglich, die systembedingten Züge eines historischen Ganzen als solche herauszuholen, und aus ihnen allein die ,eigentliche Geschichtswissenschaft zu konstituieren? Versteht sich, in einem Nebensatz wird anerkannt und damit das Gewissen des Empirikers beruhigt: Gewiß, die nackten Fakta sind nicht gleichgültig oder wertlos : sie sind sogar von der größten Wichtigkeit für die ,Physiologie der Geschichte'. Aber in der „eigentlichen“" Geschichtswissenschaft, ,führen sie uns keinen Schritt weiter“. Es sei nun unumwunden zugegeben, daß mehr und minder geistvolle Versuche in Hülle und Fülle aus Vergangenheit und Gegenwart auf diese Formel schwören könnten. Die Frage ist, ob und wie sie vor einer philosophischen Besinnung in der Geschichtswissenschaft zu bestehen vermögen.

Mir ist bei der monatelangen Beschäftigung mit dieser für die Psychologie und die gesamten Geisteswissenschaften so wichtigen Methodenfrage ein geradezu klassisches Erläuterungsbeispiel in dem überaus klaren Buche von Eduard Meyer ,Cäsars Monarchie und das Prinzipat des Pompeius" aufgefallen. E. Meyer stellt ein Modell auf, methodisch rein als Struktur gezeichnet:

„Der Krieg zwischen Cäsar und Pompejus war nicht etwa, wie er so oft, so auch von Mommsen, dargestellt ist, der Kampf zweier Prätendenten um das Königtum. Vielmehr sind es drei Gestaltungen des Staates, die hier mit. einander ringen: die alte Republik in der Form der Senatsherrschaft . . ., die Monarchie Cësars und zwischen ihnen diejenige Gestaltung, die Pompejus erstrebte, die militärische und politische Leitung des Staates durch den amtlosen Vertrauensmann des Senats und der Aristokratie, den alle seine Rivalen an Einfluß weitaus überragenden ersten Bürger, den Princeps. Die Stellung, die Pompejus für sich begehrte, und die er zuletzt, seit dem Jahre 52 wenigstens, annähernd erreicht hat, ist in der Tat in den wesentlichsten Momenten bereits die, welche das augusteische Prinzipat dem Regenten zuweist; die 
Gestaltung, welche Augustus dauernd begründet hat, steht der von Pompejus erstrebten viel näher als der des Mannes, dessen Namen er trug. Eben darin beruht die eminente weltgeschichtliche Bedeutung des Pompejus, die die Cäsars fast noch übertrifft. Sie tritt dadurch nur noch deutlicher hervor, daß er an sich keineswegs eine hervorragende, seiner Stellung innerlich gewachsene Persönlichkeit gewesen ist; gerade darin zeigt sich, wie die Entwicklung mit innerer Notwendigkeit auf diese Gestaltung hindrängt, in der sich die alten Traditionen der Republik und der Senatsherrschaft mit dem Bedürfnis nach einer einheitlichen Leitung des Weltregiments durch den Reichsfeldherrn zu verbinden und ins Gleichgewicht zu setzen versuchen. Cäsar hat diese Lösung mit der Überlegenheit des Genius geringschätzig beiseite geschoben; aber eben darum hat seine Schöpfung keine Dauer gehabt, sondern die Geschichte ist in furchtbaren Kämpfen darüber hinweggeschritten" (4/5).

Wie stark E. Meyer das Systembedingte, das Strukturmoment als solches empfindet, wird deutlich, wo er das Heute unter demselben Aspekte sieht und im Namen seiner Strukturerkenntnis eine Prophezeiung wagt: „Wenn nicht alles täuscht, wird im Laufe des nächsten Jahrhunderts die große Republik Nordamerikas . . . einer ähnlichen Krise entgegengehen" (5). Doch sehen wir davon ab. Im eigenen Unternehmen Meyers werden nun in die große staatsgeschichtliche Struktur die Persönlichkeiten des Pompejus und des Cäsar eingebaut, um einige der wichtigsten Züge am Schicksal, besonders Cäsars, daraus zu verstehen. Man beachte darin die Auseinandersetzung mit Mommsen; Kritik und Gegenentwurf sind für den Methodiker in gleichem Maße lehrreich. Lehrreich z. B. rein methodisch, die „zwei fundamentalen Gebrechen“, welche Meyer am Werke seines Vorgängers aufdeckt, zu betrachten. Das erste ist, daß Mommsen, ,als er die römische Geschichte schrieb, das Prinzipat des Augustus noch nicht gekannt und gewürdigt - das Verständnis desselben, das er uns alsdann erschlossen hat, ist vielleicht die großartigste seiner Leistungen - , und daher erscheint ihm Cäsars Staatsbau als die Grundlage des Kaisertums, seine Herrschaft gegen alle Geschichte nicht als eine mit seiner Ermordung zusammenbrechende Episode in dem Ringen um die neue Staatsgestaltung, sondern als der Abschluß der bisherigen Entwicklung und das Ende der römischen Republik "6 (327). Das ist immanente Kritik im Namen der Strukturerkenntnis an jenem historischen Ganzen, das den Augustus nicht aus- sondern einschließt. Das Argument ist nur dann bündig, wenn faktisch kein Bruch zwischen Cäsar und Augustus durch die Staatsgeschichte Roms geht, sondern eine Struktur das Geschehen, nachdem die Gleichgewichtslage der alten Republik unmöglich geworden war, bis zur Aufrichtung der neuen Gleichgewichtslage des Kaisertums beherrscht. Meyers zweites Argument greift ins Psychologische, ist ein argumentum ex homine, wenn man kurz so sagen darf. Ich stelle die entscheidenden Sätze zusammen : 
„Ein Mensch ..., wie Mommsens Cäsar hat überhaupt niemals existiert: darauf, und nicht, wie Mommsen glaubt, auf der idealen Vollendung seiner Erscheinung beruht es, daß im Gegensatz zu den lebensvollen Porträts, welche er sonst so vielfach gezeichnet hat, sein Cäsar ein Schemen ohne Fleisch und Blut geblieben ist" (328). Und worin liegt diese psychologische Unmöglichkeit? In der Annahme:, ,von Anfang an steht sein Ziel ihm klar vor Augen, und unentwegt hat er es 30 Jahre lang verfolgt.“ „, Sein Hauptziel, die Gewinnung der unumschränkten Alleinherrschaft und den Neubau des Staates auf Grund der demokratischen Ideale hat er ... nie aus dern Auge verloren, und als die Zeit gekommen war, den Bürgerkrieg bewußt herbeigeführt; und völlig klar stehen ihm seit langem nicht nur die Grundzüge, sondern selbst die Einzelheiten dieses Neubaus vor Augen" (328). Meyer erklärt, das sei, ,,als ob man dem Major und Brigadegeneral Bonaparte, dem Genossen Robespierres, bereits den Gedanken der Aufrichtung des Kaiserreichs als Verwirklichung der demokratischen Ideale der Revolution und womöglich gar der Verfassung von 1815, dem Abgeordneten Bismarck ein auch nur in den Grundlinien faßbares Bild der Wege, die zur Gründung des Deutschen Reiches geführt haben, ... zuschreiben wollte, obwohl natürlich die Gedanken, die dahin geführt haben, auch damals schon in ihrer Seele lagen und, wo der AnlaB sich bot, blitzartig aufleuchten konnten. - In noch weit höherem Maße als diese ist Cäsar in seiner Wirksamkeit von dengegebenen, fortwährend wechselnden Bedingungen des Moments bestimmt; diese richtig zu erfassen, von den Möglichkeiten, die sie umschließen, die höchste erreichbare mit sicherem Blick zu ergreifen und festzuhalten und dann, wenn er Herr der Situation geworden ist, die so gegebene Freiheit zu schöpferischem Neubau zu benutzen, dabei trotz aller tiefgreifenden Umgestaltung doch nie die Schranken überschreitend, welche auch dem stärksten Willen unüberwindbar gesetzt sind - darin besteht die Tätigkeit des wahren Sitaatsmanns" (328, die Sperrungen von mir).

Und nun fragen wir einfach, auf welcher Seite diese unübertreffliche Schilderung von der Tätigkeit des ,wahren Staatsmannes" steht, ob auf Sprangers oder unserer Seite. E. Meyer operiert fruchtbar und geschickt mit dem Strukturgedanken und verlangt doch bis ins einzelste vom vollendeten Historiker das Eingehen auf eine ,Psychophysik‘ der Ereignisse, wie man es nennen könnte. Systeme ohne Fakta sind leer, Fakta ohne Systemgedanken sind blind, so ungefähr würde sich Kant in unserer Lage ausdrücken. Darum fürchte ich, die Beinmuskeln des Sokrates werden, einmal aus Platons Schrift erweckt und als Zeugen aufgerufen, lebendig bleiben in unserer Diskussion, aber nicht zur Rechtfertigung dessen, der sie gerufen hat. Ein Photograph, der seine Platte dem Entwicklerbad überantwortet, kann mit jenem empirischen Vertrauen, auf das unser Leben in tausend Dingen gestellt ist, den Effekt voraussagen, wenn er auch nicht das mindeste von Chemie versteht. Der Historiker darf die tausend empirisch bekannten Selbstverständlichkeiten des Menschenlebens und Weltlaufes in den meisten Fällen unerwähnt übergehen, wenn er nur keine Verstöße gegen das in ihrem Bereiche Mögliche begeht. Aber daß eine vollendete Theorie des Photographierens 
Karl Bühler: Die Krise der Psychologie.

das Eingehen auf die chemische Rolle des Mediums ebensogut wie der praktische Photograph oder Amateur entbehren könnte, daß ein Ganzes der Geschichte aus reinen Strukturerkenntnissen ohne die ebenso sorgfältige, wissenschaftliche Behandlung der Fakta begriffen werden könnte, daß eine Psychologie, die ,eigentliche " Psychologie ohne Kausalforschung vollendbar wäre, das sind drei prinzipiell gleich unberechtigte Behauptungen. 